\title{
Is childhood obesity a child protection concern?
}

Pete Nelson

Paul Bissell

Lee Pollard

Catherine Homer

Vanessa Powell-Hoyland

June 2018 


\section{Contents}

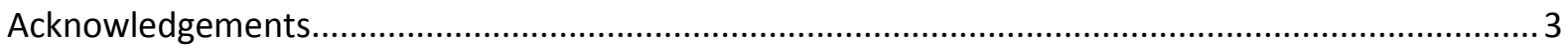

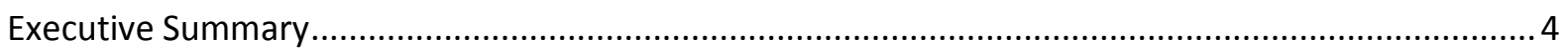

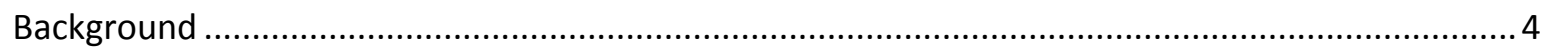

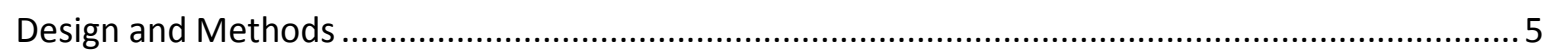

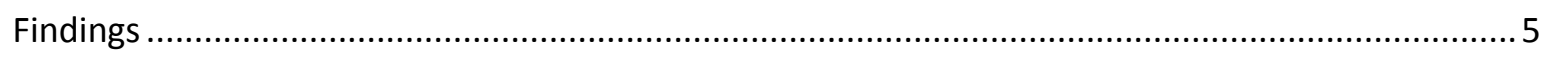

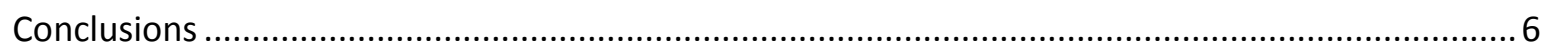

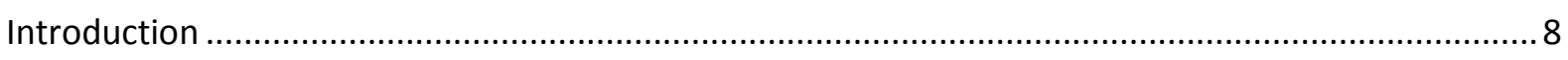

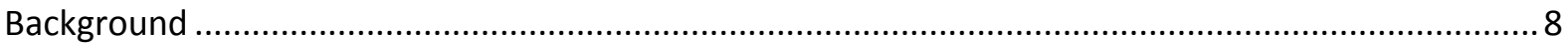

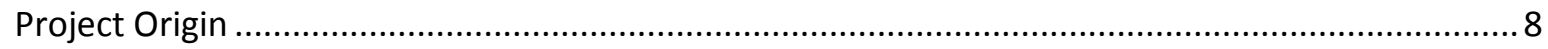

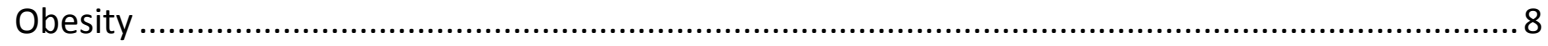

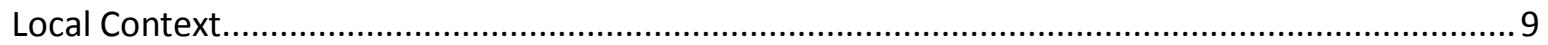

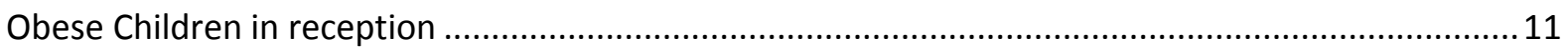

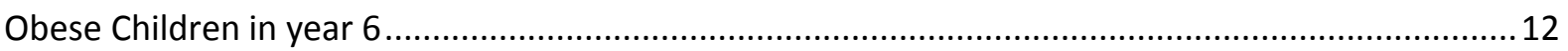

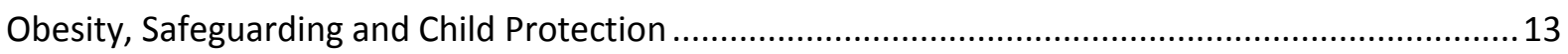

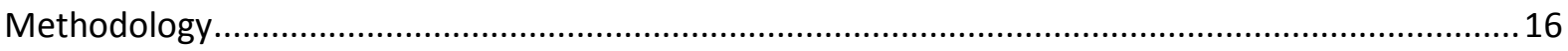

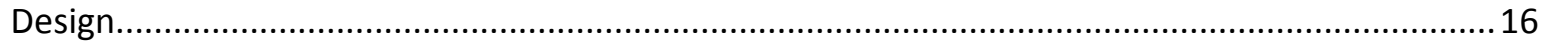

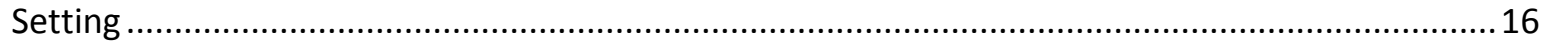

Table 1- Interview Participant Characteristics ........................................................................... 17

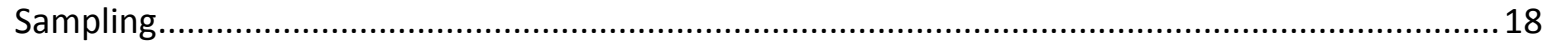

Table 2 - Focus group Participants Characteristics …................................................................... 19

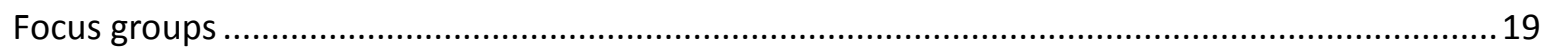

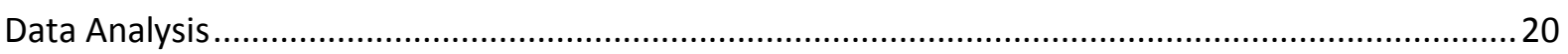

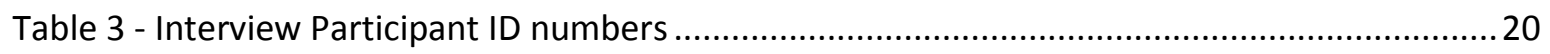

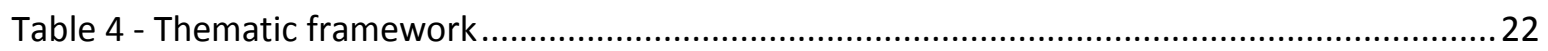

Findings …

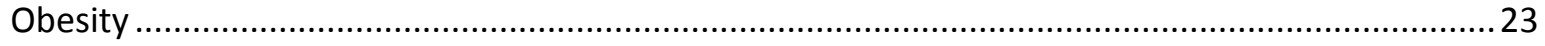

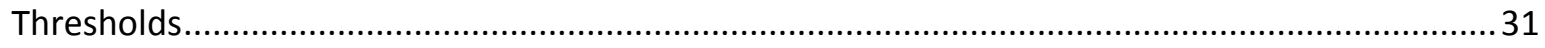

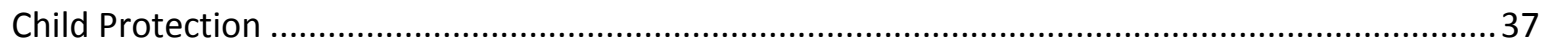

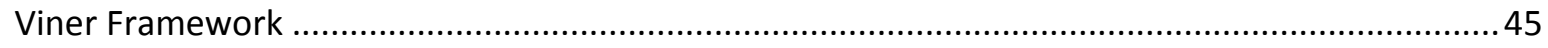

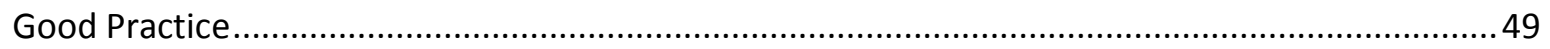

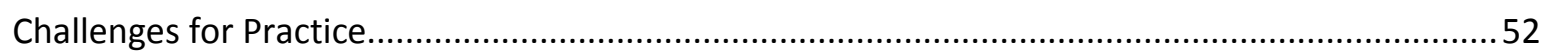


Suggestions for the future

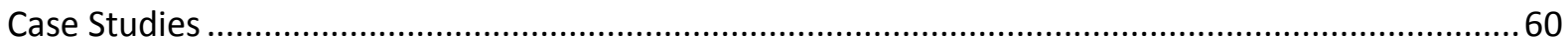

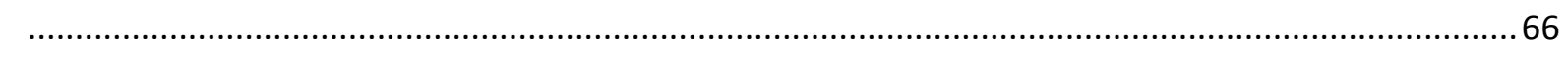

71

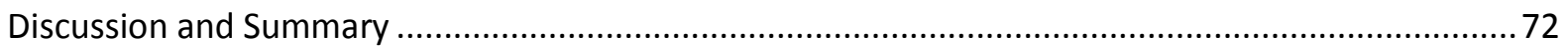

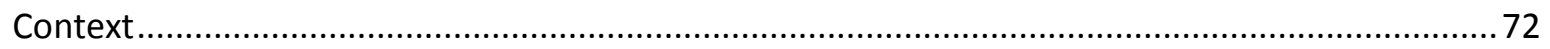

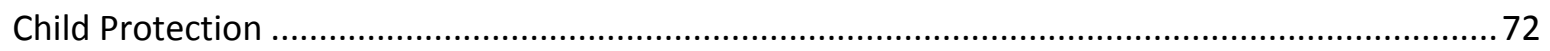

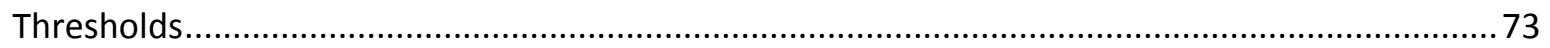

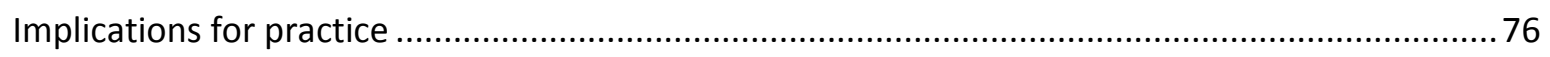

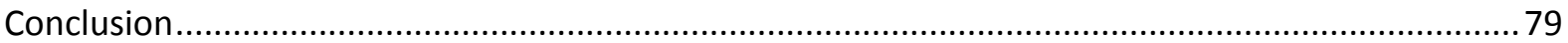

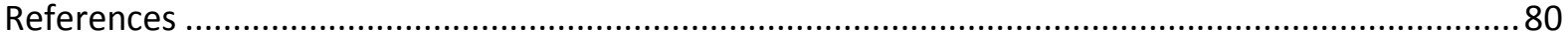

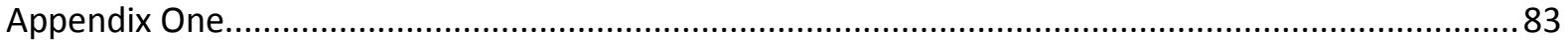

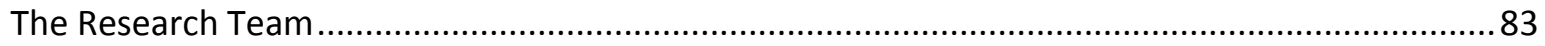

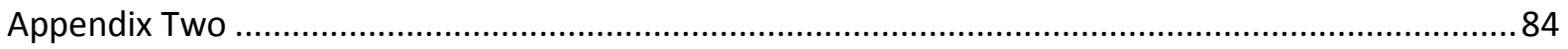

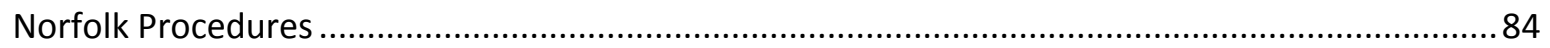

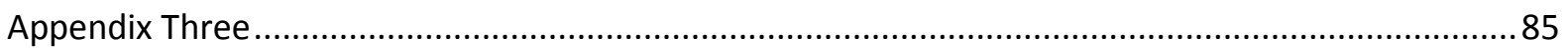

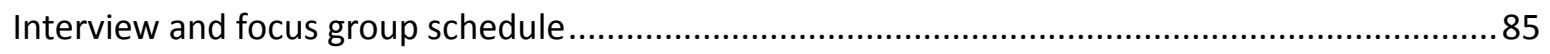

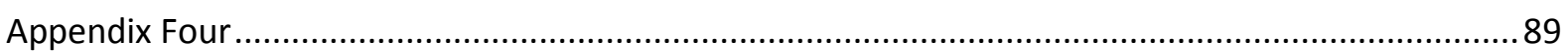

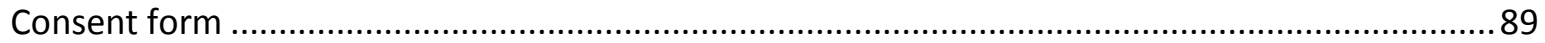

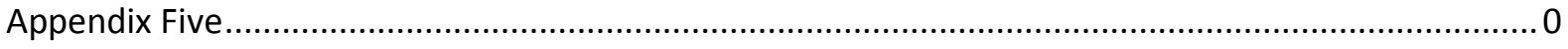

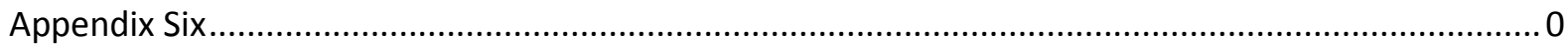

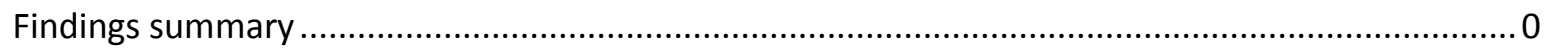




\section{Acknowledgements}

Funded \& supported by

NIHR
The research was funded and supported by NIHR CLAHRC Yorkshire and Humber. www.clahrc-yh.nihr.ac.uk. The views expressed are those of the author(s), and not necessarily those of the NHS, the NIHR or the Department of Health and Social Care.
Doncaster Council
The research was hosted by Doncaster Metropolitan Borough Council and the Doncaster Childrens Trust and we are grateful for their support in undertaking the research. The research was never intended to be and is by no means an evaluation of the services delivered by those organisations. 


\section{Executive Summary}

\section{Background}

The question as to whether childhood obesity should be considered a child protection issue has divided commentators, with many questioning whether a child should be removed from parents who do not seek to reduce their child's weight, where significant obesity is identified. This divide is reflected in the social work profession where there is resistance to a role focused on bodily surveillance, whilst also acknowledging the need to investigate neglect where evidence exists of a clear parental failure to manage a child's diet, health and fitness. Similar divisions exist in the medical profession and debates are taking place in Australia and the US but with little research to inform policy and practice. In the UK, practice varies with a consideration of obesity being incorporated in some multi-agency child protection procedures but with no mention in others and little research to explain variations. In the absence of evidence the most influential guidance remains a paper by Viner et al (2010), which concludes:

- $\quad$ Childhood obesity alone is not a child protection issue

- $\quad$ Failure to reduce overweight alone is not a child protection concern

- Consistent failure to change lifestyle and engage with outside support indicates neglect, particularly in younger children

- $\quad$ Obesity may be part of wider concerns about neglect or emotional abuse

- $\quad$ Assessment should include systemic (family and environmental) factors

It is this framework which is both widely quoted and incorporated into the child protection procedures of some local authorities but there appears to be no research which has tested its usefulness or applicability in practice.

This research project was funded by NIHR CLAHRC YH and was conducted by staff from The Department of Social Work, Social Care and Community Studies and Centre for Health and Social Care Research at Sheffield Hallam University, Doncaster MBC, Rotherham MBC and School of Human and Health Sciences Huddersfield University. Ethical approval was provided by Sheffield Hallam University and research governance from Doncaster MBC. A project advisory group was set up from health and social care professionals which met virtually at the outset of the project, to guide the direction of the research, interviewing content and protocol, and to inform sampling.

\section{Aims and Objectives}

The research aimed to understand whether childhood obesity is a child protection concern and had three objectives:

- $\quad$ To explore the current and past practice of staff working within child protection and obesity services regarding child protection and obesity

- $\quad$ To explore staff perceptions of childhood obesity as a child protection issue using interview and focus group methods

- $\quad$ To explore the use of the Viner et al (2010) framework for action to understand child protection concerns for children who are obese. 


\section{Design and Methods}

The research project conducted semi-structured interviews (N23) and facilitated focus groups (N3, N24) involving key stake holders from social care, health and education services. The professional roles of participants ranged from professionals involved in early help and family support, through to investigation and middle and senior management. Doncaster Council (DC) supported the recruitment of participants, through dissemination of information leaflets, email contact and the provision of interview facilities. All of the interviews and focus groups were undertaken in Doncaster in South Yorkshire, however the research was by no means an evaluation of current or past practice within the authority and participants were able to reflect on their experiences across geographic areas and professional roles and responsibilities. Framework Analysis methods were used to generate categories, codes and themes that capture the experiences, views and perceptions of the participants. The research team took a collective approach to the analytical process in order to develop the thematic framework.

\section{Findings}

The framework comprised of seven key themes:

Obesity: The short and long term impacts that obesity may have on a young person's physical and psychosocial health were acknowledged. Social factors relating to culture and poverty were also seen as contributing factors. Parental attitudes and perceptions were seen as playing a key role in recognising and responding to childhood obesity. The clinical nature of assessing and identifying obesity is complicated for non-health professionals.

Thresholds: For child protection services to undertake work, requests need to meet a severity threshold for interventions to occur. Thresholds were nuanced and complex and could act as inhibitors to providing services. The threshold operated not only as a line that had to be crossed in order for a referral to be accepted by social services but also in respect of individual practitioner thresholds regarding personal views and values regarding obesity, different agency thresholds, referrals for different services within an agency and also between agencies.

Child Protection: Respondents were divided as to whether child obesity was a child protection concern. For some the impact of obesity on long and short term outcomes for children made obesity unequivocally a child protection concern, yet for others excess weight itself was not sufficient. Where there was more common ground was in respect of the links between obesity and parental neglect. This could be in the form of associated factors such as failure to attend school or mental health issues but also for many respondents a failure on the part of families to engage with support plans and services offered. Those services were seen as a continuum of intervention levels from universal to statutory with child protection and legal interventions part of that continuum rather than a separate entity. A child protection approach could act as a catalyst for families to take up support as well as a gateway to more financially expensive and intensive support offers.

Viner Framework: The Viner framework was developed as a means of understanding and working with child obesity as a child protection issue. Almost all participants had no awareness of the Viner 
framework. Overall the framework was welcomed as a useful tool, with the caveat that over reliance on a framework can lead to over simple assessment. The framework was not seen as overcoming problems inherent in measuring and identifying obesity, and not identifying the association of obesity with sexual abuse.

Good Practice: Good practice was seen as beginning with a holistic understanding of obesity and its impact followed by a multi-agency approach including health, school and social care. Direct work with the whole family is given prominence in achieving change, both within and without a child protection context. Family involvement in the development and implementation of that work in a way that empowers but does not stigmatise was identified as a goal. Parental education was seen as important as part of a preventative approach and in sustaining change.

Challenges for Practice: Challenges to practice included structural issues such as a lack of funding for preventative services and a scarcity of targeted services for disadvantaged groups. Psycho-social barriers to families accepting support were identified such as poverty impacting upon individual behaviour. Multi-agency working was a source of frustration with a lack of clarity regarding roles and responsibilities. Direct work with families was central but could be contentious. Challenges included the potential reinforcement of unhealthy eating patterns and the need to balance risk management with building trust and relationships in order to bring about change.

Suggestions for Future: Suggestions included training on obesity and service availability, and providing a framework and procedures to guide practice. Evidence on short and long-term outcome measurements was identified as a deficit. More research and dissemination of findings on outcomes and what works regarding interventions is required.

\section{Conclusions}

This research has offered a unique insight into current multi-agency practice in respect of child obesity and child protection. Whether obesity alone can be a child protection concern is contested. Families who fail to recognise that child obesity is harmful to children and the failure of families to engage in support services was thought to potentially constitute neglect. When making judgements about child obesity and levels of harm, personal views about obesity and value judgements regarding parenting and children were as important, if not more so, than factual knowledge. These views come to the fore explicitly in threshold judgements and subsequent referral behaviour regarding identifying and acting on potential and actual significant harm. The services offered to and accepted by service users in respect of child obesity are both influenced by and a consequence of those threshold judgements.

Training regarding the identification, assessment and implications of child obesity was required. Given an acknowledgement of a multidisciplinary approach to child obesity assessment and service delivery being most effective, multidisciplinary training could also be most useful. Many would welcome a framework and procedures to guide, but not dictate, practice where child obesity may constitute significant harm and become a child protection concern.

Direct obesity focussed work with children and families is seen as key to bringing about change whether through universal services, family support or child protection statutory interventions. More research is required on the short and long-term effectiveness, outcomes and financial viability of those interventions to guide strategic and front line service delivery. 


\section{Key Messages from the Research}

\section{Obesity}

- $\quad$ Obesity has major consequences on a child's physical and psychosocial health which ultimately impact on child development

- $\quad$ Culture and poverty play a part in influencing family behaviours resulting in obesity

- $\quad$ Professionals considered parental behaviour around diet and physical activity and parenting skills linked to cooking and diet and managing behaviour to be amongst the causes of obesity in children

- $\quad$ Awareness and assessment of obesity is complicated for non-health care professionals who were unclear as how to define childhood obesity. This lack of clarity had the potential to impact on subsequent actions or interventions

- $\quad$ Professional responses were shaped by attitudes and experiences of obesity either personally or within a professional capacity

- $\quad$ Professionals from all disciplines had limited knowledge of the services on offer to support overweight children with role responsibility and ownership unclear

- Obesity was linked to other areas of concern - such as neglect, self-esteem, school attendance, bullying, sexual abuse and emotional abuse

\section{Child Protection}

- Whether child obesity can be a standalone child protection concern is contested

- $\quad$ Child obesity is a child protection concern when linked to child neglect

- $\quad$ Familial recognition of obesity as having significant impact on child welfare was seen as central to the effectiveness of interventions and a lack of familial engagement in the support offered central to child protection involvement

- $\quad$ For child protection services to undertake work, referrals need to meet a severity threshold for intervention to occur. This threshold is nuanced, complex and changes over time, does not operate as a single line to be crossed and can act as an inhibitor to providing services

\section{Implications for practice}

- Guidance and training on the identification, assessment and implications of child obesity would be welcomed by all professions

- $\quad$ A framework and procedures to guide multi-disciplinary practice in relation to child obesity would be welcomed

- The Viner framework although not evidence based met with some, but not universal, approval and could provide the basis for a child protection framework in relation to child obesity

- $\quad$ A multidisciplinary holistic approach is required in working with and assessing child obesity - within universal health and social care services, early intervention and child protection services

- $\quad$ Direct obesity focussed work with children and families can bring about change

- $\quad$ The short and long term effectiveness of both statutory and early help interventions in respect of child obesity was unclear to participants and is under researched 


\section{Introduction}

This report presents findings from a research project which explored an area of increasing concern to health and social care professionals; the extent to which child obesity represents a child protection issue. The research was funded and supported by the National Institute for Health Research, Collaboration for Leadership in Applied Health Research \& Care for Yorkshire \& Humber (CLAHRC-YH) and located in one Local Authority, Doncaster. The research was undertaken by the Department of Social Work Social Care and Community Studies and the Centre for Health and Social Care Research at Sheffield Hallam University.

The research aimed to understand whether childhood obesity is a child protection concern and had four objectives. Namely to:

1. Explore the current and past practice of staff working within child protection and obesity services regarding child protection and obesity

2. Explore staff perceptions of childhood obesity as a child protection issue using interview and focus group methods

3. Explore the use of the Viner et al (2010) framework for action to understand child protection concerns for children who are obese

4. To develop a protocol for future primary research

The research sought to identify existing practice, through interviews and focus groups with key stakeholders from social care, health and education in one local authority, exploring their decision making, views and experiences of working with obesity and the child protection system.

\section{Background}

\section{Project Origin}

The idea for the research came from the healthy weight network group that meets quarterly under the auspices of CLAHRC-YH. This group was previously developed under the obesity theme of South Yorkshire CLAHRC from 2008. When CLAHRC changed to Yorkshire and Humber in 2014 the group changed to a Healthy Weight theme. The network is attended by academic, NHS, local authority staff and provider services from across the $Y \& H$ region. There are regular presentations from students, academics and partners on current research projects or research issues with which partners require academic support. The research aim was initially raised as an idea by a Paediatric Consultant from Sheffield Children's Hospital who sees many children who are morbidly obese - there was a discussion on whether anyone had explored the links between child protection and obesity, and questions were raised such as are children and families supported from an early age with weight problems? Is it a safeguarding issue? Does it only become one when children are referred to specialist care?

\section{Obesity}

Obesity is a key public health concern in England, not least because of its substantial impact on morbidity and mortality, but also the wider costs to the NHS and society. Economically more is spent each year on the treatment of obesity and diabetes than on other public services (McKinsey Global Institute 2014). The Foresight report (Government Office for Science, 2007) predicted NHS costs attributable to overweight and obesity may be $£ 9.7$ billion by 2050 , with wider societal costs predicted to reach $£ 49.9$ billion per year. At the individual level, the consequences of being obese on 
physical and psychological health can be severe. Obesity reduces life expectancy by causing the onset of chronic diseases such as type 2 diabetes, cardiovascular disease and cancer (Colquitt et al 2014). Obesity is also a cause of disability, osteoarthritis (Guh et al 2009), obstructive sleep apnoea (Franco Sassi 2010, Colquitt et al 2014) and reduced quality of life (Twells et al 2013). Obesity is associated with poor psychological morbidity (Picot et al 2009) and adverse social consequences linked to stigmatisation and social isolation (Phul 2001, 2009, da Silva et al 2012).

The short-term and long-term risks of obesity for children are severe. Obese children are likely to become obese adults. Whilst symptoms of the associated morbidity may not become apparent until children reach adulthood an increased number of children are being diagnosed with illnesses such as Type 2 diabetes. In the short term, overweight and obese children suffer from the negative psychological effects of their excess weight (Reilly et al 2003). There is an increased likelihood of children suffering from depression, poor educational attainment, increased risk of peer bullying and social exclusion.

In simple terms, obesity is caused by the imbalance of energy in (food consumed through diet) and energy out (energy used by the body to be physically active) (Department of Health (DH) 2008). A worldwide decrease in levels of physical activity and an increase in the availability and consumption of energy dense food have contributed to the increased global levels of obesity. However obesity is not simply a result of overeating (Engstrom et al 2011). It is a complex, systemic problem (McKinsey Global Institute 2014) with a number of complex roots. Obesity is commonly linked to socioeconomic status and deprivation. Evidence suggests an increased prevalence in children from low-income households (National Statistics 2017).

The increased prevalence has been identified through the NCMP which measures the height and weight of over one-million children aged 4-5 and 10-11 years each year in primary schools in England. The surveillance data highlights those children from the poorest income groups of reception (aged 4-5 years) and year 6 (aged 10-11 years) are twice as likely to be obese compared to their most well off peers. 2016/17 data from the National Childhood Measurement Programme indicated that in England $9.6 \%$ of reception aged children are classed as obese and $20.0 \%$ obese at year 6 (National Statistics 2017).

Various National polices and documents produced over recent years have outlined different approaches to tackling childhood obesity with increased emphasis on a whole systems approach. The recent publication of the Childhood Obesity Plan (HM Government 2016) sets a framework to address these concerns and aims to 'significantly reduce England's rate of childhood obesity within the next 10 years'.

\section{Local Context}

The study was based in Doncaster a town in South Yorkshire which forms part of the Metropolitan Borough of Doncaster. Doncaster MBC has a resident population estimated to be just over 303,600 people (150,100 men and 153,500 women). The town itself has a population of 109,805. A large and historic market town, with a rich horse racing, manufacturing, railway and mining heritage, the town suffered from the demise of the mining industry and recession. The health of people in Doncaster is generally worse than the England average. Life expectancy for both men and women is lower than the England average. Doncaster is one of the $20 \%$ most deprived districts/unitary authorities in England (Public Health England 2016) and about 24\% $(16,035)$ of children live in low income families (HM Revenues and Customs 2016). 
The charts are based on 3 years of data from the NCMP. Children are measured at the age of 4 to 5 years (in reception year) and at the age of 10 to 11 years (year 6). The charts show the geographical location in Doncaster and how areas within Doncaster compare with the rest of England.

Chart 1. Comparative data between England, Doncaster and statistical neighbours of children aged 4-5 years (reception) who have excess weight

Obese All children with excess weight, some of whom are obese

Children aged 4-5 years who have excess weight, 2015/16 (percentage)

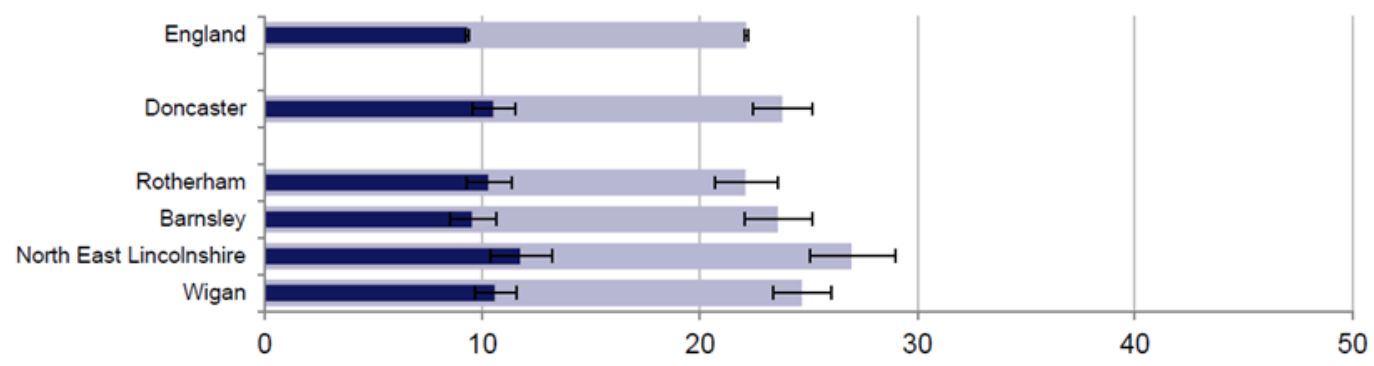

Chart 2. Comparative data between England, Doncaster and statistical neighbours of children aged 10-11 years (year 6 ) who have excess weight

Children aged 10-11 years who have excess weight, 2015/16 (percentage)

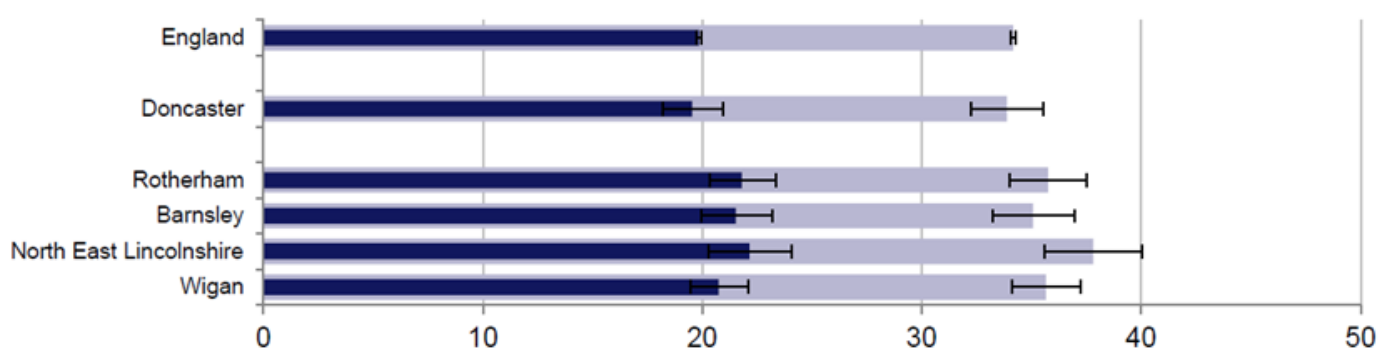

Chart 3 Geographical location of obese children in Doncaster in reception year and year 6 .

The charts were generated using data from: Department of Energy and Climate Change; Fuel poverty sub regional statistics Health and Social Care Information Centre; PHE Obesity

At the age of 4 to 5 years, $9.5 \%$ of children measured in Doncaster are assessed as obese. At the age of 10 to 11 years, $18.8 \%$ of children in Doncaster are considered obese. The charts show the prevalence of obesity within Doncaster's communities; the areas highlighted in red such as Doncaster Town Centre, Balby, Wheatley, Stainforth and Hexthorpe are the community's with the highest rates of obesity. The charts suggest that there is a comparison of the communities with high rates of obesity and the communities where children are living in low income families. 


\section{Obese Children in reception}

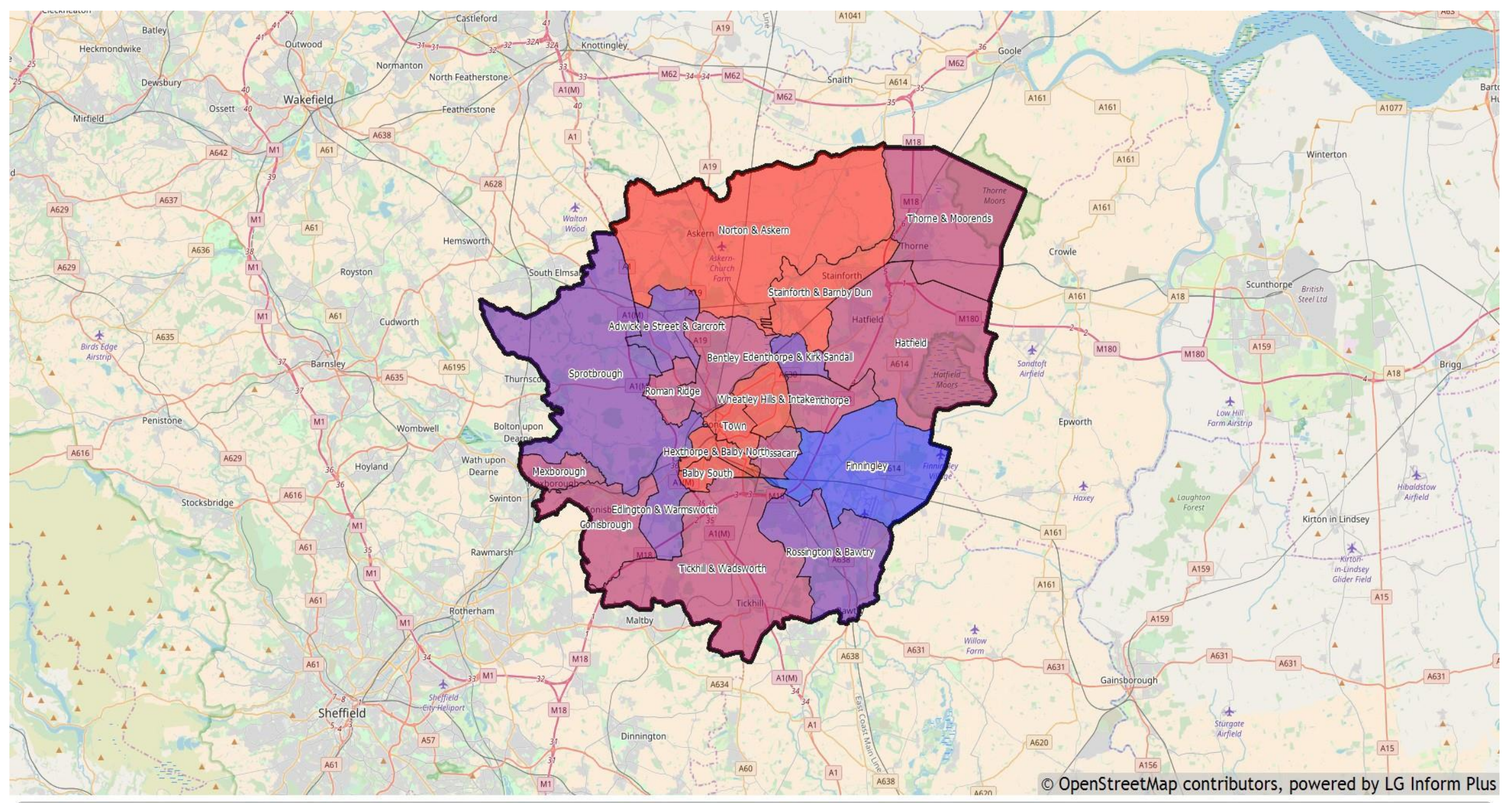

Obese children in reception year (\%) (2012/13-14/15 (academic))

$\geq 0.0 \leq 7.0 \%$

D $7.0 \leq 8.6 \%$

D $>8.6 \leq 10.4 \%$

$>10.4 \leq 20.2 \%$ 


\section{Obesity, Safeguarding and Child Protection}

Within England and Wales (but also replicated more widely) there is an important distinction between the concepts of Safeguarding and Child Protection. Safeguarding, and promoting the welfare of children, is a broader term than child protection. It encompasses protecting children from maltreatment, preventing impairment of children's health or development, and ensures children grow up in safe circumstances. Safeguarding is often seen as preventative, involving promoting the welfare of children by protecting them from harm and recognising and mitigating risks to their safety. Child protection is part of safeguarding and refers to activities undertaken to protect children suffering, or likely to suffer, significant harm as a result of the care given to a child not being what it would be reasonable to expect a parent to give to a child or that the child is beyond parental control.

The concept significant harm in relation to children was introduced under sections 31(9) and (10) of the Children Act 1989 as amended by the Adoption and Children Act 2002:

\section{Care and Supervision}

(1)On the application of any local authority or authorised person, the court may make an order-

(a)placing the child with respect to whom the application is made in the care of a designated local authority; or

(b)putting him under the supervision of a designated local authority

(2)A court may only make a care order or supervision order if it is satisfied-

(a)that the child concerned is suffering, or is likely to suffer, significant harm; and

(b)that the harm, or likelihood of harm, is attributable to-

(i)the care given to the child, or likely to be given to him if the order were not made, not being what it would be reasonable to expect a parent to give to him; or

(ii)the child's being beyond parental control.

(3)No care order or supervision order may be made with respect to a child who has reached the age of seventeen (or sixteen, in the case of a child who is married

Significant harm is therefore the threshold that justifies compulsory intervention in family life in the best interests of children.

- Harm is defined as the ill treatment (including sexual and non-physical abuse) or impairment of health (physical or mental) or development (physical, intellectual, emotional, social or behavioural) including, for example, impairment suffered from seeing or hearing the ill-treatment of another.

- Significant in relation to health or development is in comparison to what could reasonably be expected of a similar child.

- Health means physical or mental

- Development means physical, intellectual, emotional, social or behavioural development.

- III-treatment includes sexual abuse and forms of ill-treatment which are not physical.

Physical abuse, sexual abuse, emotional abuse and neglect are all categories of Significant Harm. 
There are no absolute criteria on which to rely when judging what constitutes significant harm. The key factor is that significant harm should be as a result of the care given to a child not being what it would be reasonable to expect a parent to give to a child. Where the question of whether harm suffered by a child is significant turns on the child's health and development, his health or development shall be compared with that which could reasonably be expected of a similar child. Sometimes a single violent episode may constitute significant harm but more often it is an accumulation of significant events, both acute and longstanding, which interrupt damage or change the child's development (Adcock and White 1998).

Three further legal requirements are important in guiding practice.

1. Firstly the court will only make a care or supervision order if it is satisfied that it is better than making no order at all (s.1 (5) CCA 89)

2. Secondly that if a local authority have reasonable cause to believe that a child is suffering or likely to suffer significant harm they must make enquiries to enable a decision on any necessary action to safeguard and promote the child's welfare (s.47 CCA 89)

3. Thirdly if the child is unlikely to achieve/maintain a reasonable standard of health/development but there is no immediate risk of significant harm then action and provision of services are required under S17 CA 89 in respect of a child judged to be in need

\section{Provision of services for children in need, their families and others.}

(1)It shall be the general duty of every local authority (in addition to the other duties imposed on them by this Part)-

(a)to safeguard and promote the welfare of children within their area who are in need; and

(b)so far as is consistent with that duty, to promote the upbringing of such children by their families,

by providing a range and level of services appropriate to those children's needs.

(10)For the purposes of this Part a child shall be taken to be in need if-

(a)he is unlikely to achieve or maintain, or to have the opportunity of achieving or maintaining, a reasonable standard of health or development without the provision for him of services by a local authority under this Part;

(b)his health or development is likely to be significantly impaired, or further impaired, without the provision for him of such services; or

(c)he is disabled

It is in this legal and practice context that the question of whether childhood obesity is a child protection concern is located. Does childhood obesity constitute significant harm? Does childhood obesity provide the grounds for the compulsory removal of a child from their parents?

Within the UK it is a question which has attracted considerable media interest; in the tabloid press, (Daily Mirror 2014) the broadsheets (The Independent, Johnston 2014), radio (BBC radio 4 2012) and television (BBC 2007). The impact of obesity on child health seems clear yet the public and social commentators are divided on whether a child should be removed from parents who do not seek to reduce their child's weight. It is a division which is reflected in the social work profession as comments from social workers in a discussion in Community Care (2010), indicate:

'Overseeing a child's diet, nutrition, fitness and health are key fundamental requirements for parents and carers. Failures in these areas could and should be grounds for investigating neglect and abuse.' 
'If any policy is to be implemented, it needs to be universal, not one that singles out vulnerable people because they just happen to be known to us. I would agree for support with weight management should be offered as part of a supportive service or part of a CP plan, but it should not turn us into a "fat police", which is what appears to be happening.'

Interest and contention is not restricted to the social work profession. In 2007 the British Medical Association rejected a motion that childhood obesity in under $12 \mathrm{~s}$ should result in legal protection for the child and parents being charged with neglect. In the same month a BBC report indicated that a survey of consultant paediatricians reported obesity had been a factor in 20 child protection cases in the previous year. A contrary view was provided by research indicating children with a rare genetic deletion associated with overeating had also been on the child protection register which was reported as indicating families of obese children were being unfairly treated (Viner et al 2010). Where there appears to be growing evidence is the association of obesity with childhood interpersonal violence including physical and sexual abuse and peer bullying behaviour (Midei and Matthews, 2011). Here however the primary cause for intervention is the abusive behaviour with obesity an associated factor.

In the UK there is a variety of practice with a consideration of obesity being incorporated in some multi-agency child protection procedures https://www.norfolklscb.org/about/policies-procedures/524-safeguarding-response-to-obesity-when-neglect-is-an-issue/ (see appendix two) but having no mention in others. Yet there is little research to inform either practice or policy. Data on the number of children brought into care on the basis of obesity is difficult to find. The most accessible information, obtained by the Daily Mirror in 2014 under a Freedom of Information request, indicates that over a five year period, in 128 councils between 26 and 46 obese children were taken into care. Taken as a snapshot the Mirror suggests this indicates that overall 74 obese children may have been taken into care (Bagot 2014). There appears to be little if any research evidence on the outcomes of these interventions. Neither is interest restricted to the UK with arguments in favour of obesity being seen as a child protection issue being presented in Australia (Alexander et al 2009) and the USA (Jones et al 2014). Yet as Jones et al indicate little research has been conducted to inform policies or practices that are being implemented in some states in the USA.

Whether separate guidelines on the identification of obesity as a child protection concern are required is a further contested area. Arguments indicating that a surfeit of guidelines inhibits practice are set against practitioners welcoming guidance that helps separate out the impact of poverty and education from neglect (Griffiths 2010). In the absence of evidence the most influential guidance remains the 2010 paper by Viner et al which suggests a framework to understand child protection concerns with children who are obese. Namely:

- Childhood obesity alone is not a child protection issue

- $\quad$ Failure to reduce overweight alone is not a child protection concern

- Consistent failure to change lifestyle and engage with outside support indicates neglect, particularly in younger children

- $\quad$ Obesity may be part of wider concerns about neglect or emotional abuse

- $\quad$ Assessment should include systemic (family and environmental) factors

It is this framework which is both quoted and incorporated into the child protection procedures of some local authorities (see appendix 2 for an example of fully worked up procedures) but there appears to be no research which has tested its usefulness or applicability in practice. 


\section{Methodology}

\section{Design}

The project is an in depth qualitative exploration of the current practice of staff working within child protection and obesity services regarding child protection and obesity, using interview and focus group methods. Individual semi-structured interviews were held with 23 health and social care staff and 3 focus groups held with 24 staff. The interviews and focus groups explored perceptions of childhood obesity as a child protection issue.

It is important to stress that although the research was set in Doncaster the study is by no means an evaluation of services provided in Doncaster. Participants were encouraged to discuss their views and experiences gained throughout their career and from working in a variety of roles and geographical locations.

Ethical approval was provided by Sheffield Hallam University and research governance from Doncaster MBC. A project advisory group was set up from health and social care professionals which met virtually at the outset of the project, to guide the direction of the research, interviewing content and protocol, and to inform sampling.

\section{Setting}

State support and services for children, with the exception of education and learning, is provided in Doncaster by Doncaster Children's Services Trust. The Trust is an independent company, limited by guarantee, created by the Department of Education. They work under the direction of the Secretary of State for Education, providing children's social care services for Doncaster Metropolitan Borough Council. The council retains its statutory duty and responsibility for the children of Doncaster. (http://www.doncasterchildrenstrust.co.uk/who-we-are)

The Trust began work on 1 October 2014 offering children's social care, intensive family support and youth offending services. The Trust is responsible for its own finance, staffing and property requirements, as well as the day-to-day delivery of children's social care services. The services include Early Help, Social Care, Children's Homes, Intensive Family Support, Youth Offending Services, 18+ Service and Fostering and Adoption.

Education and public health services are provided by Doncaster Metropolitan Borough Council http://www.doncaster.gov.uk/services/schools

http://www.doncaster.gov.uk/services/health-wellbeing/public-health

Primary and acute health services by Doncaster and Bassetlaw NHS foundation Trust http://www.dbh.nhs.uk/

Doncaster's obesity and deprivation profile appears in the Local Context section of the Background chapter. 


\begin{tabular}{|c|c|c|}
\hline Job Title & Role & Organisation \\
\hline Stronger Communities Manager & Manager & $\begin{array}{l}\text { Doncaster Metropolitan Borough } \\
\text { Council }\end{array}$ \\
\hline $\begin{array}{l}\text { Deputy Director of Nursing } \\
\text { Midwifery }\end{array}$ & Senior Manager & Doncaster and Bassetlaw Hospital \\
\hline $\begin{array}{l}\text { Named Nurse for Safeguarding } \\
\text { Children }\end{array}$ & $\begin{array}{l}\text { Manager / } \\
\text { Practitioner }\end{array}$ & $\begin{array}{l}\text { Rotherham Doncaster and South } \\
\text { Humber NHS Foundation Trust }\end{array}$ \\
\hline $\begin{array}{l}\text { Family Support Worker for } \\
\text { Stronger Families }\end{array}$ & Practitioner & $\begin{array}{l}\text { Doncaster Metropolitan Borough } \\
\text { Council }\end{array}$ \\
\hline $\begin{array}{l}\text { Head of Service for Learning } \\
\text { Engagement }\end{array}$ & Senior Manager & $\begin{array}{l}\text { Doncaster Metropolitan Borough } \\
\text { Council }\end{array}$ \\
\hline Public Health Specialist & Manager & $\begin{array}{l}\text { Doncaster Metropolitan Borough } \\
\text { Council }\end{array}$ \\
\hline Head of Stronger Families & Senior Manager & $\begin{array}{l}\text { Doncaster Metropolitan Borough } \\
\text { Council }\end{array}$ \\
\hline $\begin{array}{l}\text { Stronger Families Community } \\
\text { Manager }\end{array}$ & Manager & $\begin{array}{l}\text { Doncaster Metropolitan Borough } \\
\text { Council }\end{array}$ \\
\hline $\begin{array}{l}\text { Senior Environmental Health } \\
\text { Practitioner }\end{array}$ & Practitioner & $\begin{array}{l}\text { Doncaster Metropolitan Borough } \\
\text { Council }\end{array}$ \\
\hline $\begin{array}{l}\text { Named Nurse for Safeguarding } \\
\text { Children }\end{array}$ & $\begin{array}{l}\text { Manager / } \\
\text { Practitioner }\end{array}$ & Doncaster and Bassetlaw Hospital \\
\hline Lead Nurse for school Nursing & Practitioner & $\begin{array}{l}\text { Doncaster Metropolitan Borough } \\
\text { Council }\end{array}$ \\
\hline $\begin{array}{l}\text { Chair Initial Child Protection } \\
\text { Conference }\end{array}$ & Practitioner & $\begin{array}{l}\text { Doncaster Children's Services } \\
\text { Trust }\end{array}$ \\
\hline $\begin{array}{l}\text { Training and Development } \\
\text { Safeguarding Manager }\end{array}$ & Manager & $\begin{array}{l}\text { Doncaster Children's Services } \\
\text { Trust }\end{array}$ \\
\hline Supervising Social Worker & Practitioner & $\begin{array}{l}\text { Doncaster Children's Services } \\
\text { Trust }\end{array}$ \\
\hline $\begin{array}{l}\text { Child Protection Conference } \\
\text { Chair }\end{array}$ & Practitioner & $\begin{array}{l}\text { Doncaster Children's Services } \\
\text { Trust }\end{array}$ \\
\hline Independent Reviewing Officer & Practitioner & $\begin{array}{l}\text { Doncaster Children's Services } \\
\text { Trust }\end{array}$ \\
\hline $\begin{array}{l}\text { Head of Service for Safeguarding } \\
\text { and Standards and Policy }\end{array}$ & Senior Manager & $\begin{array}{l}\text { Doncaster Children's Services } \\
\text { Trust }\end{array}$ \\
\hline Independent Reviewing Officer & Practitioner & $\begin{array}{l}\text { Doncaster Children's Services } \\
\text { Trust }\end{array}$ \\
\hline GP-Senior Partner & Practitioner & NHS \\
\hline Community Staff Nurse & Practitioner & NHS \\
\hline Paediatrician & Practitioner & Sheffield Children's Hospital \\
\hline GP 2 & Practitioner & NHS \\
\hline Primary School Head Teacher & Practitioner & $\begin{array}{l}\text { Doncaster Metropolitan Borough } \\
\text { Council }\end{array}$ \\
\hline
\end{tabular}




\section{Sampling}

Sampling was conducted in a purposive manner to include a range of participants linked to their role with child protection and social care. The sample sought to cover the range of social care and social work professionals from early help through child protection investigation to adoption and from individual workers to middle and senior managers. The sample also sought to cover health services including nurses, GPs and paediatricians and education services. The sample size was limited by the funding available and consequent researcher time but was broadly successful in covering the range of participants (see table 1, page 18 for participant characteristics)

Participants were initially identified in consultation with the project advisory group. Recruitment then snowballed through identification of participants by recommendation from the wider staff group within specific professional groupings. Staff were chosen linked to their role with child protection in local authorities, primary and acute care. DMBC supported the recruitment of participants, through dissemination of information sheets, email contact and the provision of interview facilities. Given the service delivery pattern within Doncaster it was important to get buyin to the research from senior managers both in DMBC and in the Children's Trust. Once this was achieved the initial slow recruitment of social work staff in particular progressed more quickly.

Prospective participants were provided with a participant information sheet (appendix 5) and allowed time to consider participating in the study. If they agreed and following the signing of a consent form (see appendix 4) semi-structured interviews were conducted in a private area at their place of work. The interviews lasted for around 60 minutes. Focus groups were conducted both to maximise the time commitment of participants, to utilise existing staff meetings and to bring a discursive element to the data collected.

The interviews and focus groups were recorded and transcribed in full. The transcriptions were anonymised and any data identifying the individual removed. The data was stored securely within a protected base at Sheffield Hallam University in accordance with data protection protocol. Information relating to role and profession was retained as who said what and why was important for the analysis phase of the research. The number given to each participant relates to the anonymised code ascribed for purposes of data collection and analysis. See tables 1 page 18 and 2 page 20 for full details of participant characteristics.

Interviews took a semi-structured pattern and were conducted using an interview schedule devised collectively by the research team in consultation with the initial advisory group. A related schedule was used for the focus groups (see appendix 3 ) Two members of the team were responsible for undertaking interviews. Following an initial joint interview to test the schedule these were undertaken individually with PN undertaking (17) and LP (5). 
Table 2 - Focus group Participants Characteristics

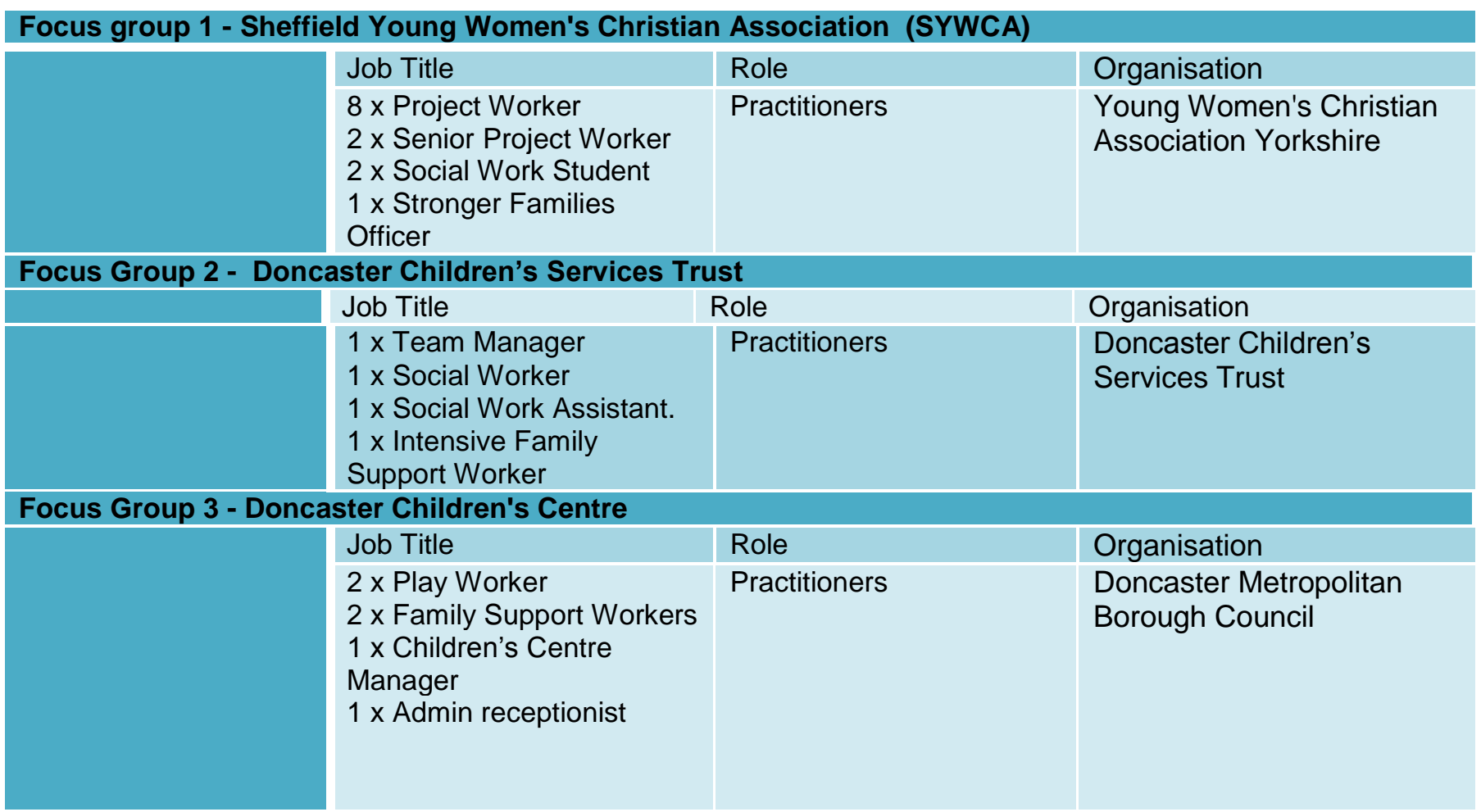

Focus groups

Three focus groups were undertaken - see table 2 . One focus group was undertaken by both researchers (PN and LP) and two by PN. The focus groups allowed the research questions to be debated by participants and individual ideas and views were challenged and tested through group discussion. Participants shared their professional experiences and case examples which then became the subject of group analysis and discussion. Consequently although guided by a schedule comparative to that used in individual interviews, the focus groups provided different data which both complemented and enriched that obtained from individual interviews. 


\section{Data Analysis}

Anonymisation was undertaken and participants were given identifying codes as set out in table 3 .

\section{Table 3 - Interview Participant ID numbers}

\begin{tabular}{|l|l|}
\hline Participant ID Number & Job Title \\
\hline 1 & Community Service Manager \\
\hline 2 & Senior Manager in Nursing Midwifery \\
\hline 3 & Named Nurse for Safeguarding Children \\
\hline 4 & Family Support Worker for Stronger Families \\
\hline 5 & Pead of Service \\
\hline 6 & Head of Service \\
\hline 7 & Community Service Manager \\
\hline 8 & Senior Environmental Health Practitioner \\
\hline 9 & Named Nurse for Safeguarding Children \\
\hline 10 & School Nurse \\
\hline 11 & Child Protection Conference Chair \\
\hline 12 & Training Manager \\
\hline 13 & Supervising Social Worker \\
\hline 14 & Child Protection Conference Chair \\
\hline 15 & Independent Reviewing Officer \\
\hline 16 & Head of Service \\
\hline 17 & Independent Reviewing Officer \\
\hline 18 & GP \\
\hline 19 & Community Staff Nurse \\
\hline 20 & Paediatrician \\
\hline 21 & GP \\
\hline 22 & Primary School Head Teacher \\
\hline 23 & \\
\hline
\end{tabular}

Following transcription, the data from all individual and group interviews were entered in Microsoft Office Word on to a password protected network available only to the research team. Framework analysis methods were used to generate categories, codes and themes that capture the experiences, views and perceptions of the sample. Framework analysis has emerged from policy research and is a pragmatic and systematic approach to qualitative data analysis. (Gale et al 2013, Ritchie and Lewis 2003) It involves a systematic process of sifting, charting and sorting the material into key issues and themes. It allows the integration of pre-existing themes into the emerging data analysis. Framework analysis has been used and is particularly useful in multi-disciplinary health research teams (Gale et al 2013).

The research team took a collective analysis approach. The whole team met together and initially read and coded three transcripts each. These were discussed and a set of categories and codes developed which formed the initial analytical framework. One researcher (PN) then read all the 
transcripts and developed a coding framework with new codes emerging and others which were conceptually related being merged. The categories were colour coded and quotations highlighted on the transcripts which related to the specific category.

VPH read and coded 5 transcripts in the light of the framework and $\mathrm{CH}$ randomly sampled already coded transcripts. The team then met again and using graphical imagery agreed a set of categories and codes. Two categories were then taken by each member of the research team and the transcripts read again in the light of those categories until no new codes emerged.

At the same time analytic memos were created by researchers in respect of the two categories of which they were undertaking final coding. These memos followed sub headings: of definition, codes, summary of findings and points for further consideration. Illustrative quotations were identified under each code.

At the next meeting the final analytic framework was agreed and data charted on to a matrix. The matrix was then collectively reviewed, alongside the analytic memos, and subsequent discussion, sought to interpret the data. The intention was to develop themes which offered some explanations for what was being presented in the data. The process was informed by the original research aims alongside concepts generated inductively from the data.

The following table displays the themes and subthemes derived from the interview and focus group data. 
Table 4 - Thematic framework

\begin{tabular}{|c|c|c|}
\hline Categories & Codes & Sub Themes \\
\hline Obesity & $\begin{array}{l}\text { Professional } \\
\text { understanding of } \\
\text { causes, } \\
\text { - Professional } \\
\text { understanding of } \\
\text { consequences } \\
\text { - Personal and } \\
\text { professional } \\
\text { experiences shape } \\
\text { professional response, } \\
\text { - Assessment and } \\
\text { identification } \\
\text { - Social factors }\end{array}$ & $\begin{array}{l}\text { - Parental behaviour } \\
\text { - Parental skills } \\
\text { - } \quad \text { Physical - short term - long term } \\
\text { - } \text { Psychosocial - short term - long term } \\
\text { - } \text { training } \\
\text { - Poverty - culture }\end{array}$ \\
\hline Thresholds & $\begin{array}{l}\text { - } \text { Ambiguity } \\
\text { - Personal } \\
\text { - } \text { Referrer's agency } \\
\text { - } \text { Perceived } \\
\text { - } \text { Actual } \\
\text { - } \text { Legal } \\
\text { - } \text { Multi-agency }\end{array}$ & $\begin{array}{l}\text { - Significant harm } \\
\text { - } \quad \text { Child in need }\end{array}$ \\
\hline $\begin{array}{l}\text { Child } \\
\text { Protection }\end{array}$ & $\begin{array}{l}\text { - Obesity is not a child } \\
\text { - Obection concern } \\
\text { - } \text { protection concern } \\
\text { - Obesity and neglect } \\
\text { - Intervention levels } \\
\text { - Prevalence }\end{array}$ & $\begin{array}{l}\text { - Universal services } \\
\text { - Prevention and early help } \\
\text { - Legal (statutory) intervention }\end{array}$ \\
\hline $\begin{array}{l}\text { Viner } \\
\text { Framework }\end{array}$ & $\begin{array}{l}\text { - Awareness } \\
\text { - Agree } \\
\text { - } \text { Disagree } \\
\text { - Ambiguous }\end{array}$ & $\begin{array}{l}\text { - Knowledge } \\
\text { - Standalone child protection concern - is - is } \\
\text { not }\end{array}$ \\
\hline $\begin{array}{l}\text { Good } \\
\text { Practice }\end{array}$ & $\begin{array}{l}\text { - } \quad \text { Multi-agency approach } \\
\text { - } \text { Holistic understanding } \\
\text { - } \text { Direct work } \\
\text { - } \text { Parental education } \\
\text { - Service user } \\
\text { involvement } \\
\text { - Preventative work }\end{array}$ & - Whole family approach \\
\hline $\begin{array}{l}\text { Challenges } \\
\text { for Practice }\end{array}$ & $\begin{array}{l}\text { - } \quad \text { Multi-agency working } \\
\text { - } \quad \text { Lack of support } \\
\text { - } \quad \text { Barriers to accepting } \\
\text { support } \\
\text { - } \quad \text { Problematic direct work }\end{array}$ & $\begin{array}{l}\text { - } \quad \text { Lack of information } \\
\text { - } \quad \text { Non statutory working with agreements } \\
\text { - } \quad \text { Lack of funding } \\
\text { - } \quad \text { Practitioners beliefs about weight } \\
\text { - Identification }\end{array}$ \\
\hline $\begin{array}{l}\text { Suggestions } \\
\text { for Future }\end{array}$ & $\begin{array}{l}\text { - Training } \\
\text { - Provide guidance, } \\
\text { procedures and } \\
\text { Framework } \\
\text { - Outcome research }\end{array}$ & $\begin{array}{l}\text { - Practice ideas } \\
\text { - Dissemination }\end{array}$ \\
\hline
\end{tabular}




\section{Findings}

The following section presents the findings in narrative form with illustrative quotations. A summary table is presented in appendix six.

\section{Obesity}

The professionals interviewed understood the short and long-term impacts obesity could have on a young person's physical and psychosocial health. Social factors such as culture and poverty combined with parent's lack of skills and knowledge about the impacts of a poor diet and their own dietary behaviours were often blamed for young people being obese. Whilst obesity training per se was not accessed by most of the professionals interviewed, many had knowledge of healthy eating and cooking programmes or local interventions that families could access. The personal experience of the interviewee with regards to obesity shaped their response to families, in terms of awareness of the issue and raising it with families they worked with. The clinical nature of assessing and identifying obesity provides complications for non-health professionals.

\section{Professional understanding of causes - complexity}

Obesity was thought to be caused by a range of factors. Participants gave various examples of complex situations and factors that influence the dietary behaviours and levels of obesity within the families they worked with. Participants talked about how the obesogenic environment, the environment in which people live influences eating behaviours and therefore the likelihood of becoming obese. Access to cheaper food is often more likely to be processed and unhealthy making it harder to have a healthy diet:

But also I think the difference in the food that's available, I think because there's a lot more processed food, a lot more stuff that's available for them to actually eat that's not good for you, like pizza, like things. If you look in our supermarkets it's cheaper to buy rubbish than it is to buy things that are healthy. And that you have to cook yourself. It's cheaper to buy a cheap pizza and fish fingers and all sorts of things that are available than it is to buy the healthy fruit and veg. (P9)

The makeup of families and the challenges of children's behaviour often mean that food and healthy eating is low down the list of priorities:

When you've got families that don't talk to each other and they all eat at different times and a mum can't control Billy and she doesn't know where he eats and this, that and the other, it's difficult to then start looking at, actually forget all that mum, but Billy needs to eat this food. She's not interested, what she actually wants is Billy to come home in the first instance. (P1)

Professionals discussed the misconceptions that people have over the influence of genetics as a cause of obesity:

Overweight children tend to come from overweight families where they think it's in the bones. So you get that drummed into you that it's not because of what I'm eating, it's because I'm going to be big anyway, so I might as well eat because it's inevitable that it's going to happen. (P14)

One respondent gave an example of deep psychological trauma that they considered to have influenced a client's weight gain:

Yeah, a young girl that's come into our accommodation and she's morbidly obese. And she'd gone through child sexual exploitation and she'd been to court, really traumatic for her and she'd put a lot of weight on through that process. She didn't tell me it was to make herself unattractive, but yeah. (FG1) 
Causes of obesity were attributed to parental behaviour by many of the respondents. Interviewees reported that the parents they worked with were often poorly educated on what constitutes a healthy diet and how parental engagement with physical activity was often lacking which would impact on their children's experience and behaviours:

We're often looking at poorly educated parents who may have had a poor diet themselves, not particularly good experience of physical activities and things like that, (P13)

Interviewees referred to cases where parents were overweight themselves and also had an unhealthy diet which manifested in their children's diets and eating behaviours therefore influencing levels of obesity:

Well the parents are overweight, so in a way that's all right. No, it's not because we actually want to be working with them as well. Oh well, dad's big, so that kind of explains it and therefore it's not a problem. Well no, it is a problem because it just tells us something about how the family operate as a whole. (P3)

Now I'm working with foster carers it's quite a common, especially on unannounced. So when we do visits. I'm just thinking of one carer in particular. Every time you see him he's giving the child a steak bake or a sausage roll. He's big himself, and although I don't discriminate, I think it does raise questions about when you're assessing people, what their attitudes are on food. And I don't think you go into it enough (P14)

Many respondents recalled accounts of parents using unhealthy food as tools to manage their child's behaviours or letting the child have control over the food they ate:

Because the parent if you like is almost deliberately trying to reward the child and push them off by feeding them inappropriate volumes of food, and indeed appropriate types of food, simply because they want them out of the way, keep them quiet, so it's easier to do so. Or they see it as a behavioural tool and method to manage their behaviour. (P8)

Mum indulged his need for food and quite often they would have Kentucky's every day, takeaways, chocolate. He chose the food when they went shopping, he picked the food. He didn't have any involvement in cooking the food, you know, the things that we would want a family to do with a child, and so his weight went up and up and he put on a huge amount of weight in a very short space of time (P11)

Income and socio economic status was considered to be an additional factor in influencing these behaviours:

So in low income groups in my experience as a child protection chair and as a social worker, it has been that it's been used as a pacifier for parents who are struggling to manage a child's behaviour. And struggle to say no. (P15)

\section{Professional understanding of causes - parental skills}

Professionals interviewed discussed how parents lacked cooking and domestic skills which meant the types of food they gave their children were often quick convenience meals that lacked any nutrition:

I think it's also skills in the kitchen as well. I think there's not many people that I work with that have got them skills to cook a healthy meal anyway. It's just get your chicken nuggets in the oven and some chips and that's it. They've not got them skills. (FG1)

They've got low social skills as parents themselves, which result in not being particularly very good from a domestic perspective and all sorts of stuff like that really (P8) 
But then again it's down to education. If it's going through generations they don't know how to cook fresh, it is beige food stuck in an oven. (P14)

This lack of cooking and domestic skills was considered to be a product of having no role models to educate and show them how to cook and prepare healthy food for their children. Even where parents may have the skills it was thought that they were often so busy with work they relied on convenience food to feed their children:

I just think sometimes families today they've had no role models, they don't know how to cook, they don't know how to have healthy meals and then you've got families at the other end of the spectrum that are busy, that work all hours, they haven't got time to cook a nutritious meal and it is something processed and quick. So I think it's about education, definitely about education to start with. (P10)

Many of the families that professionals worked with were constrained by low incomes, however professionals thought that with better budgeting skills they would be able to plan meals and make use of low cost supermarkets.

We've got some really brilliant budget supermarkets. So they could go and do that family shop. It's very, not planned, it's not thought through. They've not budgeted for the week. They're living day-byday-by-day. (P4)

Professional understanding of causes - child / young person's behaviours

Participants talked about behaviours linked to obesity being learned and developed from a young age. They felt this was harder to break and reverse the impacts particularly when the behaviours were entrenched in the whole family:

I think there's something as well about behaviours, if you get used to eating in a certain way or whatever it is that might have caused you to overeat to become obese, then sometimes it's difficult, it's just hard to break those behaviours then isn't it? (P2)

One of the issues what we find is that we've got obviously young people, again going back to learning behaviours type activity, by the time they get to a certain age it's almost obviously their lifestyle has been formed. And then when they get beyond that it's very difficult for them to change that lifestyle and that culture and that outlook on life, particularly if it's something that is embedded within the family group. (P8)

These behaviours may also lead to social isolation and therefore inhibit an active lifestyle which further exacerbates levels of overweight and obesity:

Also the lack of active lifestyle and the like comes into it, where children are socially isolated, poor social skills because of the way that they've been brought up and developed. And they go out, they have little interaction with anybody let alone physical or healthy type interaction. And that all for me has a significant impact on their development and the way that they perform during their younger years. So I think some of that activity really is commonly seen, or one of the more common themes in terms of obesity that my staff would see you see (P8)

Participants thought that a child's psychological health influenced their obesity and resulted in a cycle of depression and comfort eating:

They probably comfort eat more because they're getting overweight and they feel so low that to get out of that they'll eat more. (P14)

Professional understanding of consequences on child development - physical -short term

The impact that obesity may have on physical health in the short term was discussed. Participants reported how excess weight impacted on a child's ability to take part in physical activity and exercise: 
And then of course then there's the physical health as well. You know, you see their problems with being able to partake in sort of mainly exercise, basic things at school. (P19)

Or it may be that they're not able to do certain activities, so that would have a significant impact. And their development in, you know their physical development it could stop them from doing things that normal children would do, like playing out, like riding bikes, walking, climbing trees, all the stuff that kids do. It's quite sad. (P10)

Quite horrific examples of children whose obesity impacted on their personal hygiene and dental care were given. Staff felt children were aware of how their obesity was impacting on these areas and the effects this had on them psychologically:

One of the other things I really want to mention as well is the dental care for these children is extremely poor. (P4)

Walk to school with her usually three times a week and actually in that 25 minutes she's puffed out and her legs are aching and rubbing together. And so she does know. She does notice and then the other side of things as well is the, is her body odour. So because I think her body's working harder, she's sweating and kids do call her smelly which is obviously not very pleasant for her either. (P4)

And by the time this little girl came into school, she had acute asthma in the respect that she couldn't walk down the corridor without being extremely breathless. She was so overweight she couldn't get on and off the lavatory in the school and therefore was wetting herself all the time because she couldn't use the toilet appropriately and really suffering educationally because of the emotional aspect of her being so grossly obese. (P3)

\section{Professional understanding of consequences on child development - physical - long term}

Many of the participants had a good understanding of the long term consequences of childhood obesity on health. The consequences they reported included type 2 diabetes, high blood pressure, joint pain and asthma:

I would say long term we know it's linked to chronic health conditions. We know it's linked to diabetes, heart disease........ Long term health-wise it is a big concern for us, a big concern for us.(SNL1)

Again it's related to how high your body mass index is. The higher it is, the more likely you are to see it but, you know, high blood pressure is probably the commonest and the most undiagnosed. And if you are over the 99th centile and you've got a 15 to 20\% chance of having high blood pressure, compared to 3 or $4 \%$ of the general population. Your risk of morbidity from diabetes increases substantially so your lifetime risk of diabetes increases many fold. Your risk of myocardial infarction and early death is increased substantially, stroke etc.(P21)

But what's clear is it leads to low self-esteem. It leads to strain on the joints. It leads to numerous other physical problems. (P15)

\section{Professional understanding of consequences on child development - psychosocial -short term}

In the short term participants felt that obesity would negatively impact on a child's school attendance and academic attainment. It was also thought that being obese would increase the likelihood children would be socially isolated and bullied at school.

But in terms of overall effect on children's development, well, there is evidence, isn't there, that if a child is obese, then it may affect their schoolwork. It will affect their social development. They may get bullied at school. So there are lots and lots of connotations from it. (P6)

Some of the families we deal with where obesity is an issue it can affect things like school attendance. People who won't go to school because they get bullied. So it immediately has an impact on their lives psychologically, but also educationally (P7) 
Staff discussed examples of children whose negative perception of themselves and comparing themselves to their peers had led to them becoming emotionally withdrawn and having low selfesteem:

I did a conference this week and the boy who was twelve years old and he's significantly overweight, it harms the perception of a young person of themselves. It harms them in relation to other people. It causes in that particular case, it had caused an emotional withdrawal. (P15)

Like all areas, it's self-esteem. You know, it can at self-esteem and feel that they're different to other children, when they might look at themselves and think oh I'm in different clothes to that child or I've got a bigger jumper than so and so. (P12)

Or indeed the mental aspects, anxiety, depression, perhaps some mental health illness, created out of how their peers or how they feel confident to deal with their community around them. (P1)

One participant recalled an account of a young child whose obesity caused them to display violent behaviour which ultimately led to expulsion from mainstream schooling:

I can think of one in a primary school, very young year 1 child who was very large and clearly reacted to that through expressing very extreme and aggressive and violent behaviour towards his peer group and his teachers as well, so only in individual cases... It was a while ago. The child would attack teachers and lash out and actually because of his size that was quite difficult to contain and to deal with. And I think the child ended up being transitioned to our pupil referral unit, yeah, so removed from mainstream education because the staff couldn't cope with his behaviour. (P5)

\section{Professional understanding of consequences on child development - psychosocial - long term}

Participants discussed how obesity impacts on a child's ability to form relationships and academic achievements and how these foundations are taken forward into adult life and potential future achievements:

their self-esteem, how they perceive themselves, their relationships then with other people, that will impact them not just as they are as a child, but for their ongoing adult life and how they then look at themselves. (P2)

affect their academic abilities and not concentrating. So then their future, what they choose to do. (P14)

\section{$\underline{\text { Training }}$}

There were limited accounts of obesity related training across all professions. Trained medical professionals recalled never having had specific training on obesity:

It's not something we ever really had any training in, as an undergraduate, and we never really had any training in as a postgraduate really when I was a GP trainee. (P19)

Those that were well informed had either learned on the job or read about the issue themselves:

I've got a lot of experience. No one particularly has I suppose trained me as such but then I have learned from colleagues over the years. I've been to numerous meetings, both national and international where I've listened to other experts in the field. So I think I have had instruction and advice from other experts primarily in the medical field, you know, but also psychology, psychiatry, mental health as well. So I suppose yes I think I probably have. (P21)

Not directly, but clearly it is a growing issue, and so I have obviously read into things and read literature in journals and magazines that are sort of linked closely to my profession. But yes there isn't anything formally. (P17)

Participants talked about training they had had on healthy eating, mainly from dieticians. This training was viewed as useful as they could use strategies with the families they worked with: 
We do do training on healthy eating, and I work with a lot of third sector organisations that we commission as an authority in regards to supporting healthy eating, both in adults and in families... So for example with the stronger families we would use something such as cook and eat as a tool, not just if we think there's weight concerns within the family, but to get the family to do something together and to build confidence and communication across the family. So we actually integrate what would potentially be identified as obesity tools into the dynamics of actually, we cover it with something else. So it's actually not because you've got an obesity issue here, it's actually, this is a piece of work that we can do together, we can cook together, it's fun, we can all get involved, it strengthens our communication as a family. (P1)

the dieticians gave us some training about - would it be about two years back? - for different tiers of where we would refer into, but nothing specific that's targeted. We'll go on toolkits and resources.

\section{Personal and professional experiences shape professional response to obesity}

Participants linked their own weight and eating / physical activity behaviours to how they would respond professionally with families. Many were reluctant to raise the issue with families if they were overweight themselves:

An added thing on this I suppose it's a bit like I wouldn't trust an overweight dietician. There's a social worker who's overweight going out to families discussing them being overweight. It's very difficult isn't it? It's like overweight nurses suggesting you lose weight and when what you get back at them as well, you haven't. It's a minefield. (P14)

Even discussing weight between professionals caused controversy and anxiety:

I did raise it with the child protection chairs that it is, it did cause some controversy even in discussing it with that group of professionals, because even within that group of professionals they would have to admit that some of us are obese. (P17)

One participant gave an example that their staff member had used when challenged about their own weight during a consultation with a family they were working with:

One of my staff that is obese was able to sort of explain how she has tackled that whenever she's said she has had that example thrown at her, well why are you telling me how to feed my children, you're obviously not doing it for yourself... she says she just turned it around and basically said but I'm an adult and I've made those choices for myself. So I think she said she was quite upfront about it and I've made those choices for myself, but whenever it obviously comes to my children then I have a different responsibility. (P17)

One participant reflected on her own thoughts about the National Child Measurement Programme (NCMP). NCMP is a national surveillance programme of child weight that can be used as a method of raising the issue of weight with families. The staff member on reflected how they would feel their parenting skills were being judged and this feeling of NCMP also shaped her professional response in working with her clients:

So if I got, and speaking as a mum now, if I got a letter home to tell me that my son was obese, I'd be furious about that. And I think we don't cater to actually understanding the impact, because what basically you're doing is you're saying in some respect if society doesn't accept this overweight position, therefore somehow as a family or as a parent or as a child you are failing. (P1)

$\underline{\text { Assessment and identification - guidelines }}$

There was mixed knowledge and understanding between participants of how to assess childhood obesity using clinical guidelines. Some were able to explain the use of centile measurement charts, others knew about them but didn't necessarily understand them, where others used lay terms for describing and assessing excess weight in children: 
Obesity is a measurement on a centile chart, which I now think is called "very overweight". It used to be called "obesity" in my day and I know they changed the title to say "overweight" and "very overweight" because parents were offended by the term obesity. (P3)

I guess maybe children above the 98th centile for weight, that's maybe where sometimes where you'd be putting it really I would imagine. (P19)

Probably very limited understanding of childhood obesity, and I think very basically is that children who on their centile scores would be at the threshold that would tip them from being overweight to being obese. (P2)

How large does somebody have to be before you consider it's now a problem? Because often children do go through phases where they get a bit of puppy fat and then before they grow. When are they considered to be obese given that I'm not actually going to be able to weigh this child, or do any of the things that a doctor would to see that they were. (P9)

\section{Assessment and identification - awareness raising}

Participants expressed a need for additional training and awareness raising at a professional level as to how to identify obesity with the children they work with.

I think we can do that through training if that's what comes out of this. People need to have a better knowledge of obesity and what that means. (P3)

So I think in terms of helping us, what would help practitioners identify and respond to it is just to be more aware of it. So I think more of an awareness campaign I think of it. (P19)

Participants need more confidence in raising the issue of obesity:

As I said it's like the elephant in the room and we don't tend to address it when kids come in. But if we were more aware of thinking about neglect as possibly being part of that issue then it ought to be that we would be more likely to address it. I think we've got a little bit of a blind spot actually. So we just need to open the blind spot up. So I think in terms of helping us, what would help practitioners identify and respond to it is just to be more aware of it. So I think more of an awareness campaign I think of it. (P19)

Whilst the NCMP helps to raise the issue of weight with families, to intervene and reduce the rise in obesity, participants in this study felt that just providing a piece of paper does not help people understand the potential long term complications of being an obese child:

I know about the National Weighing Scheme that happens in schools. And it's about trying to measure and understand the scale, reasons and how to intervene around obesity in children to try and catch it at a fairly early age and monitor it as children grow to see if their weight is increasing or reducing. (P7)

But then I think perhaps, I don't know whether there's not an understanding from people that aren't from a health background what effect that could have on that child long term. So again you've got a bit of paper that says obesity; unless you explain what that means for somebody that's not from a health background might not appreciate how obesity can affect that child's physical and social development in the long term. (P3)

Participants were able to identify potential opportunities for changing practice around the area of obesity in the current system:

Well, more knowledge is always useful, isn't it? We could do some more awareness raising. I think we've got some mechanisms now within our safeguarding board here to do that fairly easily. (P3) 
Poverty was raised as a cause of obesity. Many of the participants discussed how Government reforms are impacting on families, restricting their budgets and therefore money available to buy healthy food. Many families are on extremely low incomes, with alleged low skills around budgeting.

the impact of the government reforms around benefits and how that is having an impact on lower income families and the fact that maybe they weren't able to buy the better food that they would like to buy for the children that might actually be more healthy. (P17)

I think as well the nature of the families we work with, they're all on the low end of budgeting. So they don't have access to cars, they can't afford bus fares for the whole family or a taxi there and back. (FG1)

Participants suggested that keeping a roof over the family and paying gas and electric bills is often a higher day to day priority than diet.

It's keeping a roof over their head. It's being able to buy food. We work in partnership with foodbanks, so just to eat with some of our families is a big deal. It doesn't matter what they're eating, just to eat. (FG1)

We've got some really brilliant budget supermarkets. So they could go and do that family shop. It's very, not planned, it's not thought through. They've not budgeted for the week. They're living day-byday-by-day. So the next payday as they would call it, the day they get their benefits and again I'm not being judgemental there at all but that's what they say, is treats and not thinking about have we got enough gas, electric. (P4)

Chaotic lifestyles combined with low incomes mean getting any food rather than type of food is a priority.

have a family who are already in chaotic lifestyles or in poverty and all they're bothered about is putting food on the table and it might be a takeaway if that's accessible and that's what they can afford, then I can totally understand why that would be difficult. (P6)

\section{Social factors - culture}

Participants reported how culture plays a part in obesity. Preparation of food or methods of cooking are linked to traditional heritage.

Food that's been cooked with ghee and lots of other things that mean that the child is an excessive weight and the family may struggle because they wish to hold on to their cultural heritage, to acknowledge that that's an issue. (P 15)

It's a difficult one in one sense because it operates across a lot of different classes, racial backgrounds, religious backgrounds. So in each of those groups the use of food, how food is ingested by children and prepared by children can be very different. (P15)

Now we are much more multicultural that we will get more and more referrals for different ethnicities and it's understanding their cultural issues and food is a big part isn't it in a lot of different cultures, you know, it's massive. But then I think being introduced to the English food, is that going to be a problem? Do they understand? Is there literature available? (P4)

The culture of obesity was discussed. Where the whole family are obese, this was described as part of the family culture and home environment which is conducive to influencing obesity.

But actually it's inherent generally in the whole family. An obese child generally comes from a family who also have weight issues somewhere else in the family. (P7) 
But generally it's a family issue rather than a childhood issue, I think. And one of the issues I think we have is we talk about child obesity and adult obesity and they're dealt with separately and differently and actually they're in the home eating whatever they eat together. (P7)

\section{Thresholds}

For child protection services to undertake work, requests need to meet a severity threshold for interventions to occur - the legal definition of significant harm. It was found that this threshold was nuanced and complex and could act as an inhibitor to providing services. The threshold operated not only as a line that had to be crossed in order for a referral to be accepted by social services but also in respect of individual practitioner thresholds regarding personal views and values regarding obesity; different agency thresholds; referrals for different services within an agency and also between agencies. The category emerged through the inductive process of interview analysis.

\section{Ambiguity}

In making judgements about obesity as a child protection issue and when to refer to social work or statutory investigative services the need for some kind of threshold was accepted by all interviewees.

But then where would I say somebody's overweight or somebody has a problem? At what point, as professionals on the ground we would need something clear in terms of guidance as to what we're looking at before we start referring it, otherwise we'd be referring everybody. (P9)

Well the responsibility firmly lies with the child and the parents in my book. I suppose the question is at what point, where are the thresholds for society to intervene and what should the plan be around that intervention and when does it go from a supportive intervention to a punitive intervention? (P22)

What became clear however was that there was no clear guidance but rather a wide range of ambiguity about what constituted obesity, and when obesity might amount to a child protection issue:

It could be a child protection issue, but it doesn't have to be. I think you're in that ballpark really.

Well it varies. Some social workers are very willing to pick it up and run with it. Others will go and have a chat to the family and say the parents are very nice, it's a very nice home, you know, they're not living in squalor, they're otherwise well cared for. The child clearly loves the parent. The parent clearly loves the child, you know, what's there to be done? And it doesn't go very far and I've been involved in cases where we've got as far as, you know, court with a judge taking a view and ones that, you know, social care have said no well we don't feel we have any role here. (P21)

And what level of severity and what was required in order for a referral to be accepted by CP services.

So it was quite a muddled, complicated picture, but even despite all these other concerns related to this child we could not get this referral accepted. (P3)

The lack of clarity regarding thresholds was said to be not restricted to issues relating to obesity:

We had a very serious disclosure by quite a young child of domestic violence. We referred it in, we were told it didn't meet threshold but I was so seriously concerned about that child going home to that parent that I just, well I pulled a few strings and went to the service manager of response and referral and got them to take some action that night, so that child didn't get exposed to that situation again. So we're dealing with stuff, you know, almost daily which is about referrals, but not linked to obesity. (P5) 
The lack of clarity for agencies outside of Child Protection regarding a threshold for acceptance was reflected by different practitioners within the Child Protection services, with a varying focus on parental behaviour, risk to the child, and offer and non-acceptance of early help as impacting on crossing the threshold.

Social care, our involvement is what happens if you are neglecting your child. But it shouldn't be threat. And what we should be doing is we've got to evidence before it comes to our service, I'm talking cumulative neglect, I'm not talking physical sexual abuse. But I'm talking those things that we've done everything to empower that parent and given them the strategies they need before we start sanctioning, you know what I mean. (FG2)

So it's not about that child being at risk per se; it's about how the parent responds to the professional advice that they've been given about how to manage that condition. (P17)

Personal (individual undertaking the assessment or working with the family)

In terms of identifying obesity as a reason for referral some interviewees were aware of the legal definition of significant harm and of local definitions of neglect, at least in broad terms as a threshold measure and that awareness influenced their behaviour.

Well, probably that definition, you know, when it's having a significant impact on their development and you can see that it will and this is going to have a long-term impact. Unless we intervene now, this child is not going to develop to its potential, both physically and emotionally, because it's having such a huge impact. (P3)

Equally or more important was an individual's own judgement based on their own experience, professional judgement, beliefs and value system.

So an average social worker depending on their own experiences might just say yeah well they're a bit overweight, will that just disappear, is that puppy fat? (P17)

Personal experience impacted on how obesity was seen and understood as regards the impact on an individual child and a consequent cause for action.

From my experience of seeing this young, just from my own personal experience of seeing this young chap and the social isolation that he had that I felt that there was emotional abuse as well (P16)

Professional judgement from a personal and health perspective that obesity was a safeguarding concern could lead to a referral but one which was not accepted as such by social services.

I made attempts at that time to get a referral into social services and really at that time it wasn't viewed as a safeguarding issue, although to me it was definitely one in that case. (P3)

Value judgements made by individual workers about parental behaviour influenced the judgement that a threshold had been crossed:

This is a case that we'd had to step up to child protection because they're feeding animals over children...So that's quite an unusual one. So there's lots of pets, horses, cats, dogs, there's always food in for them, but then she's phoning me for a food bank voucher. Now to me that is, that's not the right thing to do. (FG2)

For example, on one occasion I received a letter for disability living allowance asking, saying the child couldn't walk more than 100 yards and asking me to fill in the form, sign a form so they could get disability living allowance and that was purely because of nutrition obesity. And I felt actually, you know, if this child, the family are now saying this child is so disabled that they need the f50-60 a week benefit, you know, something needs to change. And so I made a referral then. (P21)

One interviewee expressed the view that personal opinion may always influence professional judgment and not all professionals would agree but that the way to approach this issue was by 
better education regarding the threshold between obesity and neglect and an acknowledgement that personal opinion may still differ.

So I think better education about at what point does being overweight start to become neglect, you know, so when is it not just a, you know, a theoretical problem. This child's overweight. But when does it really start to impact and when does the parents failure to address that impact start to become neglect and that actually it sometimes may be an element of opinion as well. Not all professionals will agree on that but that I think is the area, you know it's highlighting what exactly constitutes neglect. And as I say, I do agree it's not just the weight, it's failure to address the sequelae of the weight that tips it into safeguarding. (P21)

A lack of training and guidance led social workers to fall back on their own personal thoughts and experiences.

So I think there might, in terms of moving forward as an issue and how both the understanding as a threshold issue might be better explained if we did have some better guidance in terms of a public health about, for other professionals rather than going on their profession, their own personal, I think most social workers will just go on their own personal thoughts about what is obesity based on their own experiences rather than actually ever having, as you say, had training of being taught, this is obese and this is the implications it will have for the long-term impact on health. (P17)

\section{Assessors Agency}

Individual agencies were seen as having their own threshold for action which may or may not fit with that operated by social care. There was a lack of knowledge about the thresholds operated by the differing agencies. For example in respect of health services:

We would expect that health would be the main people to alert us to that, you know, they see every child hopefully and would be able to flag up if it is a concern. But I suppose it's where their thresholds lie as well. Would they routinely report every obese, every child that crosses over into the obese category or would they wait until it's sort of classed as morbidly obese? But you know, what's their threshold? (FG2)

This was set against a nursing perspective

I made attempts at that time to get a referral into social services and really at that time it wasn't viewed as a safeguarding issue, although to me it was definitely one in that case... So it was quite a muddled, complicated picture, but even despite all these other concerns related to this child we could not get this referral accepted. (P3)

For some social workers it would be difficult for obesity as a standalone issue to ever meet their threshold:

It wouldn't have been a child protection if it weren't for the sexual abuse that came before. It was part of the plan, but again I don't think that would meet threshold. It was just something that had been picked up by school nurses that they said they wanted to address. But yeah, I don't think it would have been child protection, just on his weight. (FG2)

The interface between different professional groups and their professional judgements about thresholds for action regarding obesity could lead to some frustration on both sides of the professional divide:

What you might get back is well we've looked at it and we're not even actioning it, or we've taken it information only because it doesn't fit our thresholds. You know, a better response would be actually at the moment this doesn't fit our thresholds and we don't think there's a role for us. However, what I suggest you do, or what I will suggest is it goes for a [health?] assessment, or I suggest you do a CAF, so that there's support for practitioners that are obviously referring these cases in when they're concerned, because you're not going to refer in if you're not concerned. (P3) 
There will be some professionals out there that don't refer because they're maybe too scared of. I mean we've had, because everybody's so busy and some of the things that come through are absolutely ludicrous, you're just blocking that, it's ridiculous...Just silly things. Mum hasn't turned up for a TAC meeting or you know, look at your thresholds document. Or almost it's like particularly when they're going off on school holidays or whatever, and it's just like a cover your back exercise. (FG2)

The quality of referrals made was identified as a potential problem in meeting child protection threshold for acceptance:

It is sometimes about the quality of the referral, I do accept that. And I think there's still a lot of work to be done with our professionals and within other parts of people that are referring in and I do accept the fact that we can strengthen our referral forms to provide that evidence. (P3)

However there was expressed a wish for greater consideration to be given to health referrals by social care:

But I think if you provide that evidence, you would want that looked at seriously because we are working in an organisation where the people doing the referrals in are professionals. You know, we're health professionals that are very experienced with children. It would be health visitors, school nursing, CAMHS workers that are very experienced in working in that area and we would hope that were those people seeing this as a significant concern, that that referral would be taken seriously and considered and there would be a good reason why it wasn't picked up. (P3)

\section{Perceived Child Protection threshold for referral acceptance}

All practitioners were aware of a threshold for referral acceptance and took the view that the threshold bar was set at a high level.

Thresholds, maybe are they different to other boroughs? They shouldn't be but I think we've all had experience somewhere with Doncaster Social Services' threshold being hard to meet. (FG1)

This view of a high threshold impacted on an individual's decision as to whether a referral should be made - We refer to them as $R \& R$, but the referral and rejection team, they were called at one time. (P3) This perception of a high threshold, perhaps based on previous experience of rejection, then impacted on current practice with referrals about obesity not being made based on an assumption of the level of thresholds rather than clear knowledge of where the threshold was located or whether issues related to obesity met that threshold.

I think teachers, school nurses, GPs are probably well aware of where they feel there are child protection issues. I think the question, often the thing is how do we interest social services, are they really going to want to take this on? And some of that is a resource issue, in that social work is stretched at the moment. (P21)

It would never have met their thresholds anyway. (FG2)

This perception of obesity as low on the tariff as a child protection concern was not limited to family support or health services but was also present within social work staff.

I think it wouldn't even pass our doors. I think if school raised an issue with obesity I think they'd speak to the school nurse. I think if it was a younger child it would be health visitor. I don't think it's taken; it's probably not taken seriously as getting the child protection. (P14)

Yeah, and I know it wouldn't take priority. If you've got three children at home at risk of sexual abuse or there's domestic violence every night, and you're getting called in about them. Do you visit them or do you visit the one to check that any weight's been lost, but you know they're safe? Physically safe. I think, I'm not minimising it because I think it is important and I do think there's health effects, but I don't think it will ever take priority over other child. I think it would always be lower of the child protection concerns. (FG2) 
There was a perception that it was easier to have issues of low weight and anorexia taken as a child protection concern than ones of obesity.

I feel it's easier to get a referral for an underweight child to be accepted, where perhaps sometimes some of the issues are the same. But it is much easier for a child that's dropping off its centile and losing weight to get that referral taken in. (P3)

\section{Actual child protection threshold for referral acceptance}

Alongside the perceived threshold it was clear from the interviews that an actual threshold was in place but the challenge was identifying where that threshold was located. Some cases were clearly seen as crossing the threshold, where for example obesity was linked to other concerns:

The referral was around excessive weight gain. The referral was around a young person at risk of sexual exploitation and the referral was around self-harm as well. My concern was that food was being used as a comfort and there's always a reason for that. (P12)

Obesity as a standalone issue could be seen as a child protection issue;

A child who came to child protection conference specifically around being obese and overweight. Yes. So with her, she was a six-year-old girl who weighed nearly 12 stone and the referral came from health...And they felt that, you know, action had to be taken in regards to not allowing her to put on more weight. (P18)

More usually factors relating to parental engagement alongside other issues which together impact on the child to cause significant harm were seen as clearly crossing the threshold.

I think the issue about how it crosses the threshold, it's about where a parent isn't engaging and then that is becoming, is starting to have that significant harm to the child in terms of their emotional wealth or around their physical health. And usually where we see that, it isn't just a single issue, there are other issues, whether it be the parents' capacity, neglect issues, omission commission, parents' mental health problems, there'll be another, there'll be a range of other stuff. (P17)

The definition of significant harm can be stated as drawing the threshold line;

But really it's about that right to family life balanced with the Human Rights Act and so therefore our thresholds, or the help that we provide as a statutory service, don't kick in until we know that a child is experiencing or at risk of significant harm. (P17)

Difficulties arise however about what that means in practice, about operationalising the definition and about managing cases that are close to the threshold.

So if they're already doing and engaged there's little value in going down the child protection route. It's where you can't get the family to either accept the child's got a problem and for me actually often the trigger for safeguarding will be around emotional and mental health and around schooling. Those are often the things that will tip it, tip the balance for me. (P21)

Yeah, was it when you were on training and you were saying some of the cases, and they were saying in the training that was social care, but when you tried ringing it in it didn't meet the threshold. (FG1)

Identifying where the threshold actually lies creates difficulties particularly for health and family support staff who are directly involved in working with families.

He didn't meet the threshold for social care. It was mainly because of the personal hygiene that the referral went in. But the oldest child there's no concerns with personal hygiene. The next one down there's no concerns with him. The youngest, she was bed wetting so that's where the personal hygiene issues because she was going to school smelling of wee. But that's been sorted out now, and it's just the child now that's obese that there are still the issues with. (FG1) 
They're saying that if you've not had early help first they won't take it, you have to have early help in first, and then if the early help has failed then they'll take it... (FG1)

I've got to the stage of referring this in because I'm now that concerned and actually the response of well we're not even going to look at it isn't helpful. (P3)

Difficulties also arise for child protection staffs who have to deal with referrals which they see as not meeting the threshold.

Well it's like when they do ring and they do say he's come in three days in a row now and he's not had his breakfast. But my response is have you spoke to mum about that? Why would you need me as a social worker to do? (FG1)

There will be some professionals out there that don't refer because they're maybe too scared of (the response). I mean we've had, because everybody's so busy and some of the things that come through are absolutely ludicrous, you're just blocking that, it's ridiculous...Just silly things. Mum hasn't turned up for a TAC meeting or you know, look at your thresholds document. Or almost it's like particularly when they're going off on school holidays or whatever, and it's just like a cover your back exercise. (FG 1)

\section{Threshold for legal action}

Once a referral is accepted by child protection the concept of thresholds again operates following assessment, in respect of how further work with a family is undertaken. Specifically thresholds operate in deciding whether to take legal action or to remove the child from the home. Parental lack of engagement is cited as one specific reason for crossing the threshold and moving into statutory proceedings as part of the Public Law Outline:

So they wouldn't accept the concerns at all. Because of that it then ended up going into PLO because of their lack of engagement. I think between the first conference and the three-month conference she'd gained more weight. And they were told that we were going into PLO. And at that time they did start to appear to engage, but it was very sort of tokenistic. (P16)

A further reason is lack of change, of having tried everything else and not achieved any improvement regarding the child's weight or wellbeing. For example residential weight reduction programmes were seen as an expensive last resort before proceedings (P16).

Just as a perception of the threshold operates in individuals making a referral so too perception of the threshold applied by the court can be seen as operating on decision making.

But it was quite frustrating really because we were in PLO but we weren't going to remove her. And it was sort of after a while, she would lose a pound, put another one back on, lose two pound, put half a pound back on. So it was just sort of a, became a bit stagnant really and we didn't really know where to go with it. Legal were saying, you know, we can't remove her on that base, if we go to court and say we want to remove her, the court isn't going to agree to that and we were sort of...(P16)

Evidence was important in having a referral accepted, so too is evidence (or the lack of it) important in crossing the threshold for legal action.

And I think the difficulty was that health then sort of retracted some of their strong views that they had initially and wouldn't give us the evidence that it was having a health impact on her. (P16)

In respect of the child living away from home and becoming looked after by the local authority, although meeting the threshold for legal action was possible, it was not required if work with the family could be undertaken by agreement. For example

So it was a case that we tried, there was intensive support with that family to try and right some of these problems, and in the end the parents recognised for themselves that they couldn't actually cope with this and they agreed to section 20 accommodation - not just in relation to the eating issues that 
were in the family, but the neglect and the chronic neglect that the children experienced in terms of how the parents could actually physically keep up a house, so the children didn't have beds and bedding and they weren't changed regularly, the house wasn't in a good state. The level of cleanliness was really, really poor. (P17)

\section{Threshold for multi-agency services}

Although not the focus of the research, interviewees shared views that suggest the complex and nuanced approach to having a referral meet the threshold for acceptance by social services is reflected in other specialist services such as children's mental health and education psychology. For example the perception of a service threshold can influence the lack of a referral for those services.

And I guess the other area it might come into is in sort of depression and anxiety and emotional disorders in children. So I guess children's mental health services. But I think they'd steer a wide berth away from it because they tend to deal with much what they would classify, I mean it's very hard to get people into the CAMHS, which is their mental health children service anyway even at the best of times (P19)

\section{Child Protection}

The question of whether child obesity alone was a child protection concern divided respondents. For some the impact of obesity on long and short term outcomes for children made obesity unequivocally a child protection concern. For others excess weight itself was not sufficient. In reporting the findings of qualitative research resorting to numbers in respect of respondents views is meaningless. It can however be illustrative of the ambiguity and contested nature of the research question. In respect of the interviews undertaken 10 respondents were of the view that child obesity was a child protection concern with a further 3 thinking it was if associated with neglect. 7 were of the view that it was not a child protection concern with 2 thinking the problem was too complex for a view either way. A similar variance of view was expressed by the focus groups.

Where there was more common ground was in respect of the links between obesity and parental neglect. This could be in the form of associated factors such as failure to attend school or mental health issues but also for many respondents a failure on the part of families to engage with support plans and services offered. Those services were seen as a continuum of intervention levels from universal to statutory with child protection and legal interventions part of that continuum rather than a separate entity. A child protection approach could act as a catalyst for families to take up support as well as a gateway to more financially expensive and intensive support offers. Assessing prevalence was hindered by a lack of data alongside the impact of individual and professional perceptions.

\section{Obesity is not a child protection concern}

For some respondents obesity alone is not a child protection issue.

I don't think on its own it's a child protection issue, unless a child is being consistently overfed deliberately. (P5)

It's not been something that you'd focus on, something we've been trained to focus on. (FG1)

Almost all of the respondents did, however feel that when other factors are present alongside obesity it could potentially become a child protection issue. The factors consisted of such issues as being able to recognise obesity, and familial failure to accept and engage with support and to change 
lifestyles where obesity was identified. The respondents emphasised that once obesity had been recognised, a failure to address the issues may be a form of neglect:

Not in itself, not if that's the only concern within the family. I don't think it warrants, I think it's just education more than anything. If there's other factors involved, and that's just an indicator of them, then maybe so. If it's neglect, if it's shown to be neglect, but not in itself. (FG1)

Failure to reduce overweight alone is not a child protection concern - i.e. if they can't lose weight, that's not a child protection concern. Failure to change lifestyle, engage with outside support indicates neglect particular in younger children, so a failure to change lifestyle, engage with outside support. (P19)

For two respondents the nuances surrounding the issue made an answer either way difficult. For example one respondent drew the distinction between a family recognising obesity and not taking action, from one who didn't recognise the issue and took no action, posing the question of whether one or the other was a child protection issue.

Again, I suppose part of it is around scales and the reason and there's the thing about, as I talked about earlier, whether or not families recognise it as an issue. If they do recognise it as an issue, but won't do anything about it, is that child protection, or if they don't recognise anything about it? I think it's not as easy as saying it should, it shouldn't. I think there's a lot of nuances surrounding it that might make that quite difficult. (P4)

\section{Obesity is a child protection concern}

For a number of practitioners the question was not nuanced at all but very clear; child obesity was a child protection concern. This clarity of view spanned professions and was not specific to health, early help or social workers. The view was perhaps held most strongly by those who had most direct service user contact.

Yes. Absolutely, categorically I do. I think if we can identify that there is no physical, medical reason for a child to be overweight, then absolutely, passionately I do, yeah. You know, a child doesn't go to the shop and buy their own food. They don't prepare it, they don't cook it. And that is a key part of parenting for me, absolutely, so yeah. (P11)

Well if they're failing to ensure that their child also is getting a healthy diet to support their wellbeing, then yeah I think it is. (FG2)

Yes because if it's taken to its extreme it can kill you. (P12)

One reason frequently given was an emphasis on both the short and long term effects of obesity.

I would probably go with yes I do think it should be a child protection concern. And I guess that my reason for thinking about that is because of the, not only the short-term, but the long-term effects that childhood obesity can have on children as they move through their childhood, but also longer term. (P2)

Absolutely...Because it's going to have an ongoing effect into adulthood. Again all the things that I've talked about, the bullying, the CSE, meeting potential, going forward into adulthood, teenagers selfharm. (FG2)

Yeah, so if a child comes in significantly overweight automatically failure to thrive. There's a failure to thrive if a child is significantly overweight, because it is those long-term health implications ain't it? Ultimately there can be death, heart attack, stroke, we're talking about, we're not talking about some impairment there. Depending on your weight it can be ultimate, and that is child protection, it's safeguarding, significant harm, it's risk of significant harm. (FG2)

A further factor informing the view was that a considerable amount of support was available to families in terms of early help to work with families outside of the child protection system, even 
where neglect was identified. Where families did not engage with this support then obesity became a child protection concern.

If there's evidence of neglect, there's a lot of early help teams and people like Stronger Families who do a lot of work with parents around routines and boundaries. And they'll cover a lot of things like getting children up, ensuring that they have breakfasts, and helping them prepare healthy meals and things like that. So I think if there was evidence that we'd needed to do all that, and then they weren't following it and there were concerns that the risk to the children were such that they were at risk of suffering significant harm, then yeah I do. (P12)

However if a parent persistently fails to meet those needs of that child and it's going to impair their health and wellbeing, then yes it should be aired at a conference and stepped up to child protection.

(FG2)

Respondents were able to identify a range of stresses on families as identified in the section on obesity, alongside the impact of a parent's self-obesity on problem identification. But as one respondent commented, it was important to apply a test of reasonableness:

That's the bits about being reasonable ain't it, about what our expectations on a parent is. And we wouldn't expect them to keep them under lock and key would we? We'd expect them to make reasonable attempts. It's when you've got the parent that dismisses it and says nah, it's not an issue to me, I'm not bothered. Or usually I have heard it dismissively as I'm big myself, so it's just in family. Well no it's not is it? And actually you need to think about what that's doing for you, and do you want your child to go down the same line? So I think it's quite clear cut actually. (FG2)

Alongside reasonableness has to be seen a level of pragmatism set against the impact on the child.

Again I think it's a question of degree of the obesity and the extent of the impact on the child. So, as I've said, you know, $20 \%$ of children in... are obese. Clearly child protection proceedings are not appropriate for the vast majority of that $20 \%$. At the other end of the spectrum there are children who are dropping out of school at 13, 14, have got type-2 diabetes, are under the childhood mental health teams because of depression and self-esteem, whose, you know, in those sorts of children perhaps start to move towards the child protection arena. (P21)

The initial and primary aim was to try to ensure compliance with the support package or plan.

Because really from a safeguarding point of view, the reasons for involving a statutory agency is to make people comply because it's the only way in some cases that you can make people comply within a child protection plan, which of course you can't do with your early help and you can't do with your child in need plan. So I think you work at the lowest level to see if you can get change and only when you can't get change at that lowest level for whatever reason, then you start looking at whether this becomes a safeguarding issue. (P10)

\section{Obesity and neglect}

Respondents consistently linked childhood obesity to neglect:

I think obesity is a much more complicated issue than just simply diet and exercise - that's the thing. I think diet and exercise seems to be the only way to actually tackle it, so therefore that's the way forward. But I mean for it to be a child protection issue, there has to be some sort of evidence of some degree of either neglect, in terms of what children eat, or neglect in terms of not encouraging the kids to do more exercise to try and lose weight to try and keep themselves healthy. So I guess it falls into the neglect region. (P22)

Some respondents saw a lack of engagement in support as indicative of neglect:

Consistent failure to change lifestyle and engage with outside support indicates neglect. (P10)

For others obesity tended to be one factor among many which contributed to the requirement for action to be taken on the basis of neglect. 
Over time the neglect was how it actually came to the attention of social care. And the issues were around neglect. And that was about the children being unkempt in school, being isolated from their peers in a school because of their unkempt nature, and at that point there were issues about both children's weight. And school were concerned about that because they were stealing other food both in the school and from other children. (P4)

There are usually other factors like, you know, just general neglect, not turning up to appointments, not addressing the child's other health needs, not getting your child to school. So rarely is it just the weight. There is usually the weight plus other factors and in those sorts of circumstances where it's really affecting the schooling, the mental health and the physical health of the child I think yes it (CP) is appropriate. (P21)

One respondent was clear that obesity should fit operational definitions of neglect and was of the opinion that it did:

And persistent it definitely is: persistent failure to meet the child's physical and psychological needs to result in serious impairments of a child's health and development. (P4)

There are complexities in practice however, for example one respondent shared the experience of a child's obesity being part of a medical condition and that neglect did not cause the obesity, but rather led to an inability on the parent's part to control and manage that condition.

The discussions that we've had are around whether obesity is an indicator and part of a neglect issue within a family. Or there are some specific conditions like, for instance is it Von Willebrand's, where clearly there are a number of issues associated with that that might be a condition that a child has, and it's about the parents understanding and knowledge about how to support and treat that. And I know that has, as a result of that, and the neglect that that parent wasn't able to manage that condition has led to some children being received into care. (P5)

\section{$\underline{\text { Intervention levels to respond }}$}

Identifying child obesity as a child protection issue involves multi-disciplinary assessment and for many respondents the lack of engagement with the support offered. A major theme from the data was the nature of that support, beginning with universal services and progressing through prevention and early help, legal intervention, and admission into care. Child protection in relation to obesity can be seen as part of a continuum of services rather than a separate entity and a potential catalyst for a family to take up a more universal offer.

\section{$\underline{\text { Universal services }}$}

Schools and nurseries were viewed as playing an important role in service provision for children and parents which could be seen as less stigmatising than social work involvement. For some respondents however a reduction in local authority service provision was seen as leading to a lessening of that resource.

The support that the parents need was often provided by local authorities' nurseries. When that was happening with that child in ..... which is not the case any longer, it was their own nurseries with fully trained NNEB staff, who at that time, you needed A-levels to do that qualification and who understood child nutrition who could work alongside the parents to support and advise them and were often seen as less of a threat, understandably, than a social worker...the support of families where childhood obesity is an issue and could be seen as a child protection issue, is not helped by losing that kind of resource. (P15)

The issue of compliance also played a part in referral to universal health services outside of the child protection system as for example in a referral to a hospital paediatrician.

I get referred families because social care have been involved usually because of non-attendance at school or something like that, and school nurse, GP, all feel the family aren't really doing much to 
address their weight and I'll often get asked to see them because I don't know, people labour under the misapprehension that if I say lose weight they do. Of course they don't. (P21)

\section{Prevention and early help}

At every level of intervention there was recognition that the earlier the work began the better the outcome was likely to be:

I think they probably would've been better if we'd picked it up earlier. (P5)

And I think picking it up early before it becomes well-established, you know, because as we've said fat children become fat adults, so nipping it in the bud early is the best way forward, I think. (P 22)

There was a challenge in providing early help however in making this acceptable to families and not alienating them from accepting support. A number of respondents identified the issues involved in the school based National Child Measurement Programme and subsequent letters to parents. When initially introduced this involved a health assessment interview between the parents of children who were showing obese and the school nurse.

And there was a mixed response from parents. Some, it wasn't a difficult conversation. Some conversations were great and they were receptive and they would take dietary advice and we would agree a plan of re-measuring perhaps in six months and seeing how things would go. Other parents were extremely angry and felt that it wasn't any of our business to address their child's weight: that was for them as a parent and that was a parenting concern, not a health concern from ours, and that was up to them. (P3)

The substitution of a letter for the interview also led to problems.

it caused a lot of upset and stress for parents that did... They thought that they were being targeted and being told that they weren't providing for the child. And they felt the letters were abrupt. And that it hadn't been discussed with them beforehand, it was just a letter through the post. (FG1)

Working with families in a non-stigmatising way whilst at the same time recognising obesity and trying to bring about change lay at the heart of early help initiatives.

I've been part of food clubs. And that's been targeted at every family, because we didn't want to single out the obese children. (FG2)

I think if you're working with children and families and you're supporting them, you need to support them on everything and every issue don't you? So if that's part of the problem then you need to address it. (FG2)

Although funding and resources could put limits on the work.

I've worked with a couple of children's centres in our area. And they've put on for parents healthy cooking groups, and they're able to take the kids in and they've made them a meal. But again with their funding and resources they can do it for a few weeks and then they don't do it again. (FG2)

Nevertheless despite pressures to direct resources to child protection a preventative approach was identified as the best long term initiative.

Because as well there is such an emphasis now on addressing primarily children on child protection planning, but what we know is that's a reactive response. It needs to happen because these children have already been identified as at risk of significant harm or suffering. But what we know is a preventative approach is what we need to go into in the longer term. And that's what we're doing all the time now in ........... to try and stop this revolving door of children coming in and out of our services. (FG2)

Central to early help is direct work with the parents and the child: 
The more intense and the more complex the intervention the more effective it is. So if you are able to put in place, you know, a community support worker who visits the family in the home, rummage in the fridge, we'll look at the other members of the household, then those sorts of programmes can be effective when it's family orientated and family structured. (P21)

And what we are doing with children is very much more doing a hell of a lot more direct work with children that we've ever done before, and a lot of that will centre around some issues around identity. So we would maybe be able to talk to a child around that, about how they're social functioning, whether they're bullied or not in school in relation to obesity issues if it's obviously glaringly obvious to the social worker. (P5)

One issue however was that intense interventions were often only available as part of a child protection plan.

\section{$\underline{\text { Legal intervention }}$}

Where early help was not successful respondents discussed the range of legal options open to them and the realities of practical implementation. There was an acknowledgement that taking a child protection approach could instil fear in families but that the fear of the consequences could initiate change.

There have been another number of occasions where the mere fact that the child is then on the child protection register galvanises the family because they're frightened of the consequences if things don't change. (P21)

The implementation of a child protection plan was seen as useful in itself particularly where obesity was linked to other risk factors.

So that (obesity) combined with self-image I felt was a very dangerous place for this child to be. And I explained to parents who I genuinely think cared about their child. I said I don't come into these meetings to chair on the assumption that you don't care about your child. What worries me, worried me is that I felt that the issue of food, because his parents said he likes to cook. I said there's nothing wrong with liking to cook, but 50 quid's worth of Indian is not liking to cook. And I said but what concerned me was that I felt they had been unwilling to challenge the seriousness of that amount of food and the vulnerability and potential poor outcomes of the issue with sexual exploitation. The outcome is the child is subject to a child protection plan. (P15)

It was through the plan that intensive work could be undertaken.

So, as part of a child protection plan, there was intensive monitoring by I suppose a family support worker who monitored what the children ate on behalf of the parents. And got the children involved in what they were eating and things like that, so it was quite a good piece of work very early on in terms of engagement with the actual children. (P5)

Where being on a plan was not sufficient and consideration needed to be given to court action and care proceedings and the potential removal of the child from their parents it was seen as important to demonstrate that every possible early help had been offered to a family.

I mean when you get to court the judge will want, the judge will sort of enquire what has been done? And the courts are no respecters of budget. So they will say well, why hasn't this been done? Why hasn't that been done? Certainly when we've been approaching court proceedings I've been aware there's been children where the LEA or social care have funded support workers to come and take the child to the park four evenings a week after school...So that when it then gets to court they can say, they can then honestly say we really have done absolutely everything. But they tend to only do that when they are aware that there's going to be judicial scrutiny or, it doesn't happen normally. (P21)

It was also at the pre court stage that more financially expensive interventions were considered such as residential summer camps. 
It was organised by Leeds Carnegie and it was a private school but during the summer, Carnegie took it over and run this summer camp for teenagers with, who were obese. And they worked on, not just, it was for a minimum of four weeks but then you could do it for six weeks. And then they worked on a variety of things, not just physical exercise although that was important but also about portion size, and they had standard bowls that they used for different things. They worked on working with young people around their emotional needs and their emotional detachments to food. And again it was a residential resource. I remember it cost an absolute fortune and we had to go through various hoops to get this. But certainly this young man was morbidly obese and I think we were at a loss what to do next, you know, he was on a CP plan. (P18)

Removing a child was seen very much as a last resort

If you've got somebody overweight and you know that's a concern, but they're achieving at school, they're doing very well, they love their parents. The parents love them. They don't make positive change through involvement, where do you go with it? Because you could cause more harm to that child removing, being in foster care when he's got loving parents. (P14)

As these two respondents indicate in the more serious cases there is a sense of 'not knowing' regarding what to do and why in balancing the potential harm from removing the child against the ongoing dangers of obesity. Examples were provided, however, of positive outcomes from legal interventions.

Generally it's been positive. You know, there, I could, I'm not going to for reasons of confidentiality but there have been a number of cases where in fact the child has been placed outside the home in a more extreme examples and there have been another number of occasions where the mere fact that the child is then on the child protection register galvanises the family because they're frightened of the consequences if things don't change. (P21)

One respondent identified a case where the children had remained permanently away from their parents.

No, they've stayed in long-term fostering. And that was really around some of the dynamics, there was no doubt that these parents didn't love their children and that they were always compliant. And they engaged really well and they had needs of their own. (P17)

More common was the aim of returning the child to the family and the work required was in many ways similar to that undertaken in early help only this time in the setting of foster care.

Working alongside with mum and the child in a foster placement assisting mother to acknowledge and understand the role of food, the role of being able to parent and say no and stick to it, manageable portions, people, you know, not providing the child with an adult portion instead of a child, (P12)

\section{Prevalence}

Identifying the prevalence of cases of child obesity where a child protection approach had been taken was difficult. An initial problem was the lack of data at organisational level within social services.

So I don't think we have any particular statistics that we could say if the children are on a child protection plan, how many would be deemed as obese by the school nurse. Maybe if the school nurses and the health authority might, will clearly have those statistics as part of our joint strategic needs analysis sort of thing and can plot the trends and growing for the future, but I think if we - I don't think there has been any work to understand how many of those children that are most vulnerable i.e. on child protection plans or in care have had them sorts of, that's not data that I'll be presented with. (P5)

At an individual level experience varied widely from no involvement or awareness of cases at all: 
I've got a caseload of nearly 70 and I haven't got any young people that beyond sort of slightly overweight. (P14)

To a wider knowledge of and active involvement in cases.

We have had in my experience both as a manager and a practitioner a number of other child protection cases, and child in need and cases where there are issues about a child's diet, and not just obesity. (P17)

I think it's increased, especially in regards to the Eastern European families that we see. (P4)

This variance was apparent in health services as well as social care. Unsurprisingly the hospital paediatrician had most knowledge and awareness but perhaps surprisingly a GP respondent had no experience of any cases.

No. Absolutely none, no. It's interesting. (P19)

The comparative lack of referrals specifically about obesity led some respondents to wonder why and ask whether this was because such cases did not exist, because they were already being well managed, or because there was a feeling that nothing could be done.

I don't have a lot of cases referred in, so I won't say it's something that people are ringing about all the time to ask our advice on. Now whether that's because there aren't issues, or because they feel there's nothing they can do, or is it that it's being handled right, or is it that actually people feel they can't do anything about it and therefore don't ring for advice? (P3)

The perception of obesity as less important compared to other health issues had the potential to impact on prevalence

But what I would say I've never had a child ever in 10 years of social work on a child protection plan solely for obesity. Whereas I had one solely for severe dental decay because they failed to meet needs. But strangely enough to say it's such an issue that is prevalent we know in.........., and more wider than that. It's all over the media now talking about childhood obesity, and adult obesity within the UK. What I'd say is yeah I have never had a case that's come in where it's been specifically this child is so significantly overweight, and we have evidence to believe the parent has failed, and that's why. As opposed to other specific health issues where cases have come in, which is quite unusual actually considering how prevalent it is, which tells us something about how we perceive it at the minute. (FG2)

For one respondent it was an overall perception of obesity as lacking importance that led to her professional frustration and potential unmet service user need.

We have children, you know, what we find is the children that are overweight, you know, we'll question in conference: are they comfort eating? Were they eating for attention? Are they eating because that's what makes them feel better? Are they eating because they're self-caring because parents aren't available to them? Are they eating because they're eating a lot of quick takeaway food and stuff? But it's never given the credence. It's never, it never is honestly. (P11)

The previous section on thresholds may well provide some insight into these questions about prevalence.

Although direct experience of working with obesity in a child protection arena was rare it is interesting that a large number of respondents had at least one case in which they had been involved and about which they could recall clearly. These cases are represented in the case studies which follow the findings chapter 9pages 62-72). 


\section{Viner Framework}

The 2010 paper by Viner et al published in the British Medical Journal suggests a framework to understand and work with child protection concerns with children who are obese. Namely:

- Childhood obesity alone is not a child protection issue

- Failure to reduce overweight alone is not a child protection concern

- Consistent failure to change lifestyle and engage with outside support indicates neglect, particularly in younger children

- Obesity may be part of wider concerns about neglect or emotional abuse

- Assessment should include systemic (family and environmental) factors

It is this framework which is both widely quoted in academic literature and incorporated into the child protection procedures of some local authorities.

Respondents were asked about their knowledge of the framework and then shown a copy of the key points and asked to give an opinion. This question occurred after they had given an opinion of whether obesity was a child protection concern so as not to influence their own views on obesity. Almost all participants had no awareness of the Viner framework. On being shown a summary, respondents were divided as to whether obesity could be a standalone child protection concern. Linking obesity to wider issues of neglect, and identifying a consistent failure to change lifestyle and engage with support as indicative of neglect had wide support. So too did the emphasis on systemic assessment. Overall the framework was welcomed as a useful tool, with the caveat that over reliance on a framework can lead to over simple assessment. The framework was not seen as overcoming problems inherent in measuring and identifying obesity, and failed to identify the association of obesity with sexual abuse.

\section{$\underline{\text { Knowledge and Awareness }}$}

None of our respondents had read the paper or were aware of its inclusion in child protection procedures. One respondent was broadly aware of the principles and content. The following responses were common:

No. I'm not. What did you call it? (P3)

I don't think we would see this in our child protection procedures. (P5)

\section{Agree}

Professionals from a range of disciplines thought that the framework confirmed their views and were of the opinion that as suggested within the framework childhood obesity alone should not be regarded as a child protection issue:

Yeah, I probably agree with all of them so childhood obesity alone is not a child protection issue. You know, so just the child being obese, you need to put it in the wider picture and the wider assessment. (P3)

So childhood obesity alone is not a child protection issue - which I think is right. Yeah because it isn't is it really. There's got to be something else that that's related to, you know, there's multiple factors. Failure to reduce overweight alone is not a child protection concern - i.e. if they can't lose weight, that's not a child protection concern. Failure to change lifestyle, engage with outside support indicates 
neglect particular in younger children, so a failure to change lifestyle, engage with outside support. (P22)

In particular the linking of obesity to wider issues of neglect had broad support.

I think it rightly identifies that it doesn't stand alone as a child protection concern, and often it's linked to neglect generally. (P12)

Obesity may be part of wider concerns about neglect. Yeah I'd agree with that. (P16)

Consistent failure to change lifestyle and engage with outside support as indicating neglect, particularly in younger children also drew wide support and confirmed the views previously expressed regarding familial engagement in support as a key factor in taking a child protection approach.

I mean I think actually I broadly agree with that in that I think that probably reflects what I've said that obesity alone is usually not a children, you know, child protection issue. It's the consistent, it's the failure to try and address it. It's the failure to go along to the lifestyle management and then, you know, the wider concerns about neglect, not attending school that tend to be the things that would for me would tip it into the safeguarding domain. (P21)

For one respondent the word 'consistent' was key:

So the consistent failure to change lifestyle and engage with outside support indicates neglect, particular in young children. Consistent is crying out to me there. So they've been offered support. I sometimes think it comes down to I don't get on with that worker. I've had that, that's happened to me and that's absolutely fine. It could be transference or whatever a reason but let's refer on and if they work with that worker absolutely great because we need these aims and objectives for this family. But I think if it's consistent failure it needs stepping up. (P4)

For social care workers that an assessment should include systemic (family and environmental) factors was obvious and part of their everyday practice:

Yeah well with respect to paediatricians if it walks like a duck and quacks like a duck, it's a duck. And I like paediatricians and they have their place but a good social worker should be looking at family and environmental issues anyway. And I don't need a paediatrician to tell me that. (P12)

For another respondent however the framework captured some of the complexity involved in assessment.

As you say it's not just about the child being overweight, it's emotionally how stable are they from a mental wellbeing perspective, social skills and all that all come into that. And for me that captures a lot of that there. It's not one issue alone is it often that can be a factor for overeating for example. Are there depression issues there, peer pressure, is it exam stresses, or is it indeed what we've already discussed in length about the way the mechanics work within the family, and how they parent their children; indeed with their own issues and problems can be another factor in that. So yes, I would go some way to agreeing that that's a fair framework. (P8)

Overall for the majority of the respondents having any framework to make sense of child obesity was useful.

Yes I would say it's great to have a framework. (P1)

Furthermore this specific framework was seen as accurate, practical and helpful

So I think it's quite useful. It's quite simple. It's quite usable. I think if somebody had that in the back of their workbook and they could refer to it quite quickly and understand it and help inform their decision-making. (P7) 


\section{Disagree}

A number of respondents who held the view that child obesity could be a standalone issue if not in general at least in specific cases disagreed with the framework in the respect of several of the points.

Failure to reduce overweight alone is not a child protection concern - I would say it is. I would say it is. (P11)

I think I disagree with the first one, because I think that's your starting point isn't it of looking at childhood obesity. Yes you would consider the other factors but I still feel that I do think, I think because of the longer term impact that obesity can have on that child then I would still feel it's a concern. (P2)

So the first statement is, and it seems to be put here as a statement of fact, which I would disagree with, and it says childhood obesity alone is not a child protection issue. And I think potentially it could be. I mean if you thought about a hypothetical extreme example and say you have a five year-old who's 12 stone there is no medical condition that would cause that. That has to be about the parents because the child isn't old enough to have caused that entirely themselves. And I would say in an extreme example like that then it is a child protection issue. (P22)

For some respondents their own direct practice experience contradicted the framework:

Likewise, failure to reduce overweight alone is not a child protection concern - I disagree with that. Because I think again health professionals in ....... were screaming from the top of the children's hospital about this young lad because they were saying it were a child protection concern, so they would disagree with these because they were putting pressure on us to get something done. To the point where they were saying if, you know, I think if hadn't have done what we did then they'd be sort of contacting the director saying you should be doing more. (P18)

Yeah and the bit here about it may be part of wider concerns about neglect or emotional abuse, it could be but in my case it wasn't...that case that I had, you know, that fits into it was around obesity alone. Not any other factor, there was no other concerns at all. There was no evidence of any other type of neglect, no emotional abuse, no sort of poor home conditions, no lack of care; it was sort of over the top care. (P18)

A further criticism was that the framework in mentioning neglect and emotional abuse did not go far enough particularly in not mentioning the link to sexual abuse.

And I would add sexual abuse on there. It says neglect and emotional and doesn't mention sexual. It could even be physical. You know, the child for whatever reason it's an escape from physical abuse. So I would say any abuse. You don't need to define. (P3)

A further respondent built on this view, by drawing parallels with other health conditions and also the link to sexual abuse, to make the point that failure to reduce overweight alone could be a child protection issue.

Failure to reduce overweight alone is not a child protection issue. I disagree with that because if at any of the meetings we go to where a practitioner has said to the parent or carer that this child is extremely obese and it's going to impact on their health, I don't know much, I know a little bit about diabetes and they choose not to do something about it once they're given information and it's not just given that information, it's actually doing that practical stuff. So are they registered with a GP? Are they going? Have they had a regular healthcare, is it updated? Is anything different? Have we explored that this youngsters eating maybe? I've worked with a case previously where a girl actually selfneglected but it then came out that she'd been sexually abused and her thoughts of that was if I have nits, if I smell they're not going to touch me. So if all that is assessed and assessed properly and thoroughly and it is a health issue and the parents or carers are not doing anything towards that I don't agree with that statement. (P2) 
The usefulness of the framework was seen to some extent as profession specific and being particularly relevant to those working regularly with a family rather than those who had occasional contact.

I think that would be more relevant for somebody like Stronger Families team where they're actually working with the family that has identified problems already. And that might be part of the whole issue, a lack of understanding about how to cook food, prepare food that's cheap and nutritious might be something that they should be looking at more often. But from my perspective, from what I do, (Environmental health) I don't think that would. That wouldn't be clear enough. (P9)

\section{$\underline{\text { Ambiguous }}$}

For some respondents there was ambivalence about the tool that reflected the lack of clarity in measuring obesity and what that might mean for a child protection approach.

I was just thinking that the top one, the childhood obesity, although it's not a child protection issue, if it was to become a child protection issue where do we measure obesity? Because you're always going to get people saying oh this child's obese, she's a stone overweight. But then on the flipside of that you've got someone who's six stone overweight, so where do you draw the line? Where's the balance? Because you always get people reporting things about, they overreact about things don't they? So are we going to get people phoning up all the time saying this kid's put weight on, you know what I mean. It's where do you, where does it go? (FG2)

With greater knowledge of obesity and the impact on children perhaps came greater questioning of the statements in the framework in the light of awareness of the complexity involved in any assessment.

I did start looking at a bit on the internet last night and it talked about sexual abuse, you know, the link between sexual abuse and obesity. And you've got to be thinking about those things and that's why your assessment needs to be very comprehensive. What else do we know about this family? What else is going on in this family? What might be going on in this family? What do we know about siblings or other people attached to this family? So some of these statements are a bit black and white, really, aren't they, to say whether you agree or not? (P3)

I think the first two are the two where I'm, I guess they're the ones that differ with the opinion that I've already given. I think in the second one, the failure to reduce overweight alone is not a child protection concern, I think you need to look at that in conjunction with the last one, the assessment should include the systemic factors, you know, the family, the environment, and I think that you would then look at obesity being part of wider concerns. I think you'd need to do those as you were making that judgement of failure to reduce weight alone isn't a child protection concern. To understand why there might be that failure to reduce the child being overweight. And I think I disagree with the first one, because I think that's your starting point isn't it of looking at childhood obesity. Yes you would consider the other factors but I still feel that I do think, I think because of the longer term impact that obesity can have on that child then I would still feel it's a concern (P2)

There was a warning that, although a framework could be useful, over-reliance on Viner as with any framework could lead to over simple assessments.

So I think with, as with many of these frameworks and processes you can't use them in a one dimensional way, because you can often be wrong. You know, like I was talking about the toxic trio before, just because you've got alcohol, drugs, mental health issues in a family, doesn't mean that those parents are not good parents, they can be. (P5) 


\section{Good Practice}

Throughout the research interviews respondents provided examples of good practice, not only in reflection on their own work and that of others, but also regarding their aspirations. Good practice was seen as beginning with a holistic understanding of obesity and its impact followed by a multiagency approach including health, school and social care. Direct work with the whole family is given prominence in achieving change, both within and without a child protection context. Family involvement in the development and implementation of that work in a way that empowers but does not stigmatise was identified as a goal. Parental education was seen as important as part of a preventative approach and in sustaining change.

Use of multi-agency approach following CP referral

The need for a multiagency approach across child protection was discussed on numerous occasions and was seen as central to effective work. Highlighting the complexity and the vast knowledge base required to support children with obesity within child protection, with suggestions that a multiagency approach would strengthen and enable additional support.

Well it needs a multi-agency response doesn't it? Health and school and social care working together and doing a holistic assessment which looks at the whole family and environmental factors. The health assessment is important isn't it, because then there's a way to measure and it can be factual about the child. But then you need to consider the other psychological factors what might be playing on this child. And you have to do all that in a way what's not further abusive to that child, and do it in a way that's supportive and sensitive. (P12)

The Participant was one of many who highlighted how schools, health and social care working together can create a better support network for children and their families.

\section{$\underline{\text { Holistic understanding of obesity and its impacts }}$}

There was a wide range of examples highlighting the need for the multi-agency approach to inform holistic assessments to be undertaken to achieve a better outcome for children and their families.

So, in terms of our holistic assessments of children, I would be hoping that our social workers will be taking into consideration children's health and wellbeing, and seeking advice and contributions from the school nurse and/or the health visitor depending on the age of the children in relation to both a child's weight and their emotional and social presentation, and there the emotional and social presentation are part of the domains on which we would be looking to assess children. (P17)

The emphasis on assessment spanned all respondents from senior managers to family support workers and encompassed all levels of intervention from early help to child protection.

It's about doing the holistic assessment isn't it and finding out absolutely everything behind it. Because there could be lots of reasons why that child is like that. I don't mean, you know, it could be the social isolation, the bullying. There could be lots of things behind it. (FG1)

\section{Direct work}

No matter how good the assessment, however, respondents indicated that it was primarily through direct work with children and families that change could be brought about. Participants indicated that it may take a child protection approach to act as a catalyst for families to engage in the work and in some cases the removal of the child, but the work still needed to be undertaken whether in a foster care setting, residential setting or the family home. The interviewees provided insights into a range of options for dealing with issues relating to childhood obesity.

For example, one respondent described work with a child in foster care: 
We have a lot of cases actually with children that hoard food... They've never known when the meal's coming from. And a bit like when you put a dog bowl out for a dog and they don't, unless you balance how much they have because they'd carry on eating forever... They never know when to stop. And it's not their fault that they don't know when that foster carer is going to get another shop in. But then they'll take things and hide it and so they can be munching all through the night and you don't know... What I've said to them is have something, I've called it a tin, like a don't have to ask tin. So that they know that there's always, and that's got nuts in it and bits of fruit and stuff. (P14)

Direct work with the children around self-esteem and identity was suggested:

And what we are doing with children is very much more doing a hell of a lot more direct work with children that we've ever done before, and a lot of that will centre around some issues around identity. So we would maybe be able to talk to a child around that, about how they're social functioning, whether they're bullied or not in school in relation to obesity issues if it's obviously glaringly obvious to the social worker. (P17)

Residential placements for children who had been identified as having weight issues were a further option.

It was organised by Leeds Carnegie and it was a private school but during the summer, Carnegie took it over and run this summer camp for teenagers with, who were obese. And they worked on, not just, it was for a minimum of four weeks but then you could do it for six weeks. And then they worked on a variety of things, not just physical exercise although that was important but also about portion size, and they had standard bowls that they used for different things. They worked on working with young people around their emotional needs and their emotional detachments to food. (P16)

This example highlights however, that good practice involves seeing direct work as part of an overall plan and one intervention in isolation may not prove successful. Direct work with the child may also require simultaneous work with the family:

So he attended the group, he lost, I think he lost a couple of stones in a month. It was quite dramatic. And we went for a review and the option was for him to stop another two or three weeks. And his mum and mum's partner refused. They said oh no, we want him at home, we miss him, we want him back. And he was missing them. But so, you know, I mean there were no orders or anything he was just on a CP plan. So we had to, you know, we had to abide by the parents decision. (P16)

Good practice within child protection involves marrying involvement of the child and family in direct work, such that they are central to the plan and activity whilst being aware of the need for protection and risk management.

I'm not turning round and saying I think you're fat. I think you're obese and I think that, it's not done like that. It's not as direct as saying this is what I'm worried about. You're telling me that you're being bullied. How do you think we can make things a bit better? And actually what they do is they come up with their own little plan. Oh I could go ice skating more often. Great. So they've actually come up with their own plan. But then it's my job to make sure it's overseen because obviously factor in disguise compliance and mum yeah, yeah, they've done that this week and they haven't. They're just telling us what they feel we need to hear. (P4)

A wide range of practical ideas and interventions were put forward to support weight management as part of a family support programme and early help.

Something we have done, we've decided that to increase his physical education.... Now he's started riding to school and back and he's joining a dance activity at school as well as basketball. So we're monitoring the progress to see if we can bring his weight down with a healthy balance as well, and see what happens there. And we're taking a diary sheet, and then we've agreed, then at some point we'll then go and visit the GP and say right this is what we've done, we're hitting the right lines, what do you suggest now, what can you offer now? (FG1)

Examples were also provided of initiatives that focussed on prevention: 
So for instance one of the things that's happening over in our children's centres is they're trying to set up community cafés so they can bring families and children in and teach them to cook as a family, talk to them about the nutritional balance of food, and talk about obesity and effect it has on children. Because, you know, there is a recognised link isn't there between poor diet and engagement with school, so that's why most schools have breakfast clubs because it's been proven that if a child has a breakfast they are more engaged and ready to learn in the morning. (P5)

\section{Parental education}

Good practice involves acknowledgement of the difficulties families face around understanding weight management and healthy eating and the need for education.

I know two mums that I work with, they've been advised to give their children 1,500 calories a day. But they have no idea what 1,500 calories looks like in terms of meals, and what kind of stuff has really got high calories and what stuff has got quite low. (FG1)

Well I found this really good calorie counter on the NHS website. So it's got every kind of food you can think of, every drink that you can think of. And we've gone through those together, good calories and bad calories and good sugars and bad sugars, and it talks you through that step by step. So I've used that app with both families. (FG1)

Education can also involve being clear and frank with families about the consequences of obesity:

And also being pretty clear with people about, you know, because there's high levels of type 2 diabetes and all the rest of it, of the consequences of not doing it. And sometimes it's not about being crude with people but it's about being blunt, by being clear. (P12)

Service user involvement - Whole family approach

As also indicated in the section on direct work respondents were clear that good practice involved ensuring a whole family approach was undertaken.

But generally it's a family issue rather than a childhood issue, I think. And one of the issues I think we have is we talk about child obesity and adult obesity and they're dealt with separately and differently and actually they're in the home eating whatever they eat together. (P7)

Taking a whole family approach includes involving all family members including male members of the household not just mothers.

In my experience you need to get the male members of the family on board because often you find mums on board but it's dad who stamps his foot and says well I want oven chips or, you know, so you need everybody to be on board. And if you can get that family-centric approach where everyone buys in you're successful. (P21)

A whole family approach requires children and families to be centrally involved in each stage of professional involvement from identification, assessment to planning, direct work and review.

It weren't until we were doing our family assessment that I asked, and I was doing three houses with this boy and I asked him what are you worried about? And he said I'm overweight. He identified that himself. And then the family followed up by saying yes he is overweight, we try and limit his food, we put healthy food in front of him, we try and portion size it, we don't know where to go from there, we don't know what else to do. So that's when we just came up with this plan for now, see how that works, if that has an impact and then we'll take that further. (FG1)

Involving families in the development of the support required can lead to better outcomes and falling back on a one size fits all approach to family support is unlikely to be successful.

If you've got a parent with low confidence, who doesn't go out, the last thing they're going to want to do is go and join a group a people in a strange place where they don't know. So it's got to be 
something that, you've got to work with the family for a solution rather than tell them what the solution is. And I think that's been a mistake in the past as well. (FG1)

There are numerous challenges working with families around weight management, the stigma of the child measurement programme often upsets families and therefore can cause a difficult starting point for case workers.

And some families might not want to hear it. And that's one of the problems, isn't it? It's empowering them to realise that it's something that they need to do for their child and not everybody's ready for that... I think anything with the words child protection in and they'd probably run a mile. They'd feel guilty. They'd feel defensive. If that was mentioned with my child, then I would be really upset. (P6)

A key message here is empowering service users through the work undertaken, albeit work that may require a child protection approach. Involving service users does not mean avoiding discussing difficult issues but rather working towards a successful outcome.

I'm a big believer if you approach things in the right way you can tell the most difficult news to anybody as long as you say it in the right way, and you tell them there's a problem, tell them there's a solution that they can, that's the bit. If you're going to identify a problem, give them something to work with so they can sort it out. Don't just throw it out there otherwise you're not going to achieve change are you? (P4)

\section{Challenges for Practice}

Alongside indicating good practice respondents also indicated the challenges they faced and where they thought practice could be improved. At times these could be two sides of the same coin. Examples included structural issues such as a lack of funding for preventative services and a scarcity of targeted services for disadvantaged groups. Psychosocial barriers to families accepting support were identified, as in the way poverty interacts with the individual service user to drive behaviour. Multi-agency working was a source of frustration with a lack of clarity identified regarding roles and responsibilities. Direct work with families was central but could be problematic, potentially reinforcing unhealthy eating patterns and needing to balance risk management with building trust and relationships in order to bring about change. A tension was identified between the difficulty of having obesity accepted as a child protection concern, yet only being able to access intensive support or expensive residential input as part of or as an alternative to, court proceedings.

\section{Multi-agency working}

Multi-agency working is an example of where respondents indicated the centrality to good practice but also the challenges and frustrations they faced. There could be a range of professionals working with a family but a lack of clarity over roles and responsibility to raise and manage the concern of obesity.

The school nurse is on board and she's the one that did the referral to the dietician. And we both have been doing direct work with them. So I think it just depends what professional, and what their knowledge is of it, and whether or not they're willing to do the referrals and give advice out. (FG1)

There tended to be reliance by social care on health services to advise regarding obesity

You're reliant upon health professionals giving you that appropriate advice. (P18)

Social care indicated they would like greater clarity from health professionals and also to take the lead on obesity in core groups involved in a child protection plan: 
And I think from a health professional's perspective I think they need to be maybe a bit more clearer, and that's what I think what conference chairs were saying that they would need to be guided by a health professional about saying whether this is just a stage of development or whether actually this is something that needs to be addressed at part of a plan to support a family. (P17)

They (CP Chairs) see this as a health issue and they see that's where the school nurse and/or the health visitor has a key role to play in the core group about supporting a parent to understand. (P17)

Health professionals in turn indicated the frustrations and struggle they had to have obesity issues taken seriously in core groups and conferences. One school nurse, rather than having a key role in conferences and core groups, felt undervalued as a professional and thought obesity was marginalised:

What we find is the children that are overweight, you know, we'll question in conference...But it's never given the credence. It's never, it never is honestly. (P11)

So, you know, what happens then is, is that it becomes an add-on. You know, we then see that child and oh actually we're at conference for $X, Y$ and $Z$ reason, but actually also this child is overweight. So in the bigger scheme of things it's always minimised. (P11)

I don't think health is given the respect it deserves for a child that's on a plan... So we're coming away from case conferences now with no role for health professionals of a child that may be obese but they don't see that as neglect. (P11)

Frustrations and a certain lack of clarity re roles were also apparent between the range of differing voluntary and local authority family support services.

Early help are working with the family as well. They are aware, but I'm really not quite sure what advice they've been given. They tend to just at the moment signpost rather than direct work. (FG1)

We do work in partnership with them (Early Help) in a lot of cases. They will refer to us when they, they will probably work for so many weeks, and then they will say right well they don't need us now, it needs you. (FG1)

It's the intensive family support team, and they will go in and work directly with the family on issues around parenting, around if they can get CAMHS involved. It's quite wide. It's the step before social care. So things that social workers used to do the early help intensive family team now do that. We do it too but hey ho. (FG1)

A division of roles is present here, alongside a change in roles and this can lead to mixed messages for families.

And they'll have a specific type of work they do. So if they went in and it was a parenting issue, they'd deal with the parenting but they will not deal with anything else.

It's just that one.

So if there's like housing and everything like that, that just gets left. They do their piece of work as they call it. So if it's a 12-week piece of work on what they're doing, and then they go out and that's when...

That's when we're in doing the rest of it. (FG1)

Limitations of professional's knowledge and experiences, working only within their field can create gaps in services and support for families.

But what, I think what does worry me is when these cases are highlighted it is the lack of information and the support from other people for the families. Sometimes we can be struggling a bit as to where we're getting that support from for the family. Like you did, you got onto the national health website, 
you sourced it, you did it, but there wasn't anything put into place from a school nurse or, do you see what I mean? (FG1)

The need for more multiagency work is evident; however putting this into practice can be difficult.

\section{Lack of support}

There is clear evidence of the lack of support in the wider context, staff not being aware of the support available, interventions being cut or reduced and no longer meeting the needs of families. One example is a perceived reduction in funding for services for preventative and weight management services.

A little bit like a lot of the dietary things that are in..., all of those lower tiers of weight management in ... have all lost their funding since the budget cuts have come through really. (P19)

But at the moment the budgets are so constrained in ...that they've actually pulled all their weight management programmes in.... Despite the fact that we're the second fattest place in the country with $76 \%$ of adults and children being overweight or obese in ...there is no budget allocated to it at the moment. (P22)

A further challenge are the lack of targeted services for specific groups with those with special educational needs and those who do not have English as a first language being specifically identified as having unmet need.

There's very little available for individuals who've got special educational needs in terms of lifestyle intervention. The additional problem with that group is food is often used as a reward and to control and manage their behaviour. So parents will often, you know, they come to see me about their weight, and oh if you're good you'll get a McDonalds on the way home. I can see why they do it and the children are often very food centric and within the special schools system particularly as you move higher up the schools, up the school age group, it tends to focus on life skills and a lot of that is about feeding yourself, cooking for yourself. So and of course if you've cooked a cake you're going to eat it. So there's a little bit of a tension there between, you know, the sorts of activities that the children enjoy and what ideally l'd like them to do and have. (P21)

So, you know, tailor to the family they say but in my experience they don't manage families where English isn't the first language. So, you know, I have significant issues about the provision for Slovak, Roma families where obesities are a big issue and children with educational difficulties are not easy to manage within those settings. And there's virtually nothing for them. (P21)

\section{Barriers to accepting support}

Where support in relation to obesity was offered respondents identified that families often presented and were presented with barriers to taking up support. Some of these were the consequences of poverty

The impact of the government reforms around benefits and how that is having an impact on lower income families and the fact that maybe they weren't able to buy the better food that they would like to buy for the children that might actually be more healthy. (P5)

The barrier to following advice given re healthy food was not just in respect of the immediate cost but also access to cheap healthy alternatives with those food outlets not available in the immediate vicinity of low income housing.

I think as well the nature of the families we work with, they're all on the low end of budgeting. So they don't have access to cars, they can't afford bus fares for the whole family or a taxi there and back. (FG1) 
Look at a mum with three kids, I can't get on a bus with the pushchair - a mum said the other day that she was turned down from getting on a bus because there was already pushchairs on the bus. Again it's a barrier. (FG1)

Other barriers were identified in what were described as 'mind sets', a particular way of thinking about food which was difficult to change.

I think trying to change people's mentality and way of doing things, particularly in South Yorkshire where you and I live, is going to be very, very difficult. (P22)

This mind set is seen as a barrier to some of the supportive ways of working with families.

Yeah, and even trying to get them to come up with their solutions and using the motivational interviewing. Right well what can we do, let's look at what. But then it can be things like we're not used to, I don't go out of house, I don't do that. (FG1)

A further barrier is that for many families obesity is one problem amongst many and just as obesity falls down the priority order for professionals so too the priority is less for families.

Yeah, and she enjoyed working on it. I worked with her direct, and she actually enjoyed the work, and she felt like she got a lot from it. But because her life was so chaotic, and then she got pregnant again, her third pregnancy at the age of 18, it soon goes to the bottom of the list of priorities. (FG1)

\section{Problematic direct work}

Just as direct work was fundamental to good practice respondents thought that some work practices created barriers and could contribute to the problem.

I think it's, contradict ourselves now. I've been a child protection social worker before, and you do direct work with the child and you go to McDonald's. There's contact, you take them into McDonald's. I know we have a youth club for looked after children where they can have their tea. It's a menu, I've got pay, whether it's sausage chips and beans, and then biscuits; there's no fruit, so we're doing it to them as well. (P14)

The potential non-identification of obesity in assessment created an initial challenge for direct work

We had got a really good early help system in Doncaster. That's something we've developed and worked really hard on who can support these families at a lower level. But I struggle with why we wouldn't do anything about it, and why it is missed, why it is under the radar actually. It's only as we're talking about it because I wouldn't normally think about it. (FG2)

Having overcome the issue of identification there remains the challenge of what to do about it and the potential problem that identification can become an end in itself.

So what I'm getting at is we might identify it, but if you send somebody a letter, you say to me OK, so it's like saying to somebody you're in debt. But if you don't identify how they're going to get out of debt what's the point? Why do it? (FG2)

There was a perceived reluctance on the part of social workers to undertake direct work in relation to obesity but rather (historically at least) to refer on to others in a way which was not helpful to families.

So to be fair although we are moving back to getting down in the nitty gritty and actually doing it ourselves, there is a history of this referral on process. And we are as Doncaster as a trust to move away from that and go back to well what is the social worker going to do about it? But essentially though we're not health experts either, and what I would say is I always err on the, make sure it is somebody. If you've identified a problem make sure it's the best suited person who can go and address that issue. I think social workers could do more alongside school nursing to support in addressing that issue. (FG2) 
The view of obesity as a side issue can inform the time and importance afforded particularly within social work child protection visits.

But then I go back to the fact that we've never, we don't normally have a case where it's primarily. If we went out and it was sexual abuse they wouldn't skirt round it, they'd talk about sexual abuse. But because obesity is maybe a side issue, and they go and do a child protection visit, they're usually consumed in dealing with the primary issue that's come in that then have we got time to get to the obesity? I don't think it's just dismissed, I'm saying I don't know whether enough time is afforded to then deal with side issues. (FG2)

Respondents identified a tension and challenge between an overzealous approach which risks stigmatising and traumatising parents set against an appropriate response that does not marginalise or trivialise the issue.

She wanted the early help assessment but she didn't find them helpful. But she felt because it had gone through referral and response to our team that they would get involved. And it didn't even meet their thresholds. And the relief when I said look it went through their, it didn't not meet their threshold, it came to us. So I'm just wondering how that felt for that family, because it wasn't about home life or anything. He'd got friends, he was quite happy, no issues at all in school other than he was overweight. (FG2)

There needs to be a follow on. I would expect then the parents would be invited in for a chat, a coffee chat and not an interrogation, to be asked about how things are going. And then the child in an age appropriate manner to be spoken to about their weight, and how they feel. And that can all be done in a nice way. It doesn't have to be done in an interrogation, to get to the bottom of what's going on. And then look at a plan if need be. But I think more needs to be done to satisfy ourselves as professionals that it's being addressed and that it's not a neglectful issue. I don't know if we're doing enough. (FG2)

There were challenges for practice identified in working both within and without child protection services and that non statutory working by agreement required the building and consolidating of relationships with the family.

I think this is where we have to be, we're not statutory, and we can only work with families on what they identify that they feel they want the support with. We can probe, we can lead, but we can't force anything that they don't want to do. So if they say, and you don't, and because of your working relationship like we've just said, you know, you can't let that be well you're not coming anymore because it's, I don't like what you're saying. You've got to keep that relationship because of everything else that you're working. So you can gently prompt and you can say it, but if they clamp down then there's absolutely nothing we can do about that. (FG1)

The challenge here is that worry about relationship breakdown leads to a lack of a child protection referral where that may be appropriate and in the child's best interest. Alternatively for some respondents focussing on obesity as an issue and undertaking direct with children brings the danger of potential eating disorders where low weight is a problem. It is unlikely; however, that direct work would not be undertaken with an anorexic child because of the danger of obesity.

So if it becomes suddenly a big issue about calories and diet for kids, will that then ultimately lead them into having some abnormal idea of what eating is about. So that is another sort of I guess a danger. And I think all of that is quite complex is what I would say. (P19)

There's also that side of it where do you want a child to, you can also cause them harm by saying you need to lose weight all the time, you need to watch what you eat. Somebody can go on to have, I know it's a very flippant, a wide statement but they can then go on to have eating disorders. Do you let them be children? (P14)

A tension was identified between the difficulty of having obesity accepted as a child protection concern, yet only being able to access intensive support or expensive residential input as part of or as an alternative to court proceedings. 
I mean when you get to court the judge will want, the judge will sort of enquire what has been done? And the courts are no respecters of budget. So they will say well, why hasn't this been done? Why hasn't that been done? Certainly when we've been approaching court proceedings I've been aware there's been children where the LEA or social care have funded support workers to come and take the child to the park four evenings a week after school...So that when it then gets to court they can say, they can then honestly say we really have done absolutely everything. But they tend to only do that when they are aware that there's going to be judicial scrutiny or, it doesn't happen normally. (P21)

\section{Suggestions for the future}

This category relates to ideas interviewees put forward as to what would assist practitioners working with child obesity where safeguarding issues are present. These suggestions are strategic or relate to organisational service delivery rather than individual practice. They included training on obesity and service availability, and providing a framework and procedures to guide practice. Evidence on short and long-term outcome measurements was identified as a deficit and more research and dissemination of findings on outcomes and what works regarding interventions regarding child obesity is required.

\section{Training}

Obtaining training on child obesity was identified as important by and for all professionals, both health and social care. With the exception of the school nurses and paediatrician no one had received training about obesity.

Better training, because I've certainly had no training. You know, what l've always done is, you refer to health professionals, but certainly l've had no specific training in, either as a practitioner or as a team manager, you're reliant upon health professionals giving you that appropriate advice. (P14)

The training needed to be focussed and to meet an identified need for better analysis in assessments and greater rigour in evidencing referrals.

You know, it's the analysis that people struggle with. They struggle with this concept of an analysis and what this means for this child. And that's where some of the referrals aren't as strong as they could be, you know, from some of ours. (P3)

The training should also be more than surface deep... I think there needs to be articles and journals that relate to it as well because social workers still don't do enough research. And they need to because they need to have informed practice. It's not point in telling somebody little Johnny is fat and then you don't have the evidence to back up what you're saying. (P12)

Training should explore the links between obesity and neglect and consequent safeguarding issues. For example:

So I think better education about at what point does being overweight start to become neglect, you know, so when is it not just a, you know, a theoretical problem. This child's overweight. But when does it really start to impact and when does the parents failure to address that impact start to become neglect and that actually it sometimes may be an element of opinion as well. Not all professionals will agree on that but that I think is the area, you know it's highlighting what exactly constitutes neglect. And as I say, I do agree it's not just the weight, it's failure to address the sequelae of the weight that tips it into safeguarding. (P21)

Training would also enable better knowledge of services provided by different professional groupings;

Training definitely. I'm not sure if everybody is aware of the work that public health does. I know because I am seconded over from the trust I was, didn't realise the team was so big and so dynamic 
and exactly what they did and the resources we can tap into. So I think the trust and DMBC definitely need to do a bit more joined-up working in regards to that. (PN)

There was some difference in responses as to whether the training should be focussed on early help workers "I'd maybe like to see some targeted training with early help workers, probably more so than social workers if I'm being honest (FG2) or be more widely targeted to enable social workers to be less reliant on health workers but also to enable them to evaluate evidence presented in referrals.

\section{Provide guidance, procedures and a framework}

There was widespread support for a framework and procedures to assist practice

I think it should (obesity be a CP concern) yeah. But I think there should be maybe a bit more of like a framework around it, something that we can work better with. (P14)

Well, I think something like that (the Viner Framework) would be good because we have a consistent framework then to work from. At the moment, I'm not sure what a worker would refer to if they felt that there was a child protection issue linked to obesity. So I think something like that helps give them that framework to go to. (P7)

For some practitioners guidance is seen as coming from health

"I think better guidance from health as a way of countering a reliance on personal views and experiences by social workers. (P14)

So I think there might, in terms of moving forward as an issue and how both the understanding as a threshold issue might be better explained if we did have some better guidance in terms of a public health about, for other professionals rather than going on their profession, their own personal, I think most social workers will just go on their own personal thoughts about what is obesity based on their own experiences rather than actually ever having, as you say, had training of being taught, this is obese and this is the implications it will have for the long-term impact on health. (P17)

The differences identified in the research programme as a whole, regarding obesity being seen or not seen as a standalone safeguarding issue, need resolving to enable consistent guidance.

We need to have some consistency about what we're saying we need to tackle. And at what stages we need to tackle it at. And why it would enter a child protection arena not as an issue in itself, but because about the parents' ability to tackle it. So I think we would need that all round piece of guidance really, set in the context of we know it's an increasing problem in society. But I think there does need to be some balance with that in terms of the state intervention and linking that with poverty. (P17)

\section{Outcome research and dissemination}

Overall there was a lack of knowledge expressed by virtually all participants about what worked regarding interventions, whether Early Help or under a child protection label. Respondents tended to rely on their own personal or practice experience of what appeared to work in the past.

Was it effective? I don't know... but was it just because mum was going to the paediatrician or was it about these TAC (Team Around the Child) meetings, I don't know. (FG2)

Knowledge of research findings specifically related to interventions regarding child obesity and their outcomes appeared to be limited to the paediatrician.

There is some modest benefit for the sorts of programmes which are available which, you know, generally run once a week at a local sports centre. They encourage the parents to stay but most parents don't stay they go home and they just leave the child for the hour-and-a-half. I think those are of relatively modest benefit. And if you look at the research evidence, the evidence is the more complex and the more structured the programme and the more intensive it is, the more effective it is. (P21) 
Where there is evidence however that is not without question. For example regarding evaluations of residential intensive support for children:

Carnegie, the short-term data's very good; the longer term data is somewhat lacking in my experience. They've not particularly put it out into the public domain and the data that is in the public domain there tends to be the recall bias of those that have lost weight in the six weeks and keep it off tend to be the ones that go back to the follow-up groups. Those who put it on don't. So when you're only following up 40\% of your group, my question is always what happened to the $60 \%$ that haven't come back to the follow-up? (P21)

The suggestion was made that a full cost effective evaluation was required of what best achieved the outcomes required by families, health, educationalists and social care.

So, you know, putting my researcher hat on I'd say let's have a proper cost effectiveness evaluation of you know, if we're going to spend $£ 6-8,000$ what do we spend it on? Bariatric surgery, weight management programme or, you know, intensive support in the community where do you get what's most acceptable to the families, what's most, you know, what achieves the outcomes that we as health professionals want? What achieves the outcomes that the educationalists are looking for in terms of reengagement with school? (P21) 


\section{Case Studies}

The following six case studies demonstrate how the categories and themes identified in the findings interact together in specific pieces of practice with service users identified by the participants. They begin to demonstrate how practice experience unifies personal and professional views on child obesity and the impact this has on the how and what of service provision.

As part of the data collection interviewees and focus group participants were asked about current and previous professional experience of working with child obesity in respect of child protection. The following case studies are chosen from the range of experience shared. They are specific to the individual identified and use the respondent's words to tell the story of how a case progressed under child protection. This is then followed by a commentary from the researcher which starts to make the links between the findings and the discussion which follows the case studies.

The case studies are chosen to exemplify both past and current provision. Case studies of Child D, Child $\mathrm{E}$ and Family $\mathrm{F}$ refer to past experience whereas Child $\mathrm{A}, \mathrm{B}$ and $\mathrm{C}$ refer to more recent or current practice. The examples of more distant practice identify that working with child obesity as a child protection concern is not new, and also allow the respondents to reflect on their work with an almost Wordsworthian approach of 'emotion recollected in tranquillity'. More recent practice has immediacy and demonstrates the passion and emotions involved in working with child obesity and child protection.

The case studies are also chosen to demonstrate practice at different stages of intervention and child protection involvement. They begin with a case being worked within family support but at the cusp of child protection referral. This is followed by an example of a case which was a child protection referral but deemed not to meet the threshold and is now being worked as a family support case. The following case is at the early stage of assessment but one which has met the threshold for child protection. The next three all reflect on sustained periods of work within child protection. The first involving consideration of court action but falling short of removing the child, the second involving removing the child to foster care but with eventual family rehabilitation, and the final involving long term foster care but with family agreement.

All children in the case studies are White British unless otherwise stated. 
Child $A$ is 10 years old, one of 3 children to a single parent with no involvement in the family by her father. The FSW visits the family up to 3 times a week. There is a team around the child in place which consists of stronger families, school, school nurse, and the safeguarding manager at both primary and secondary schools. The family had social care involvement in the past in relation to domestic abuse.

And what I first noticed when I went into the house, there's photos of these children and I didn't actually recognise her, because the girl that I've met was, and though this sounds really awful, was probably two or three sizes bigger. I didn't recognise her, her features, everything about her, her hair and just a really sad young lady really.

A is bullied and initial work focussed on building confidence and self-esteem. For example:

They can't get uniform to fit her. We can't buy anything off the peg. So for back to school of September last year I had to do quite a lot of research into school uniforms and actually British Home Stores was the only one that I could find where we could actually go in, try things on and they looked, say for example a blue gingham summer dress, but it just very subtly says like plus or something. So they, all the kids look the same but it's got very, just little differences, elastic in the arms, elastic in the waist.

The work on finding an appropriate uniform was effective in enabling school attendance:

So she felt really great about her new school uniform. She wasn't aware at all that it was a plus size garment and went off to school quite happy and settled into the next year at school.

Engagement with PE, swimming or after school activities where she needs to change remained problematic:

And school have been quite good that they've put in small measures for her to go into a cubicle when she's putting her costume on but the kids do call her not very pleasant names.

The worker encouraged all the children in the family to engage in a 'Change for Life' project with stickers, charts and pedometers which lasted for 2 months but had little support from their mother;

Mum historically doesn't see things through. So the kids were doing it themselves or with me but then not with mum who's not particularly mobile. Not through any disability she's just got, she just has problems with her feet so she's not very active herself and I would say would be overweight rather than obese. So I think because mum doesn't pro-social model or do much with the children then that's had an effect on the children.

More effective is seen to be the use of sports centres which are free to use for Troubled Families and the family visit every week. School attendance is, however, after a good start becoming problematic.

She's a school refuser recently, copying from her brother actually, and I walked to school with her usually three times a week and actually in that 25 minutes she's puffed out and her legs are aching and rubbing together. And so she does know. She does notice and then the other side of things as well is the, is her body odour. So because I think her body's working harder, she's sweating and kids do call her smelly which is obviously not very pleasant for her either.

Given the focus on exercise was not working the FSW focussed on food and for the 3 times a week she visited she witnessed healthy meals with an agreed reduction in fizzy pop and the substitution of cordial. Sustaining change between visits was more problematic:

I'm slowly seeing things reintroduced, energy drinks, lots of processed food and I'm finding this a lot with my families, their supermarket shop is Iceland because what'll happen is they can go I think if you spend over 120 it's free delivery. So a lot of the food is processed, high calories, quick, microwave burgers and that kind of stuff. 
The challenge faced by workers and families and the nuanced complexities of the interchange between poverty, food and obesity is exemplified by the following exchange:

They live near McDonald's which is unfortunate. I mean it's literally not even five minutes' walk away and they save the bus tokens because if you get a bus ticket in Doncaster on the back of the ticket you can get either a Burger King or a McDonald's meal for 11.99 instead of I don't know the $£ 4$ whatever they are. So mum will give the children $f 2$ each to go and get a big mac and fries, so l've said to her that's $\mathrm{f} 8$ for herself and the three children, I can do a three course meal for 18 so she challenged me to that. They've also really fortunate that they've got a local Lidl. So she went off to McDonald's, I went off to Lidl and cooked a three course meal for $\mathrm{f8}$. So I just need to, like I say again, pro-social model that this can be done with a little bit more effort, but what her counterargument to that was I used electric and gas. So yes it was $£ 8$ and it took the time but my counterargument back to that is, this mum's on benefits and doesn't work and she has got the time. And actually that again goes back to that neglect route of are you providing a healthy balanced diet for your children?

The lack of sustained change is causing the professional group to consider a referral to social care:

This case is on the verge of being stepped back up to social care. Whether or not it hits those criteria is a different matter, but I feel that I've got to be honest and say actually this would, this could be seen by an outsider looking in as neglect.

The assessment of neglect relates not just to obesity but to a constellation of presenting factors partially linked to mother's mental health problems.

They're not thriving, they're not having fun, and their basic needs are not being met, such as I would go and there's no sheets on the bed and their house is not in the greatest of states. But that's improved. So we have peaks and troughs but I think that is definitely linked into mum's mental health. So if mum's feeling great things are great and if mum's not things very quickly lapse. And then the eldest daughter who's actually doing really well at school and not overweight, she would take on the parenting role for mum.

The frustration of working with the family and apparent lack of change in the case leads to the consideration of a social care referral, which in turn leads to an initial response from the mother but one which the worker does not see as a genuine change:

...then the next day there was a bowl of fruit and I said to her why have you done that? Well that's what you want to see... so if they know that why are they not doing it on a regular basis?...So I think it is dare I say laziness, the mental health, because everything's there for them to do that, cooker, microwave, pots and pans, you know, everything's there to do it, it's just doing it.

For this worker there were similarities with other families who live in an unplanned day to day manner:

It's very, not planned, it's not thought through. They've not budgeted for the week. They're living dayby-day-by-day. So the next payday as they would call it, the day they get their benefits and again I'm not being judgemental there at all but that's what they say, is treats and not thinking about have we got enough gas, electric.

Consequently obesity alone is a child protection issue relating often to the poor choices families make in the context of limited budgets. 
Examples are cited of putting alcohol and smoking before food, and the purchase of food for pets with a reliance on food banks to feed children. The consequences of obesity which stretch into adulthood justify identifying and working with these families in the context of neglect.

So I would be, I actually would be quite happy to put a referral in to step up to social care as a professional if I thought that (obesity) was an issue.

I would see that child now and see that impact on that child. So because I'm going into the family home, school seeing the child in school and yes I would see the child in school but I'm also seeing all the other stuff that's going off as well. So if the fridge is full of crisps, pop, you know, and there is no other form of food I feel that that is neglect. And sometimes I don't feel the family would think that was neglect. It's a treat, it's they're doing well at school. And they would use it as a treat or a bribe or they're not eating their dinner so we're going to give them a bowl of ice cream.

\section{Commentary}

- This case demonstrates the realities of a child living with obesity and the challenges of working with a family to bring about change.

- There is an overall context of poverty and limited finance and the case indicates the interplay between poverty and family decision making regarding food.

- There is a multi-disciplinary response in the context of a team around the child

- Intensive work is being undertaken with the family focussing on exercise and diet

- The case provides examples of small pieces of work that can be effective - for example a school uniform in a plus size but one which does not identify the child as 'other' facilitating school attendance.

- The case provides examples of work which does not produce sustained change in terms of diet.

- Lack of improved change with the children's weight and wellbeing (although the lack of deterioration could be identified as a positive, though is not,) alongside frustration on the workers part at not being able to bring about change, influences the decision to make a potential referral to child protection.

- The referral and the need to meet a threshold for acceptance identify a range of neglect factors alongside parental mental health problems.

- The worker identifies the challenge of identifying when a threshold to make a referral is crossed lying to an extent within the workers own assessment and own threshold - for example indicating that someone looking in would identify the family situation as neglectful - alongside wondering if the family would meet the social care threshold for acceptance.

- The perceived threat of a child protection referral elicits a parental response albeit one which could appear superficial. However the possibility remains that working within a statutory framework may embed the change in lifestyle required.

- It is difficult to identify what extra work or activities could be undertaken with the family other than seeking to remove the children for a period of time. Consequently either the threat of removal would need to be sufficient to bring about change not obtained by working to support the family or the children would need to looked after. 


\section{Case Study B}

$B$ is an 11 year old boy who is overweight and seeing a paediatrician and a referral was made to the referral and response team (the immediate response team who manage initial child protection referrals) in social services. The referral did not meet their threshold and was passed to the intensive support team.

The referral was screened and a team around the child was recommended. This is a multi-agency professional group who coordinate services and monitor progress through regular meetings.

The child is described as continuing to see the paediatrician:

Losing weight slowly, playing sports and quite healthy... he was seeing a paediatrician and in four months if he's continuing to lose gradually then they'll sign him off, so he was doing really well.

The mother was happy to accept early help assessment but did not find the team around the child meetings helpful. The meetings had been going on for 6 months when mother phoned distressed about the meetings. She described feeling forced into attending and anxious that if she didn't attend there would be a referral to safeguarding and child protection services.

Really anxious and really upset on the phone, and felt victimised actually that she kind of, kind of like the unspoken threat of if you don't carry on with these meetings we may have to refer to safeguarding. It would never have met their thresholds anyway, and she was tearful and relieved that she did not - it was a voluntary thing to go to these team-around-the-child meetings. But how it had portrayed to her it didn't feel for her that way. She had to pass the phone onto a friend she was that upset.

The worker thought these meetings were making her really upset and anxious, and it shouldn't be like that.

So I'm just wondering how that felt for that family, because it wasn't about home life or anything. $H e^{\prime} d$ got friends, he was quite happy; no issues at all in school other than he was overweight.

I'm thinking of the impact that must have on that young person if that's the only issue in his life.

The focus group took the view that this family had come forward for support but got

A really bad experience... It's either child protection isn't it or, and if it's not then. And we know parents engage better on a voluntary basis when they're taking ownership of it, rather than when it's forced on people. If they're not at risk of significant harm, we know that. You know, but to, like that lady was saying she felt forced into it and didn't find it helpful at all, and it could have a much nicer experience for her, and the young person as well obviously.

\section{Commentary}

- The case described is seen as an example of where obesity is a standalone issue and no other issues regarding wider neglect are present.

- A referral is made to social services who do not think the case meets their threshold

- The referrer (apparently the paediatrician) did think it met the threshold

- Family support services become involved and a team around the child formed which together with the paediatrician appear to be meeting with some success regarding weight loss.

- The perceived threat of a child protection response if compliance with family support is not sustained is seen as having a harmful impact on the mother and potentially on the child.

- How a child protection approach is implemented is important if the aim is to empower the family to achieve change.

- The conclusion for the describing worker and finding wide support in the focus group is that seeing obesity alone as a child protection concern is harmful to families. 


\section{Case Study C}

A 10-12 year old boy was initially referred to social services by the CEOP (on line child protection police) who had identified that the child had been posting intimate parts of his body on line. This was explained by his parents as the boy 'exploring his sexuality'. The worker took the view that you need to be deeply troubled that this is what he's doing because this is not healthy.

Assessment then identified a complex interweaving of issues of which obesity was one.

The referral was around excessive weight gain. The referral was around a young person at risk of sexual exploitation and the referral was around self-harm as well. My concern was that food was being used as a comfort and there's always a reason for that.

The child had removed $£ 50$ from his parent's bank account which he had spent on food. The parents are described as not taking this behaviour seriously explaining the boy 'liked to cook'. Taken together with the explanation of sexualised behaviour this led the worker to the view that the parents

'had been unwilling to challenge the seriousness of that amount of food and the vulnerability and potential poor outcomes of the issue with sexual exploitation.'

The impact on the child was that: he's significantly overweight; it (obesity) harms the perception of a young person of themselves. It harms them in relation to other people. It causes in that particular case, it had caused an emotional withdrawal.

A multi-agency assessment followed which resulted in a child protection conference.

The multi-agency involvement created challenges in that: you can have ten professionals going into a house and you end up not knowing any more than you first started out knowing. The challenge was ensuring role clarification.

A further challenge involved working with middle class parents who could potentially intimidate social workers.

I talked to the social worker in this particular matter and he was frightened by the father. And I'd heard that this man was horrendous and everybody had had a difficult time - what we had was an articulate middle class parent who could marshal, get all his ducks in a row.

The impact of social class and a perception of the support provided by social care agencies led to services offered being reluctantly viewed

Because when we were in there and the parent was suggested a parenting course he immediately turned round and said but that's only for drug addicts and single parents.

For this worker it was important how the offer of help was tailored to the specifics of the family situation - "one of the things social workers need to get better at is tailoring the services that are offered" because if not the "boy gets lost between the cracks".

Direct work with the child also presented challenges:

I said to the worker you have to chase it, you have to chase it and the boy had said to me you're making me feel uncomfortable. You're saying I'm a bad person. And I said to him, you're intelligent, which the boy is, I said and you're old enough to understand and for me to give you a direct answer. I said where in the conversation I had with you did I say you were a bad person? I said nowhere. So he said well no you didn't say that, change of tack, it just makes me feel bad. I said that's fine, because you're not in a great place, but I said I didn't say you were a bad person. I said you're obviously getting upset so I said I'm prepared to leave it here, I said but we'll talk again. I said you can't, I said we don't want to make him feel terrible, but at the same time he's got into a mechanism of if he puts those barriers up people back off. 
The assessments presented at the conference brought together differing views with a psychiatric opinion being that the boy was not suffering from a mental health problem conflicting with one presented by social care:

So basically what the psychiatrist was coming out with was he had no suicidal ideation, a posh name for saying he's not mentally ill. I said but something's clearly not right. So I said whether it fits a nice medical tick box, because he's not mad, bad and dangerous to know, I said we have an 11year-old who is exposing their nether regions to strange men and saying he wants to meet them. He's eating far too much and he's grossly obese, cutting and trying to kill himself. By anybody's definition that's a mental illness.

For this worker the view was taken that children's mental health services (CAMHS) followed a traditional medical model which didn't fit into place with people particularly those who may have suffered trauma and the fact that there is often no easy outcome of an assessment was a problem for mental health assessments.

Taken together the case conference chair described a complex set of dynamics and acknowledged that they were at the beginning of the journey in finding out what was happening for this young person but at present it was a very dangerous place for this child to be and the outcome of the conference was the child being placed on a child protection plan.

\section{Commentary}

This is a recent case which illustrates the bringing together of different elements of concern of which obesity is one. The case illustrates current judgement making alongside an example of a threshold for referral being crossed.

- The case is at an early stage regarding outcomes and demonstrates the issues involved in assessment and initial progression into a child protection process.

- This case meets a threshold for intervention through a bringing together of complex factors of which obesity is one albeit an important one.

- The lack of parental acknowledgement of the issues informs the decision to follow a child protection route

- Social class plays a part in the action of professionals and the parental uptake of services offered

- Multi-agency involvement can create challenges in respect of role clarification as well as understanding of respective assessments 


\section{Case Study D}

Child D came to the IRO's attention through a social work team manager supervising the social worker responsible for the case. D was a six year old girl weighing 12 stone and was referred to social care by school nurses. Health visiting services had been monitoring her before she was five at which point she was passed over to the school nursing team. Health visitors had passed on their concerns:

And they felt that, you know, action had to be taken in regards to not allowing her to put on more weight.

A core assessment was undertaken which identified issues around the parent's understanding of the concerns and their ability to work with services to reduce her weight. A child protection conference took place specifically around the child being obese and overweight. D was placed on a child protection plan for neglect.

Which was quite interesting because she was sort of, in every other area she was the opposite to being neglected. She was born by IVF, born on Christmas Day, and she was very much the princess of the house, only child. So the parents in their view felt that, you know, she had absolutely everything that she needed and wanted, down to whatever she demanded she got - which was part of the problem, yeah. So they wouldn't accept the concerns at all.

The child gained more weight between the first conference and the three month conference. The lack of engagement led to social services going into PLO (When social services are very concerned about the welfare of a child, the social worker may wish to consider taking the case to court so they can make orders to protect the child. PLO stands for 'Public Law Outline', a set of rules which tells social workers how to deal with these sorts of cases.) At this stage the family appeared to engage but this was described as tokenistic. Direct work was undertaken with the child at school and role play in the kitchen area of the classroom indicated

she would like a big pile of chips and that kind of thing. So that's sort of evidence that they weren't really working with her.

Child D also had dietician and paediatrician appointments.

Mum refused to work with the paediatrician because they shared the same concerns and was quite stern around mum and dad needing to take action.

But the dietician was working with them and $(D)$ started to sort of lose weight very steadily, but the dietician said that she would want her to not lose any more than one to two pound a week. And then mum became very focused on that and was saying, you know, she can't lose weight fast because the dietician has said that she can only lose, and we've said well that's maybe a minimum guide. But she wouldn't have that, it was, you know, that's what they've said and she's not losing any more than that.

The case then became

a bit stagnant really - she would lose a pound, put another one back on. The case is described as quite frustrating really because we were in PLO but we weren't going to remove her. We didn't really know where to go with it. Legal were saying, you know, we can't remove her on that base, if we go to court and say we want to remove her, the court isn't going to agree to that ...

The health service are then seen as retracting their original strong views and not providing evidence of impact on health that would persuade a court to order the removal of the child:

Because she was doing things, she was joining in at school. And she was getting out of breath and she couldn't manage things that the other children could manage, but they were saying that she wasn't at a sort of immediate risk in regards to her health and that she could have some longer term issues if she didn't lose weight over time. But they also said, you know, she's going to grow in height and things like that. So it was a bit like we didn't have the evidence to back up the harm really. 
The PLO was ended and work continued with the family on the basis of a child protection plan. Slow progress was made. Child $D$ attended a local initiative of a before and after school sports club. Intended as a 6-12 week programme this was rolled forward as the child and mother seemed to be engaging. Social services paid for swimming lessons to which mum took her and:

Parents were told they had to walk to and from school. They were doing that most of the time. Apart from if it was raining because mum then argued that it would cause her a health issue because she'd get a cold.

The potential impact of emotional harm was acknowledged:

And a lot of work was done with her about how she saw herself, because we wanted to know what impact it was having on her emotionally. But because parents were very nurturing, very loving and things like that, it didn't appear to be having that much of an impact. She would describe herself as beautiful and things like that because that was the message that they were giving to her; whereas, you know, if the parents weren't like that I think it would've been quite different for her.

The IRO thought childhood obesity should be regarded as a child protection concern

I think it should yeah. But I think there should be maybe a bit more of like a framework around it, something that we can work better with. Because on that, I mean that one was really frustrating because we didn't, even though the initial concerns were health and they were sort of jumping up and down saying you need to do something with this child, they didn't then help us with the evidence to prove that it was harm.

The IRO disagreed with the Viner framework saying that in this case childhood obesity alone is a child protection issue.

This was only case experienced in nine years where obesity was the primary reason for child protection intervention.

Yeah well I think it must be that they're not coming to our attention..., what's the threshold for it coming to our attention. How, if we're confused about some of the issues around where it fits in child protection then I'm sure other agencies are and, you know, we would expect that health would be the main people to alert us to that, you know, they see every child hopefully and would be able to flag up if it is a concern. But I suppose it's where their thresholds lie as well. Would they routinely report every obese, every child that crosses over into the obese category or would they wait until it's sort of classed as morbidly obese?

\section{Commentary}

- The case demonstrates the 'messiness' of practice and the frustrations of working with parents who are seen as not engaging. Direct work is required from within a child protection framework which is not a panacea for success.

- In this case the concept of threshold impacted on the case, not on initial referral by health services or on progression from assessment to child protection plan to proposed legal proceedings by social workers, but as regards to the assumed threshold for the court to take action on the part of local authority solicitors.

- Initial concerns were highlighted by health services and pressure for action was applied by health services but evidence to prove the harm to the child and the causal link with obesity was seen as not forthcoming from health services.

- The concept of a threshold on the part of health referrals was seen as one reason for the overall lack of child protection cases. The threshold for health to identify a case as serious enough for a referral and the assumed threshold held by health workers as to what constitutes the threshold for acceptance of a referral by social care.

- If health did refer more cases then social services would need thresholds in place for referral and response which took into consideration resources and funding for interventions required to bring about change.

- Confusion in social services as to where obesity fits within child protection would indicate other agencies are also confused. 


\section{Case study E}

The case was worked when the child protection chair was a Social Worker in the 1990s. The case concerns a 4 year old child who weighed five stone, born to a young mother who had been previously abused.

The four-year-old that was five stone and what was clear is that mum, who was a very young mother, came from a home where she had suffered significant abuse. She then went on at 17 to have a young child and she could not manage the emotions that the child came with. So her way of parenting to avoid conflict, to keep the child quiet, was to substitute boundary setting, substitute getting close to the child and being able to register as a parent the changing moods and when you needed to respond to things by providing food.

The child was subject to an initial child protection conference and placed on a plan and ended up going into proceedings. The outcome was a care order and the child was placed with foster parents. Direct work was then undertaken with mother and child in the foster home.

Working alongside with mum and the child in a foster placement assisting mother to acknowledge and understand the role of food, the role of being able to parent and say no and stick to it, manageable portions, people, you know, not providing the child with an adult portion instead of a child,

And we worked with her to understand that what she thought was partly to calm her own insecurities about being a mum, partly because she thought she was being good to her child, was actually making the child unhealthy and fat. And that being loving was saying no and being loving was to have portions that were small.

Over a two year period after the order was made the child was placed home with parents on placement and an eventual revocation of the care order. Services involved included health, children's social care, legal services and the local nursery. The nursery was seen as key both as a community hub and also a source of trained staff, but unfortunately a resource that was no longer available.

The support that the parents need was often provided by local authorities' nurseries. When that was happening with that child which is not the case any longer, it was their own nurseries with fully trained NNEB staff, who at that time, you needed A-levels to do that qualification and who understood child nutrition who could work alongside the parents to support and advise them and were often seen as less of a threat, understandably, than a social worker...the support of families where childhood obesity is an

\section{Commentary} issue and could be seen as a child protection issue, is not helped by losing that kind of resource.

- This case occurred around 20 years ago in a different city to which the respondent now worked and demonstrates that a child protection approach to obesity is not new.

- In this case the initial referral was for obesity and weight issues alongside parenting ability and capacity.

- Underlying causes regarding previous abuse were identified in the mother which had consequent impact on parenting.

- Thresholds were not an issue in respect of taking legal proceedings, obtaining a care order and child $\mathrm{E}$ entering foster care.

- Historically thresholds may well have been and most probably were different.

- Multi-disciplinary direct work was undertaken with mother and child from the basis of a foster placement. This work was sustained over a two year period.

- Nursery staff were seen as instrumental in providing support. A resource that the respondent thought was no longer available in the same way.

- The outcome was weight reduction, improved parenting and a successful revocation of the care order. 


\section{Case Study F}

The respondent worked with the case as a social worker and then as a supervising team manager.

Family $\mathrm{F}$ concerns parents with learning disabilities and two children, the youngest aged 7 had von Willebrand disease and the older child was 9 . In summary the children came into care: and that was about the parent's response to that diagnosis and their ability to put in place the advice and guidance that had been given by hospital staff and the consultant who was dealing with that child.

The parents and children were seen as having worked with a range of professionals with the children attending school and hospital appointments and there being a good support network around the parents and children. Issues however came to arise around neglect.

And that was about the children being unkempt in school, being isolated from their peers in a school because of their unkempt nature, and at that point there were issues about both children's weight. And school were concerned about that because they were stealing other food both in the school and from other children... physically (they) could be deemed as obese or overweight as children in comparison to their peers.

School nurses became involved and were concerned that the parent's learning difficulties limited their ability to put advice into practice. The family were referred at that point as a general neglect case and a child protection plan put in place.

Investigations were ongoing with paediatricians about the children's weight. And what the parents described in their way, bearing in mind they had moderate learning difficulties, they never felt that they could fill the children, the children were always hungry ... So, as part of a child protection plan, there was intensive monitoring by a family support worker who monitored what the children ate on behalf of the parents. And got the children involved in what they were eating and things like that, so it was quite a good piece of work very early on in terms of engagement with the actual children.

The child who was not diagnosed with von Willebrand disease worked with the school nurse to implement a better eating plan, and that helped that child's self-esteem. For the child that had the von Willebrand disease it was a very different story because they didn't have the same control mechanisms as their sibling. Intensive support was provided to the family.

In the end the parents recognised for themselves that they couldn't actually cope with this and they agreed to section 20 accommodation - not just in relation to the eating issues that were in the family, but the neglect and the chronic neglect that the children experienced in terms of how the parents could actually physically keep up a house, so the children didn't have beds and bedding and they were changed regularly, the house wasn't in a good state. The level of cleanliness was really, really poor. So this was, amongst a whole load of other issues, these children had some sort of health problems that were taken in the wider care plan.

The children came into care and were placed together with a foster parent who was able to maintain the eating regime with the child without the condition and maintain contact with the parents who recognised they could not care for the children. The children remained in long term foster care. The police did not press charges against the parents.

Outcomes for the children was seen as good with needed medical attention, reduced weight, increased self-esteem and no longer ostracised in school. The children's development was delayed through neglect which earlier intervention may have prevented but not to a degree that could not be corrected.

For this interviewee childhood obesity alone should not be regarded as a child protection concern.

So if it's being dealt with at that early help level and it's being dealt with effectively, then I wouldn't see a reason to refer it so social care and usually it wouldn't be a reason to refer in itself. 
No, not unless there is an issue that isn't being appropriately dealt with by the parent. And that's about safeguarding and significant harm. And that's when a child reaches that level, well then clearly the state needs to intervene to protect children. And so yes we would intervene if it gets to that level, but really it's about that right to family life balanced with the Human Rights Act and so therefore our thresholds, or the help that we provide as a statutory service, don't kick in until we know that a child is experiencing or at risk of significant harm. And I suppose if professionals feel that parents aren't able to deal with those issues, for whatever reason, commission or omission, then that will be something then where the state does have to intervene.

There is a need for guidance from health professionals in order to guide other professionals in respect of an intervention. Current SW assessment is seen as relying on personal experiences with the potential for health services contributing to guidance to aid practice.

And I think from a health professional's perspective I think they need to be maybe a bit more clearer, and that's what I think what conference chairs were saying that they would need to be guided by a health professional about saying whether this is just a stage of development or whether actually this is something that needs to be addressed at part of a plan to support a family. And I think because, to be obese, you don't actually have to be that overweight to actually be categorised as obese. It's whenever we get into the morbid obesity and whatever comes after that. And I suppose it's maybe having an understanding of which of them would be worrying to a health professional to warrant then a proactive work as part of a wider child protection plan with the family.

\section{Commentary}

- Thresholds for intervention were crossed easily as the main reason for referral was neglect with obesity one aspect of a range of wider concerns - together these constituted significant harm.

- Legal thresholds were not an issue as parents voluntarily agreed to foster care and the local authority committed to long term foster care rather than seeking adoption.

- The parents were unable to implement guidance and support offered because of their learning disability

- A threshold for intervention is seen as being closely allied with significant harm. If obesity is dealt with effectively by early help then there should be no reason for referral.

- Whether to refer and what threshold to set in accepting that referral would be aided by clear guidance from health professionals to assist in making a judgement about what constitutes morbid obesity. 


\section{Discussion and Summary}

\section{Context}

A key challenge for social work concerns the extent to which a child protection paradigm continues to define professional identity. Debates in the UK and more widely are challenging that paradigm by considering whether child wellbeing is better served by broader definitions of child maltreatment with safeguarding being located within a public health agenda, rather than a narrow focus on significant harm and child protection (Higgins 2017). The findings from this research are centrally located within that debate.

To revisit the introduction to the report obesity is a key public health concern, not least because of its substantial impact on morbidity and mortality, child development, links to child sexual abuse and the wider costs to the health service and society. Whether childhood obesity should be considered a child protection issue has divided commentators, with many questioning whether a child should be removed from parents who do not seek to reduce their child's weight, where significant obesity is identified. This divide is reflected in the social work profession where there is resistance to a role focused on bodily surveillance, whilst also acknowledging the need to investigate neglect where evidence exists of a clear parental failure to manage a child's diet, health and fitness. Similar divisions exist in the medical profession and debates are taking place in Australia (Alexander et al 2009) and the US (Jones et al 2014) but with little research to inform policy and practice. In the UK, there is a variety of practice with a consideration of obesity being incorporated in some multi-agency child protection procedures (see appendix 2 for an example of integrated procedures) but with no mention in others and little research to explain variations.

\section{Child Protection}

The extent to which child obesity represents a child protection issue is contested; within academic and professional literature, within varied multi-professional practice in the UK and internationally and by the participants to this research. As we state in the findings section - in reporting the findings of qualitative research resorting to numbers in respect of respondent's views is meaningless. It can however be illustrative of the ambiguity and contested nature of the research question. In respect of the interviews undertaken in this research ten respondents were of the view that child obesity was a child protection concern with a further three thinking it was if associated with neglect. 7 were of the view that it was not a child protection concern with three thinking the problem was too complex for a view either way. A similar variance of view was expressed by the focus groups.

Where there was more common ground was in respect of the links between obesity and parental neglect. This could be in the form of associated factors such as failure to attend school or mental health issues but also for many respondents a failure on the part of families to engage with support plans and services offered. A child protection referral and subsequent action is unlikely to take place until some form of support has been offered to the child and family and seen not to be successful. Where this lack of success can be linked to parental failure to take up support and make changes then a consequent link is made to parental neglect. 
Child protection services were seen by many participants as a continuum of intervention levels from universal to statutory with child protection and legal interventions part of that continuum rather than a separate entity. A child protection approach could act as a catalyst for families to take up support as well as a gateway to more financially expensive and intensive support offers. For some participants a child protection approach could also act as an inhibitor to parents accessing support fearing blame and condemnation for their inability to bring about change in their children's weight. This view has some support in medical literature which indicates that health services find obesity extremely difficult to treat and blaming parents is merely passing responsibility and 'smacks of hypocrisy' (Fitzpatrick 2008:742). As the case studies illustrate it was possible for work with families to become 'stuck' and a child protection referral could be seen as one way of motivating families to engage with the support offered. At times this approach was described as meeting with some success but the challenge for all professionals is to avoid bringing families into the child protection system because they cannot think of what else to do.

The focus of the support offered depended to an extent on the knowledge about obesity held by the individual. The professionals interviewed all understood the short and long-term impacts obesity could have on a young person's physical and psychosocial health, although the depth of knowledge varied. Obesity training per se was not accessed by most of the professionals interviewed, and the clinical nature of assessing and identifying obesity provided difficulties and complications for nonhealth professionals. The emphasis given to their knowledge regarding the level of impact, the seriousness of the impact and whether action should be taken to reduce the impact varied on the basis of personal values and beliefs about obesity and children rather than any evidence base. Social factors such as culture and poverty combined with parent's lack of skills and knowledge about the impacts of a poor diet and their own dietary behaviours were often blamed for young people being obese. There was an acknowledgement of the impact of poverty on obesity but greater emphasis was given to parental responsibility. This emphasis became greater and more dominant as an individualised child protection approach took hold with interventions focussing on maximising household income rarely mentioned.

\section{Thresholds}

For child protection services to undertake work, requests need to meet a severity threshold for interventions to occur.

The term 'thresholds' is used widely in the UK to indicate the level at which the concerns regarding a child would be considered sufficient to trigger a service response. Thus there would be different thresholds of need that would lead to family support services, to investigations of alleged abuse following initial referral, to decisions about whether a child should be made subject to a child protection plan, to court decisions about whether the evidence is sufficient to make a Care Order (removing the child from home) and so on. Platt and Turney (2013)

The research found that in respect of child obesity this threshold was nuanced and complex and could potentially act as an inhibitor to providing services.

Significant harm as defined in 31 of the Children Act 1989 is the threshold that justifies compulsory intervention in family life in the best interests of children. There are no absolute criteria on which to rely when judging what constitutes significant harm. The key factor is that significant harm should be 
as a result of the care given to a child not being what it would be reasonable to expect a parent to give to a child. Where the question of whether harm suffered by a child is significant turns on the child's health and development, his health or development shall be compared with that which could reasonably be expected of a similar child.

This research found that in the consideration of childhood obesity and making judgements regarding whether obesity amounted to significant harm, both as regards to a child's health and the extent to which parental care was contributory, a test of reasonableness was problematic. The threshold judgement of what constituted significant harm operated not only as a line that had to be crossed in order for a referral to be accepted by social services but also in respect of individual practitioner thresholds regarding personal views and values regarding obesity; different agency thresholds; referrals for different services within an agency and also between agencies. In particular what emerged from the research was that both individual and agency assumptions about thresholds were as important as the actual thresholds themselves.

Child protection services and the concept of thresholds have long had a complex relationship and the issue is by no means restricted to childhood obesity. Brandon et al (2008) identified that thresholds into and between services emerged as a significant theme in cases of child death or serious injury through abuse or neglect. Community Care (Garboden 2010) identified in 2010 that a consistent criticism across all Ofsted reports on local authority safeguarding related to thresholds in respect of inconsistency in application, a lack of clarity between agencies and a variation of response from individual workers. An analysis of all Ofsted inspections carried out under the single inspection framework up to $31 / 8 / 15$ found that of the 59 inspections 26 or $44 \%$ identified confusion around thresholds and an inconsistent understanding of thresholds in partner agencies and within children's services (Stevenson 2015). These criticisms have been sustained over time and a look at any recent Ofsted report where criticisms have been made will confirm 'poor' threshold application as a factor in 'inadequate' ratings of services (Stevenson 2016). There is also an assumption held by front line practitioners across disciplines that thresholds have risen over time, particularly in respect of neglect cases, and for example a recent review of school nurses carried out by the Children's Commissioner for England found that school nurses felt child protection thresholds were 'too high' and that $41 \%$ of 382 surveyed 'were unsatisfied with the outcomes of at least half of the referrals they make' (Children's Commissioner (2016). This was a finding that is supported by the school nurses in our research.

For the participants in our research thresholds were important to everyone irrespective of profession or status. Participants were asked to reflect on both current and past practice, which could have taken place over a range of settings and geographical areas, and over a period of time. In discussing work relating to childhood obesity and child protection the concept of thresholds continually came to the fore. In considering the findings it is important to guard against a simplistic reading and setting up false binaries of the type of 'obesity would never meet their/our thresholds'. As the findings section on thresholds and particularly the case studies indicate thresholds operate in a complex and nuanced manner. At an individual practitioner level, personal beliefs and values about obesity impacted on assessment, and assumptions about child protection thresholds being high could then guide future action without testing the actual threshold by making a referral. For non-medical staff the lack of detailed knowledge about obesity or a framework to guide judgement making reinforced the reliance on personal beliefs about child obesity - crudely whether this amounted to 'puppy fat' or parental neglect. At an agency level participants discussed the way individual threshold decisions impacted on meeting their own agency threshold for a child 
protection concern and then on whether this would meet a social care threshold. Similar processes then operated within agencies regarding whether to refer for specialist support through mental health services or to take legal action in the courts.

That there is some variation in decision making about thresholds is hardly surprising given that central to the process is professional judgement making about unique individual situations. To seek national conformity is perhaps a fool's errand. As one participant summed up the problem from a medical perspective - 'When do we say Oh well you are going to die young but whey hey and when do we decide to do something about it? ' In a review of threshold research Platt and Turney (2013) suggest that conceiving of a threshold as a 'linear and rational' concept operating on a continuum of need is an over simplification. They argue firstly that risks to child welfare cannot be measured in a 'technical-rational' way that compares for example the experience of a child whose access to health care for an illness has been neglected, with one who has been witness to domestic violence and seek to apply the same threshold. 'The experience of each child is different and those differences predict different outcomes'. Secondly they argue that a technical rational approach is too narrow and 'fails to address the complexity of the decision making process assuming... a rationality that does not exist in practice'. The findings from our research strongly support this second point, and overall in respect of child obesity support Platt and Turney's analysis that 'threshold decisions are mediated through various sense making strategies at local level'.

Yet variations in child protection procedures in the UK relating to obesity are stark, and where more expensive and intensive residential and intensive outreach support packages were reported to be only available once families entered the child protection system, then the experiences of families are directly affected by the perceived applications of thresholds on practitioner decision making. One approach adopted by some safeguarding boards is to introduce a framework for understanding child obesity into child protection procedures in order to aid decision making. The 2010 paper by Viner et al published in the British Medical Journal is the framework which is both widely quoted in academic literature and incorporated into the child protection procedures of some local authorities, but is one which does not appear to have been evaluated or researched. The framework states:

Childhood obesity alone is not a child protection issue

$>$ Failure to reduce overweight alone is not a child protection concern

$>$ Consistent failure to change lifestyle and engage with outside support indicates neglect, particularly in younger children

$>$ Obesity may be part of wider concerns about neglect or emotional abuse

$>$ Assessment should include systemic (family and environmental) factors

Almost all participants had no awareness of the Viner framework. Interestingly this lack of awareness was present in both medical and social care participants. On being shown a summary, respondents were divided as to whether obesity could be a standalone child protection concern, supporting their views on the basis of professional experience of direct work with families and also their own personal conceptualisation of obesity and it's causes. Linking obesity to wider issues of neglect, and identifying a consistent failure on the part of parents to change lifestyle and engage with support as indicative of neglect had wide support. So too did the emphasis on systemic assessment. Overall the framework was welcomed as a useful tool, with the caveat that over reliance on a framework can lead to over-simple assessment. The framework was not seen as overcoming problems inherent in measuring and identifying obesity, and failed to overtly identify 
the association of obesity with sexual abuse. The framework does however have the potential to assist in the sense making strategies of local threshold decision making.

\section{Implications for practice}

Throughout the research interviews respondents provided examples of what was described as good practice, not only in reflection on their own work and that of others, but also regarding their aspirations. Good practice was seen as beginning with a holistic understanding of obesity and its impact followed by a multi-agency approach including health, school and social care. Direct work with the whole family was given prominence in achieving change, both within and without a child protection context. Family involvement in the development and implementation of that work in a way that empowers but does not stigmatise was identified as a goal. Parental education was seen as important as part of a preventative approach and in sustaining change. The identification of direct work with the child and family being central, and for this work to be undertaken whether or not the child is receiving universal services, family support, is subject to a child protection plan or is living in foster care seems important. As a number of research reports have indicated, the fact of having been removed from parental care and being a looked after child is no guarantee of protection from obesity (Hadfield and Preece 2008, Croft and Frith 2011).

Alongside indicating good practice respondents also indicated the challenges they faced and where they thought practice could be improved. At times these could be two sides of the same coin. Multiagency working which was identified as central to good practice was also a source of frustration with a lack of clarity identified regarding roles and responsibilities. Challenges included structural issues such as a perceived lack of funding for preventative services and a scarcity of targeted services for disadvantaged groups. Psychosocial barriers to families accepting support were identified, as in the way poverty interacted with the individual service user to drive behaviour. Tension was identified between the difficulty of having obesity accepted as a child protection concern, yet only being able to access intensive support or expensive residential input as part of or as an alternative to court proceedings.

Direct work with families was central but could be problematic, potentially reinforcing unhealthy eating patterns through longstanding work practices and needing to balance risk management with building trust and relationships in order to bring about change. One particular challenge related to participant's own relationship with body weight either individually or in respect of a family member. Whether and how to challenge a service user over the potential obesity of their children when the worker could themselves be considered obese caused problems for some participants. There are parallels here with the better known issue of worker alcohol use impacting on the assessment of service user substance use, but with obesity the tension is more obviously public. The problems were not unsurmountable and participants described the strategies they used, but particularly in reflecting on their own children's weight issues some participants were acutely aware of the emotional impact of raising obesity as an issue with parents.

Participants also put forward a number of proposals as to what would assist practitioners working with child obesity and safeguarding issues in the future. These suggestions were strategic or related to organisational service delivery rather than individual practice. They included training on obesity to include identification, assessment and implications and also service availability; practitioners from all disciplines were unclear as to what was available to support families and how those services could 
be accessed. Overall a framework and procedures to guide practice in respect of obesity would be welcomed. Evidence on short and long term outcome measurements was identified as a deficit and more research and dissemination of findings on outcomes and what works regarding interventions regarding child obesity would help practitioners. Child obesity is an issue that crosses professional divides and this presents challenges for making research findings accessible to all; a paper in the British Medical Journal is unlikely to be read by social workers. 


\section{Key Messages from the Research}

\section{Obesity}

- Obesity has major consequences on a child's physical and psychosocial health which ultimately impacts on child development.

- $\quad$ Culture and poverty play a part in influencing family behaviours resulting in obesity.

- $\quad$ Professionals considered parental behaviour around diet and physical activity and parenting skills linked to cooking and diet and managing behaviour to be amongst the causes of obesity in children.

- $\quad$ Awareness and assessment of obesity is complicated for non-health care professionals who were unclear as how to define childhood obesity. This lack of clarity had the potential to impact on subsequent actions or interventions.

- $\quad$ Professional responses were shaped by attitudes and experiences of obesity either personally or within a professional capacity

- $\quad$ Professionals from all disciplines had limited knowledge of the services on offer to support overweight children with role responsibility and ownership unclear.

- Obesity was linked to other areas of concern - such as neglect, self-esteem, school attendance, bullying, sexual abuse and emotional abuse.

\section{Child Protection}

- Whether child obesity can be a standalone child protection concern is contested.

- $\quad$ Child obesity is a child protection concern when linked to child neglect

- $\quad$ Familial recognition of obesity as having significant impact on child welfare was seen as central to the effectiveness of interventions and a lack of familial engagement in the support offered central to child protection involvement.

- $\quad$ For child protection services to undertake work, referrals need to meet a severity threshold for intervention to occur. This threshold is nuanced, complex and changes over time, does not operate as a single line to be crossed and can act as an inhibitor to providing services.

\section{Implications for practice}

- $\quad$ Guidance and training on the identification, assessment and implications of child obesity would be welcomed by all professions

- $\quad$ A framework and procedures to guide multi-disciplinary practice in relation to child obesity would be welcomed.

- The Viner framework although not evidence based met with some, but not universal, approval and could provide the basis for a child protection framework in relation to child obesity.

- A multi - disciplinary holistic approach is required in working with and assessing child obesity - within universal health and social care services, early intervention and child protection services.

- $\quad$ Direct obesity focussed work with children and families can bring about change

- $\quad$ The short and long term effectiveness of both statutory and early help interventions in respect of child obesity was unclear to participants and is under researched. 


\section{Conclusion}

This research has offered a unique insight into current multi-agency practice in respect of child obesity and child protection. What emerges is a contested view as to whether obesity alone can be a child protection concern, and to a lesser extent whether non-familial recognition of obesity as potentially harmful to children, and non-familial engagement in support services offered, amounts to neglect. In making judgements about child obesity and levels of harm personal views about obesity and value judgements regarding parenting and children are as important, if not more so, than factual knowledge. These views come to the fore explicitly in threshold judgements and subsequent referral behaviour regarding identifying and acting on potential and actual significant harm. The services offered to and accepted by service users in respect of child obesity are both influenced by and a consequence of those threshold judgements.

Practitioners acknowledged a variation in practice and all professions identified a need for training regarding the identification, assessment and implications of child obesity. Given an acknowledgement of a multi-disciplinary approach to child obesity assessment and service delivery being most effective, multi-disciplinary training could also be most useful. Many would welcome a framework and procedures to guide, but not dictate, practice where child obesity may constitute significant harm and become a child protection concern.

Direct obesity focussed work with children and families is seen as key to bringing about change whether through universal services, family support or child protection statutory interventions. More research is required on the short and long-term effectiveness, outcomes and financial viability of those interventions to guide strategic and front line service delivery. 


\section{References}

Adcock, M. and White, R., 1998. Significant Harm, Croydon.

Adoption and Children Act, 2002 HMSO: London

Alexander, S. M., Baur, L. A., Magnusson, R., \& Tobin, B. (2009). When does severe childhood obesity become a child protection issue. Med J Aust, 190(3), 136-139

Bagot, M (2014) Seventy-four kids taken into care for their own protection as they are too fat. Daily Mirror 27 February 2014 http://www.mirror.co.uk/news/uk-news/seventy-four-kids-taken-careprotection-3190690 last accessed 13/11/17

BBC NEWS (2007) Obese boy to remain with mother

http://news.bbc.co.uk/1/hi/health/6402113.stm last accessed 13/11/17

Brandon, M., Belderson, P., Warren, C., Gardner, R., Howe, D., Dodsworth, J. and Black, J., 2008. The preoccupation with thresholds in cases of child death or serious injury through abuse and neglect.

Child Abuse Review, 17(5), pp.313-330.

Children Act 1989, London: HMSO

Children's Commissioner (2016) Lightning Review School Nurses Children's access to school nurses to improve wellbeing and protect them from harm. September 2016 Children's Commissioner for England. London

Colquitt JL, Pickett K, Loveman E, Frampton GK. Surgery for weight loss in adults. Cochrane Database of Systematic Reviews 2014, Issue 8. Art. No.: CD003641. DOI: 10.1002/14651858.CD003641.pub4.

Croft, G. and Frith, K., 2011. Obesity in looked after children: findings of a local audit and strategies for intervention. Adoption \& Fostering, 35(2), pp.86-90.

da Silva SSP, da Costa MA. Obesity and Treatment Meanings in Bariatric Surgery Candidates: A Qualitative Study. Obesity Surgery 2012;22(11):1714-1722

Daphne P Guh, Wei Zhang, Nick Bansback, Zubin Amarsi, C Laird Birmingham and Aslam H Anis (2009). The incidence of co-morbidities related to obesity and overweight: a systematic review and meta-analysis. BMC Public Health

Department of Health (2008). Healthy Weight, Healthy Lives: A Cross Government Strategy for England. [online]. The Stationary Office. London. Available from:

http://webarchive.nationalarchives.gov.uk/20100407220245/http://www.dh.gov.uk/prod consum dh/groups/dh digitalassets/documents/digitalasset/dh 084024.pdf

Doncaster Joint Strategic Needs Assessment (2014). [online] available from:

http://www.teamdoncaster.org.uk/ioint-strategic-needs-assessment

Engstrom M, Wiklund M, Olsen MF, Lonroth H, Forsberg A. (2011). The Meaning of Awaiting Bariatric Surgery due to Morbid Obesity. Open Journal of Nursing. 5:1-8 
Fitzpatrick, M. (2008). Obesity - not a child protection issue. The British Journal of General Practice, 58(555), 742.

Franco, S., 2010. Obesity and the economics of prevention: fit not fat. Organization for the Economic Cooperation and Development: Paris, France.

Gale N Heath G Cameron E et al. . Using the framework method for the analysis of qualitative data in multi-disciplinary health research. BMC Med Res Methodol 2013;13:117.

Garboden, M (2010) How much risk is safe?, Community Care, 1 July 2010

Government Office for Science (2007) Tackling Obesities: Future Choices. London: Department for Innovation. Available from: http://www.bis.gov.uk/assets/bispartners/foresight/docs/obesity/17.pdf

Grady, H (2012) Should extremely obese children be taken into care? BBC Radio 4 http://www.bbc.co.uk/news/health-19267308 last accessed 13/11/17

Griffiths J (2010) Is obesity a child protection issue? Community Care August 272010

Guh DP, Zhang W, Bansback N, Amarsi Z, Birmingham CL, Anis AH. The incidence of comorbidities related to obesity and overweight: a systematic review and meta-analysis. BMC Public Health: 2009; 9: 88 .

Hadfield, S.C. and Preece, P.M., 2008. Obesity in looked after children: is foster care protective from the dangers of obesity?. Child: care, health and development, 34(6), pp.710-712.

Higgins, M., 2017. Child protection social work in England: How can it be reformed?. The British Journal of Social Work, 47(2), pp.293-307.

HM Government. (2016) The Childhood Obesity Plan [online] available from:

https://www.gov.uk/government/publications/childhood-obesity-a-plan-for-action/childhoodobesity-a-plan-for-action

HM Revenue and Customs (Personal Tax Credits: Related Statistics - Child Poverty Statistics) www.gov.uk/government/statistics/personal-tax-credits-children-in-low-income-families-localmeasure-2014-snapshot-as-at-31-august-2014-30-september-2016

Johnston, I (2014) Children taken into care for being too fat the Independent http://www.independent.co.uk/life-style/health-and-families/health-news/children-taken-into-carefor-being-too-fat-9158809.html last accessed 21/11/17

Jones, D. J., Gonzalez, M., Ward, D. S., Vaughn, A., Emunah, J., Miller, L., \& Anton, M. (2014). Should child obesity be an issue for child protective services? A call for more research on this critical public health issue. Trauma, Violence, \& Abuse, 15(2), 113-125

McKinsey Global Institute (2014). Overcoming obesity: An initial economic analysis. McKinsey \& Company

Midei AJ, Matthews KA (2011). Interpersonal violence in childhood as a risk factor for obesity: a systematic review of the literature and proposed pathways. PubMed 
National Statistics. (2017, Oct 17). National Child Measurement Programme. Retrieved Nov 22, 2017, from NHS Digital:https://digital.nhs.uk/catalogue/PUB30113

Picot J, Jones J, Colquitt JL, Gospodarevskaya E, Loveman E, Baxter L, Clegg AJ. (2009) The clinical effectiveness and cost-effectiveness of bariatric surgery for obesity. PubMed

Platt, D. and Turney, D., 2013. Making threshold decisions in child protection: A conceptual analysis. British Journal of Social Work, 44(6), pp.1472-1490.

Public Health England (2016) Doncaster Unitary Authority Health Profile. Retrieved Nov 222017 from http://fingertipsreports.phe.org.uk/health-profiles/2016/e08000017.pdf\&time period=2016

Public Health England (2017). Public Health Profiles. Retrieved Nov 22, 2017, from https://fingertips.phe.org.uk/search/obesity\#page/3/gid/1/pat/6/par/E12000003/ati/102/are/E080 00017/iid/20601/age/200/sex/4

Puhl, R., \& Brownell, K.D. (2001). Bias, discrimination, and obesity. Obesity Research, 9, 788-804 Phul RM, Heuer CA (2009). The stigma of obesity: a review and update. Obesity, 17: 941-964.

Reilly JJ, Methven E, McDowell ZC, et al Health consequences of obesity Archives of Disease in Childhood 2003;88:748-752. http://adc.bmj.com/content/88/9/748

Ritchie J. Lewis J. Qualitative research practice: a guide for social science students and researchers. Sage, 2003

Stevenson (2015) Are child protection thresholds too high? Community Care September 102015 http://www.communitycare.co.uk/2015/09/10/child-protection-thresholds-high/

Stevenson (2016) 'Poor' threshold application a factor in council's 'inadequate' Ofsted report Community Care September 202016 http://www.communitycare.co.uk/2016/09/20/poorthreshold-application-factor-councils-inadequate-ofsted-report/

The Foresight Report (Government Office for Science, 2007) https://www.gov.uk/government/uploads/system/uploads/attachment_data/file/295149/07-1662obesity-modelling-trends.pdf

Twells LK, Gregory DM, Reddigan J, et al. Current and predicted prevalence of obesity in Canada: a trend analysis. CMAJ Open 2014; 2:E18-26.

Viner, R. M., Roche, E., Maguire, S. A., \& Nicholls, D. E. (2010). Childhood protection and obesity: Framework for practice. British Medical Journal, 341, c3074 


\section{Appendix One}

\section{The Research Team}

Peter Nelson P.Nelson@shu.ac.uk

Principal Lecturer, Department of Social Work Social Care and Community Studies, Sheffield Hallam University

Paul Bissell P.Bissell@hud.ac.uk

Dean, School of Human and Health Sciences, University of Huddersfield

Lee Pollard L.Pollard@shu.ac.uk

Senior Lecturer Department of Social Work Social Care and Community Studies, Sheffield Hallam University

\section{Catherine Homer C.Homer@shu.ac.uk}

Research Fellow, Centre for Health and Social Care Research, Sheffield Hallam University

Vanessa Powell-Hoyland Vanessa.powell-hoyland@doncaster.gov.uk

Public Health Specialist, Doncaster Metropolitan Borough Council 
Appendix Two

Norfolk Procedures

https://www.norfolklscb.org/wp-content/uploads/2016/02/obesity policy.pdf

https://www.norfolklscb.org/about/policies-procedures/5-24-safeguarding-response-toobesity-when-neglect-is-an-issue/ 


\title{
Appendix Three
}

\author{
Interview and focus group schedule
}

\section{CHILD PROTECTION AND OBESITY}

\section{SEMI-STRUCTURED INTERVIEW QUESTIONS AND SCRIPT}

Welcome my name is...

The overall aim of the research is to aid the understanding of issues relating to childhood obesity as a potential child protection concern. The aim of this interview is to explore current practice and staff perceptions relating to the subject. The interview will be recorded and transcribed in full. The transcriptions will be anonymised and any data identifying staff or service users will be removed.

The results will be used for dissemination via conferences and research publications and to inform future practice relating to protecting children where childhood obesity may be an issue.

The interview should last no more than an hour.

Here is a copy of the information sheet and if you have no further questions a copy of the consent form for you to sign.

Role

1. What is your current job title?

2. Which agency do you work for?

3. What do you do in your professional role?

Obesity

1. What is your understanding of child obesity?

2. What impact do you think child obesity has on child development?

3. Have you had any training on child obesity?

4. Have you had any involvement in your work with child obesity issues?

- could you tell me about your involvement?

- were other agencies involved and if so what was their involvement?

Child Protection

1. In your opinion should childhood obesity be regarded as a child protection concern? (Objective 2)

-Yes- Please tell me why? 
-No-Please tell me why?

2. Could you provide any examples from your current practice where you have identified child protection concerns where childhood obesity may have been a factor? (Objectives 1 and 2)

-What issues triggered you concern/s?

-What action/s did you take?

-What other individuals or agencies did you involve if any and why?

-In your opinion, how effective were the responses and outcomes?

3. Are you aware of the Viner (2010) Framework for Action to Understand Child Protection Concerns for Children who are Obese? (Objective 3)

Yes -No - record awareness

Here is a copy of the framework - What, in your opinion are the strengths and weaknesses of the framework?

4. In your opinion what would help practitioners to identify and respond to child protection concerns where obesity is an issue? (Objective 4)

5. Have you any other comments to make regarding our discussion? (Objectives 1-4) 


\section{FOCUS GROUP PROMPTS AND FACILITATOR SCRIPT}

Welcome/Introductions, our/my role is to facilitate the group discussion

The overall aim of the research is to aid the understanding of issues relating to childhood obesity as a potential child protection concern. The aim of this focus group is to explore current practice and staff perceptions relating to the subject.

The focus group discussions will be recorded and transcribed in full. The transcriptions will be anonymised and any data identifying staff or service users will be removed

The results will be used for dissemination via conferences and research publications and to inform future practice relating to protecting children where childhood obesity may be an issue.

You were selected because you may have experience of directly working in this area

Please remember: Please could we ensure that only one person is speaking at a time. There are no right or wrong answers, only differing points of view. Although you might not agree with some of the opinions within the group, please listen respectfully and challenge appropriately if needed.

Please address your discussion and comments to other group members rather than the facilitator.

Here is a copy of the information sheet relating to the research - Are there any questions? If there are no more questions could you please sign the consent form before we begin.

\section{FOCUS GROUP PROMPTS}

When speaking for the first time it would be useful to state your role.

1. What is your understanding of child obesity?

2. What impact do you think child obesity has on child development?

3. In the groups opinion should childhood obesity be regarded as a child protection concern? (Objective 2)

Please explain why?

4. Could anyone provide examples from their current practice where they have identified child protection concerns where childhood obesity may have been a factor? (Objectives 1 and 2 )

-What issues triggered the concern/s?

-What action/s was taken?

-What other individuals or agencies were involved if any and why?

-In your opinion, how effective were the responses and outcomes?

5. Is anyone in the group aware of the Viner (2016) Framework for Action to Understand Child Protection Concerns for Children who are Obese? (Objective 3) 
Here is a copy of the framework

What, in your opinion are the strengths and weaknesses of the framework?

6. As a group of practitioners what do you think would help your practice in identifying and responding to child protection concerns where obesity may be an issue? (Objective 4)

7. Have you any other comments to make regarding our discussion? (Objectives 1-4) 


\section{Appendix Four}

\section{Consent form}

Participant ld:

\section{CONSENT FORM}

\section{Is childhood obesity an overlooked child protection concern?}

Name of Researcher:

Please initial box

1. I confirm that I have read and understand the information sheet for the above study and have had the opportunity to ask questions.

2. I understand that my participation is voluntary and that I am free to withdraw at any time from the discussion researcher, without giving any reason. My care and legal rights will not be affected.

3. I agree to my discussion being recorded using a digital recorder or hand written notes for the purposes of the research. I understand that I may ask for recording to be stopped at any time.

4. I agree to the use of extracts from my discussion being used in published reports and presentations resulting from the research. I understand that all personal details will be removed and I will not be identified in any published work.

5. I agree to take part in the above study

Name of research participant

Name of person taking consent (if different from researcher)

$\overline{\text { Date Signature }}$

Date Signature

Date Signature

Researcher 


\section{Appendix Five}

\section{Obesity and Child Protection}

What is the project about?

The aim of the project is to explore the current practice and perceptions of staff working within child protection and public health services regarding child protection and obesity. The project will seek answers to the question 'Is childhood obesity a child protection concern?'

Where are you doing the project?

The project is being undertaken in Doncaster.

\section{What will the information be used for?}

The results will be used to help local and national organisations understand more about the links between obesity and child protection in order to inform future practice. All the results and contributions will be anonymous.

Who is doing this project?

The project is being undertaken by Sheffield Hallam University Centre for Health and Social Care Research; the Department of Social Work Social Care and Community Studies and Sheffield University School of Health and Related Research. The project is funded by the National Institute for Health Research (NIHR) Collaboration for Leadership in Applied Health Research and Care (CLAHRC Yorkshire and Humber)

\section{How much time is involved?}

We would like to either interview you or invite you to participate in a focus group for between 30 minutes to an hour to explore your knowledge, views and experience of childhood obesity and any relationship with child protection.
Has this study got ethical approval?

Yes, it has ethical approval from Sheffield Hallam University, and has been granted research governance by Doncaster MBC.

\section{What happens after the study?}

Following completion of the study we will organise a dissemination event in order to share our findings with participants.

Can I change my mind about being involved after I have signed the consent form?

Yes, you can withdraw from the study at any time, and ask for your information not to be included.

\section{I want to help, what shall I do now?}

If you are happy to be involved in the study please contact us by email and we can arrange for you to sign the consent form and interview you at your convenience.

\section{Our contact details:}

Peter Nelson Principal Lecturer/Resource Manager Department of Social Work Social Care and Community Studies

Sheffield Hallam University Robert Winston Building

11-15 Broomhall Road Sheffield

S10 $2 B P$

+44(0) 1142252407

p.nelson@shu.ac.uk

http://www.shu.ac.uk/research/hsc/about-us/pete-nelson 


\section{Appendix Six}

\section{Findings summary}

\begin{tabular}{|c|c|c|}
\hline Categories & Codes & Commentary \\
\hline Obesity & $\begin{array}{l}\text { Professional } \\
\text { understanding of causes, } \\
\text { Professional } \\
\text { understanding of } \\
\text { consequences } \\
\text { - Training } \\
\text { - Personal and professional } \\
\text { experiences shape } \\
\text { professional response, } \\
\text { Assessment and } \\
\text { identification } \\
\text { Social factors }\end{array}$ & $\begin{array}{l}\text { The professionals interviewed understood the short and } \\
\text { long term impacts obesity could have on a young person's } \\
\text { physical and psychosocial health. Social factors such as } \\
\text { culture and poverty combined with parent's lack of skills } \\
\text { and knowledge about the impacts of a poor diet and their } \\
\text { own dietary behaviours were often blamed for young } \\
\text { people being obese. Whilst obesity training per se was not } \\
\text { accessed by most of the professionals interviewed, many } \\
\text { had knowledge of healthy eating and cooking programmes } \\
\text { or local interventions that families could access. The } \\
\text { personal experience of the interviewee with regards to } \\
\text { obesity shaped their response to families, in terms of } \\
\text { awareness of the issue and raising it with families they } \\
\text { worked with. The clinical nature of assessing and } \\
\text { identifying obesity provides complications for non-health } \\
\text { professionals. }\end{array}$ \\
\hline Thresholds & $\begin{array}{ll}\text { - } & \text { Ambiguity } \\
\text { - } & \text { Personal } \\
\text { - } & \text { Referrer's agency } \\
\text { - } & \text { Perceived } \\
\text { - } & \text { Actual } \\
\text { - } & \text { legal } \\
\text { - } & \text { Multi-agency }\end{array}$ & $\begin{array}{l}\text { For child protection services to undertake work, requests } \\
\text { need to meet a severity threshold for interventions to } \\
\text { occur. It was found that this threshold was nuanced and } \\
\text { complex and could act as an inhibitor to providing } \\
\text { services. The threshold operated not only as a line that } \\
\text { had to be crossed in order for a referral to be accepted by } \\
\text { social services but also in respect of individual practitioner } \\
\text { thresholds regarding personal views and values regarding } \\
\text { obesity, different agency thresholds, referrals for different } \\
\text { services within an agency and also between agencies. The } \\
\text { category emerged through the inductive process of } \\
\text { interview analysis as a major finding. }\end{array}$ \\
\hline $\begin{array}{l}\text { Child } \\
\text { Protection }\end{array}$ & $\begin{array}{l}\text { Obesity is a child } \\
\text { protection concern } \\
\text { - Obesity is not a child } \\
\text { protection concern } \\
\text { - Obesity and neglect } \\
\text { - Intervention levels } \\
\text { - Prevalence. }\end{array}$ & $\begin{array}{l}\text { The question of whether child obesity alone was a child } \\
\text { protection concern divided respondents. For some the } \\
\text { impact of obesity on long and short term outcomes for } \\
\text { children made obesity unequivocally a child protection } \\
\text { concern. For others excess weight of itself was not } \\
\text { sufficient. Where there was more common ground was in } \\
\text { respect of the links between obesity and parental neglect. } \\
\text { This could be in the form of associated factors such as } \\
\text { failure to attend school or mental health issues but also } \\
\text { for many respondents a failure on the part of families to } \\
\text { engage with support plans and services offered. Those } \\
\text { services were seen as a continuum of intervention levels } \\
\text { from universal to statutory with child protection and legal } \\
\text { interventions part of that continuum rather than a } \\
\text { separate entity. A child protection approach could act as a } \\
\text { catalyst for families to take up support as well as a } \\
\text { gateway to more financially expensive and intensive } \\
\text { support offers. Assessing prevalence was hindered by a } \\
\text { lack of data alongside the impact of individual and } \\
\text { professional perceptions. }\end{array}$ \\
\hline
\end{tabular}




\begin{tabular}{|c|c|c|}
\hline $\begin{array}{l}\text { Viner } \\
\text { Framework }\end{array}$ & $\begin{array}{l}\text { - } \text { Awareness } \\
\text { - } \text { Agree } \\
\text { - } \text { Disagree } \\
\text { - }\end{array}$ & $\begin{array}{l}\text { The Viner framework was developed by a team of } \\
\text { paediatricians as a means of understanding and working } \\
\text { with child obesity as a child protection issue. It has been } \\
\text { incorporated into some child protection procedures in } \\
\text { parts of the UK. Almost all participants } \\
\text { had no awareness of the Viner framework. On being } \\
\text { shown a summary, respondents were divided as to } \\
\text { whether obesity could be a standalone child protection } \\
\text { concern. Linking obesity to wider issues of neglect, and } \\
\text { identifying a consistent failure to change lifestyle and } \\
\text { engage with support as indicative of neglect had wide } \\
\text { support. So too did the emphasis on systemic assessment. } \\
\text { Overall the framework was welcomed as a useful tool, } \\
\text { with the caveat that over reliance on a framework can } \\
\text { lead to over simple assessment. The framework was not } \\
\text { seen as overcoming problems inherent in measuring and } \\
\text { identifying obesity, and in not identifying the association } \\
\text { of obesity with sexual abuse. }\end{array}$ \\
\hline $\begin{array}{l}\text { Good } \\
\text { Practice }\end{array}$ & $\begin{array}{l}\text { - } \quad \text { Multi-agency approach } \\
\text { - } \quad \text { Holistic understanding } \\
\text { - } \quad \text { Parental education } \\
\text { - } \quad \text { Service user involvement }\end{array}$ & $\begin{array}{l}\text { Good practice was seen as beginning with a holistic } \\
\text { understanding of obesity and its impact followed by a } \\
\text { multi-agency approach including health, school and social } \\
\text { care. Direct work with the whole family is given } \\
\text { prominence in achieving change, both within and without } \\
\text { a child protection context. Family involvement in the } \\
\text { development and implementation of that work in a way } \\
\text { that empowers but does not stigmatise was identified as a } \\
\text { goal. Parental education was seen as important as part of } \\
\text { a preventative approach and in sustaining change. }\end{array}$ \\
\hline $\begin{array}{l}\text { Challenges } \\
\text { for Practice }\end{array}$ & $\begin{array}{l}\text { - } \quad \text { Multi-agency working } \\
\text { - } \quad \text { Back of support } \\
\text { Barriers to accepting } \\
\text { - } \quad \text { Pupport } \\
\quad \text { roblematic direct work }\end{array}$ & $\begin{array}{l}\text { Challenges to practice and where participants thought } \\
\text { practice could be improved included structural issues such } \\
\text { as a lack of funding for preventative services and a scarcity } \\
\text { of targeted services for disadvantaged groups. Psycho- } \\
\text { social barriers to families accepting support were } \\
\text { identified, as in the way poverty interacts with the } \\
\text { individual to drive behaviour. Multi -agency working was a } \\
\text { source of frustration with a lack of clarity regarding roles } \\
\text { and responsibilities. Direct work with families was central } \\
\text { but could be problematic, potentially reinforcing } \\
\text { unhealthy eating patterns and needing to balance risk } \\
\text { management with building trust and relationships in order } \\
\text { to bring about change. }\end{array}$ \\
\hline $\begin{array}{l}\text { Suggestions } \\
\text { for Future }\end{array}$ & $\begin{array}{l}\text { - } \quad \text { Training } \\
\text { Provide guidance, } \\
\text { procedures and a } \\
\text { framework } \\
\text { - Outcome research }\end{array}$ & $\begin{array}{l}\text { This category relates to the ideas interviewees put } \\
\text { forward as to what would assist practitioners working with } \\
\text { child obesity where safeguarding issues are present. These } \\
\text { included training on obesity and service availability, and } \\
\text { providing a framework and procedures to guide practice. } \\
\text { Evidence on short and long term outcome measurements } \\
\text { was identified as a deficit and more research and } \\
\text { dissemination of findings on outcomes and what works } \\
\text { regarding interventions is required. }\end{array}$ \\
\hline
\end{tabular}




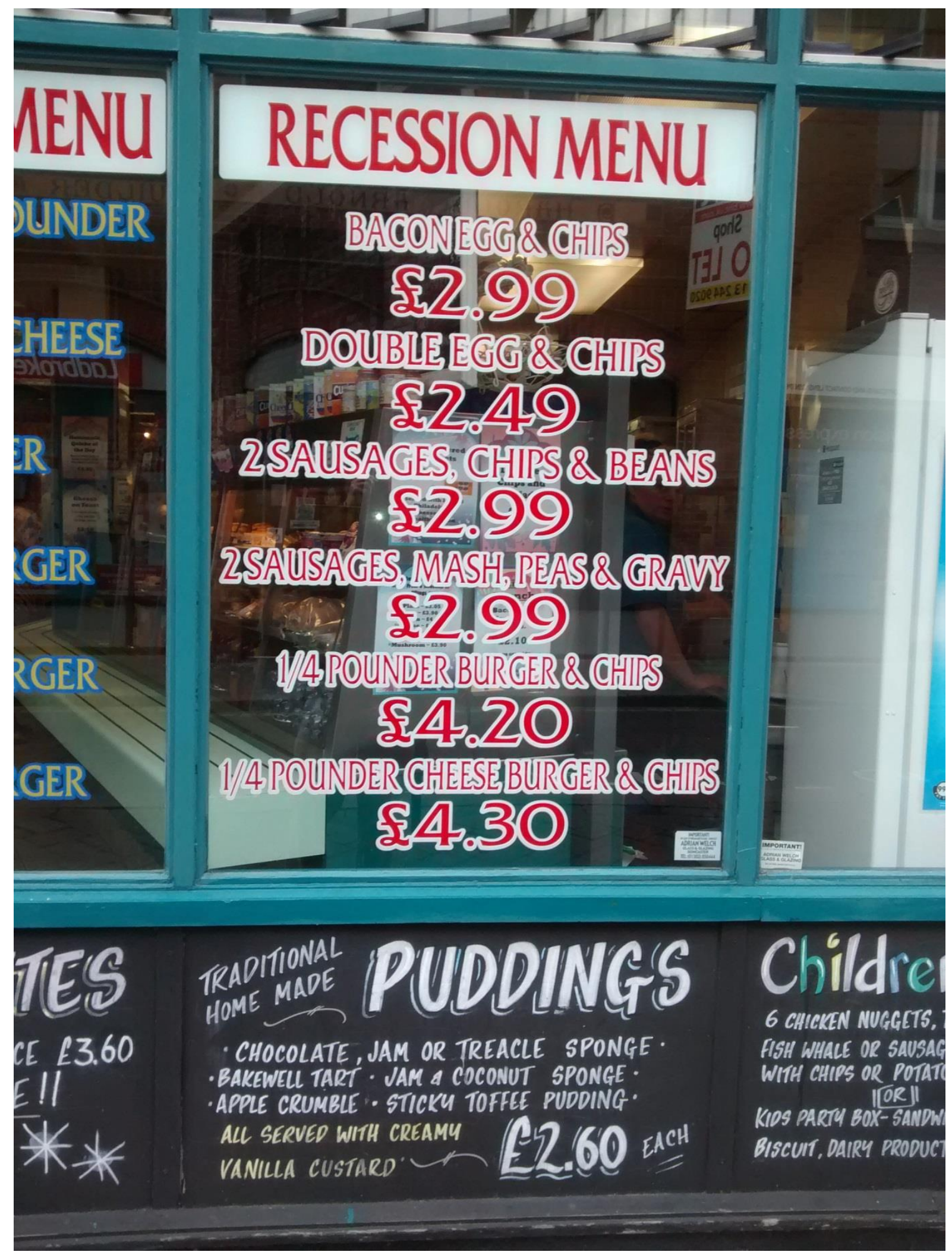




\section{Sheffield Hallam University}

Is childhood obesity a child protection concern?

NELSON, Pete <http://orcid.org/0000-0002-5124-1897>, BISSELL, Paul, POLLARD, Lee, HOMER, Catherine <http://orcid.org/0000-0003-2571-6008> and POWELL-HOYLAND, Vanessa

Available from the Sheffield Hallam University Research Archive (SHURA) at:

http://shura.shu.ac.uk/22295/

\section{Copyright and re-use policy}

Please visit http://shura.shu.ac.uk/22295/ and http://shura.shu.ac.uk/information.html for further details about copyright and re-use permissions. 